Florida International University FIU Digital Commons

6-24-2014

\title{
Racialized Sexualities within the Romance Tour Industry: the Influence of Affect and Emotion Upon Transnational Hierarchies of Desire
}

Julia H. Meszaros

Florida International University, jmesz001@fiu.edu

DOI: $10.25148 /$ etd.FI14071123

Follow this and additional works at: https://digitalcommons.fiu.edu/etd

\section{Recommended Citation}

Meszaros, Julia H., "Racialized Sexualities within the Romance Tour Industry: the Influence of Affect and Emotion Upon Transnational Hierarchies of Desire" (2014). FIU Electronic Theses and Dissertations. 1458.

https://digitalcommons.fiu.edu/etd/1458 


\section{FLORIDA INTERNATIONAL UNIVERSITY}

Miami, Florida

\section{RACIALIZED SEXUALITIES WITHIN THE ROMANCE TOUR INDUSTRY: \\ THE INFLUENCE OF AFFECT AND EMOTION UPON TRANSNATIONAL HIERARCHIES OF DESIRE}

A dissertation submitted in partial fulfillment of

the requirements for the degree of

DOCTOR OF PHILOSOPHY

in

GLOBAL AND SOCIOCULTURAL STUDIES

by

Julia Meszaros

2014 
To: Interim Dean Michael R. Heithaus

College of Arts and Sciences

This dissertation, written by Julia Meszaros, and entitled Racialized Sexualities within the Romance Tour Industry: the Influence of Affect and Emotion Upon Transnational Hierarchies of Desire, having been approved in respect to style and intellectual content, is referred to you for judgment.

We have read this dissertation and recommend that it be approved.

$\begin{array}{r}\hline \text { Alexandra Diallo } \\ \hline \text { Jean Rahier } \\ \hline \text { Percy Hintzen } \\ \hline \text { Caroline Faria } \\ \hline \text { Vrushali Patil, Major Professor }\end{array}$

Date of Defense: June 24, 2014

The dissertation of Julia Meszaros is approved.

Interim Dean Michael R. Heithaus College of Arts and Sciences

Dean Lakshmi N. Reddi University Graduate School

Florida International University, 2014 
(C) Copyright 2014 by Julia Meszaros

All rights reserved. 


\section{DEDICATION}

I dedicate my dissertation to my supportive parents and my academic inspiration, Victoria Jean Bertics, may she rest in peace. 


\section{ACKNOWLEDGMENTS}

I wish to acknowledge the unwavering support of my family, friends, colleagues, and professors, who all made the completion of this dissertation possible. Their tireless work and feedback inspired me to continue along this arduous process, and inspired me to create a work that I believe is truly a contribution to existing scholarship. I would like to extend a large amount of gratitude to my advisor and chair, Dr. Vrushali Patil, for her continuing support and feedback throughout my entire dissertation process. Dr. Patil has been an integral part of my dissertation project since its inception, and I am eternally grateful to her for helping to situate my project within a larger transnational feminist framework. I am also indebted to Dr. Caroline Faria for continually providing me with extensive feedback and a generous amount of personal support throughout the entire dissertation process. Dr. Percy Hintzen played an important role in developing my theoretical framework, and he continuously provides me with a vision of what a lifelong scholar looks like. Dr. Jean Rahier has also provided me with important insights into ethnographic fieldwork and the complex ways in which critical tourism frames my work. Dr. Alexandra Diallo has also provided me with important and integral feedback throughout my entire dissertation process. In addition to the support of my committee at FIU, I would like to thank Dr. KumKum Sangari at University of Wisconsin-Milwaukee for inspiring the choice of my topic and Dr. Michael Kimmel at the State University of New York-Stonybrook for his invaluable feedback on my project.

In addition to my academic support network, I want to extend an immense amount of gratitude to the owners and employees of A Foreign Affair, who generously allowed me to observe their company’s tours in any site that I chose. I especially want to thank 
John Adams for his support of my research and his belief in my objectivity as a researcher. Without the support of John and his employees, this research project would have never been completed. In addition to John, I would like to thank Katherine Orrego Jimenez, Diana Salazar, Laura Causado, Robie Jean Mante Socos, Zzel Heyrana, Natalia Komorova, and Helen Roldan-Cayanong. These employees (and former employees) of A Foreign Affair provided me with invaluable insights into the romance tour industry, as well as referred me to potential women interviewees. I want to also take a moment to extend my eternal gratitude to all of the men and women I interviewed during my fieldwork process; I cannot name them here, as I have promised to protect their anonymity. Without their participation, this project would not exist.

I also want to acknowledge the generous financial support I have received throughout my entire dissertation process from Florida International University. I am especially grateful for the Doctoral Evidence Acquisition Grant and the Dissertation Year Fellowship from the University Graduate School at FIU. My transnational fieldwork in Ukraine, Colombia, and the Philippines was made possible with this generous financial support. Without the generous support of FIU as an institution, I would not have been able to undertake such an ambitious research project. In terms of personal expressions of gratitude, this dissertation would not be possible without the unwavering support of Csilla Meszaros and Attila Meszaros. 


\title{
ABSTRACT OF THE DISSERTATION
}

RACIALIZED SEXUALITIES WITHIN THE ROMANCE TOUR INDUSTRY: THE INFLUENCE OF AFFECTS AND EMOTIONS UPON TRANSNATIONAL HIERARCHIES OF DESIRE

\author{
by \\ Julia Meszaros \\ Florida International University, 2014 \\ Miami, Florida \\ Professor Vrushali Patil, Major Professor
}

Online international introduction sites that offer romance tours to American men in search of a foreign bride are an important and rapidly growing component of the internet dating industry; the number of these agencies in the U.S. tripled from two hundred to six hundred in the past 10 years. Previous scholars have examined the so-called 'mail order bride' industry in order to demonstrate that the women involved are agents and not victims. Many scholars have also highlighted the importance of race in shaping American men's desires in one particular region or country. My dissertation provides an important addition to the literature surrounding romance tourism by including participants from all three major regions associated with romance tourism: Eastern Europe, South America, and Southeast Asia. I collected the data for the dissertation by becoming a participant observer of a romance tour in Ukraine, Colombia, and the Philippines. I argue that romance tourism is an important example of the global intimate, and the ways in which globalized processes are created and sustained through everyday intimate emotions and interactions. By examining the ways in which the emotions of desire, disgust, and anxiety 
influence individual romance tour participant's constructions of racialized hierarchies, the links between individual emotions and global systems are revealed. The concept of the global intimate challenges the hierarchy of scale that places the body, the home, and the intimate on a much lower level than the scale of the global or the national, and at the same time challenges the binary that divides the individual from the global. Through highlighting the different emotional negotiations that are constantly occurring in the romance tour industry, I highlight the important ways in which individual emotions and affects influence global processes on a large scale and vice versa. 


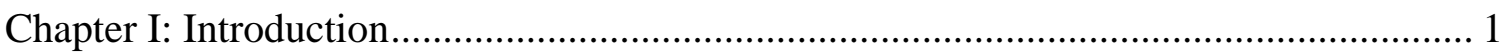

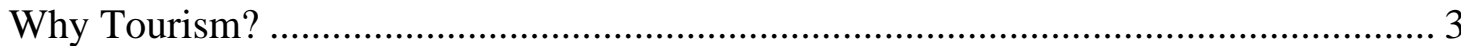

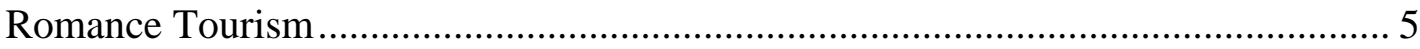

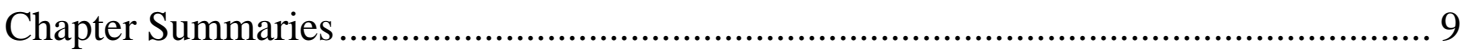

Chapter II: Theory and Methods............................................................................. 13

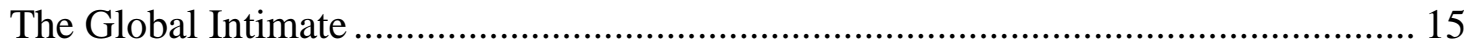

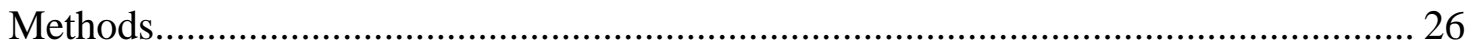

Global Ethnography ………………………………….................................... 29

Chapter III: Colonial Genealogies and Legacies of Intimate Tourism .............................. 41

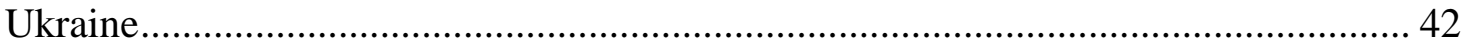

Development of Intimate Tourism................................................................. 45

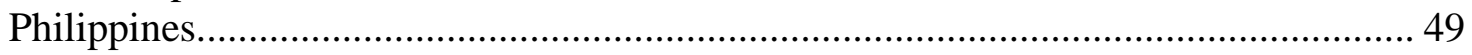

Development of Intimate Tourism................................................................... 52

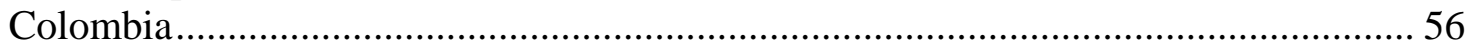

Development of Intimate Tourism....................................................................... 59

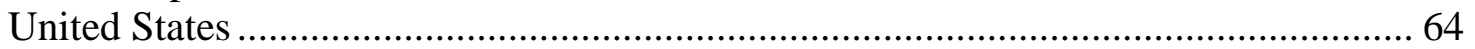

Chapter IV: Desire for the Exotic Light Woman and a Transnational Brad Pitt.............. 67

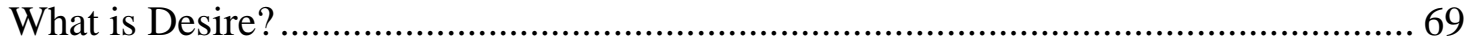

Desiring a Foreign June Cleaver.............................................................................. 73

Desiring Educated Slavic Supermodels .............................................................. 75

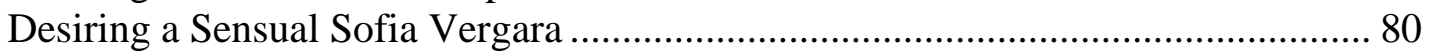

Desiring the Exotic Girl Next Door ......................................................................... 83

Desiring Transnationally Mobile Brad Pitts ................................................................ 89

Financially Stable Brad Pitts................................................................................... 93

Appearance does not Matter, or Does it?.................................................................. 99

Chapter V: Disgust and a Move to the Transnational .................................................... 108

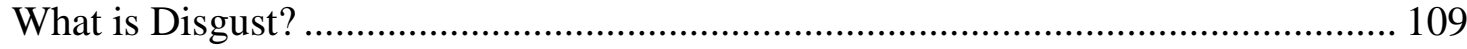

From June Cleaver to Roseanne Barr ……………............................................... 115

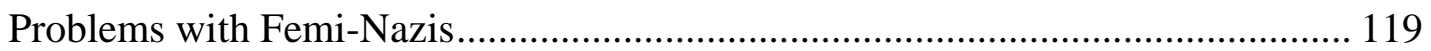

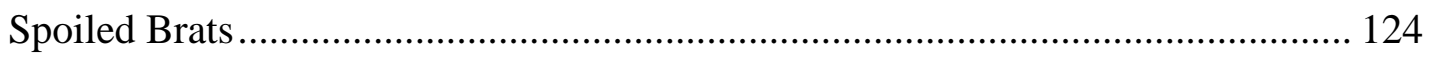

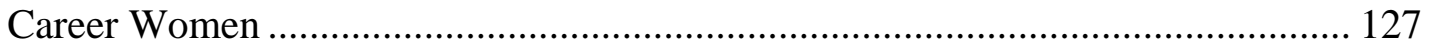

Blackness at the Bottom of the Marriage Queue ...................................................... 130

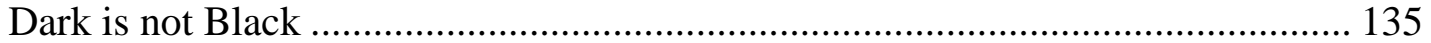

The Trouble with Local Masculinities..................................................................... 137

Not all American Men are White...................................................................... 145

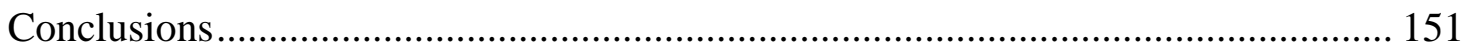


Chapter VI: Anxiety Surrounding Scammers, Gold-diggers, and Abusers .................... 153

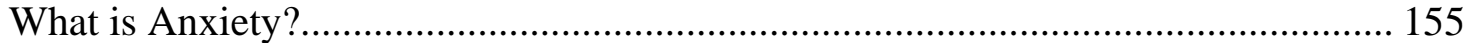

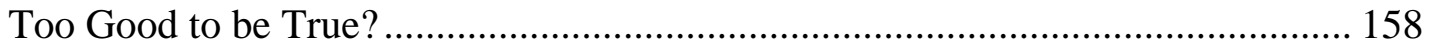

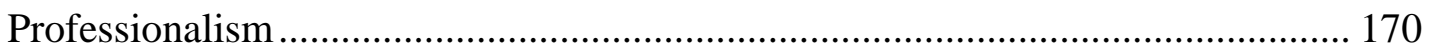

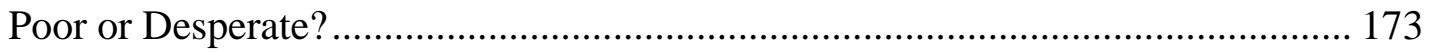

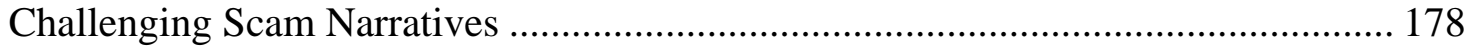

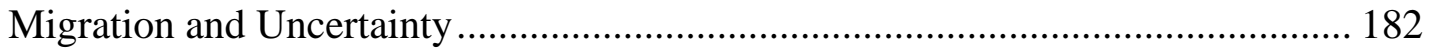

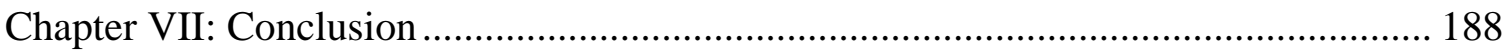

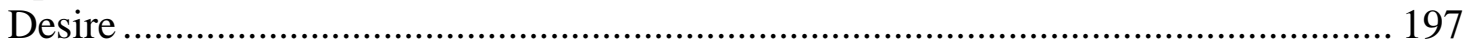

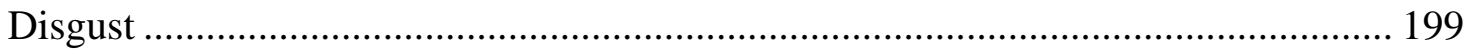

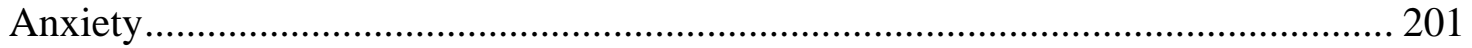

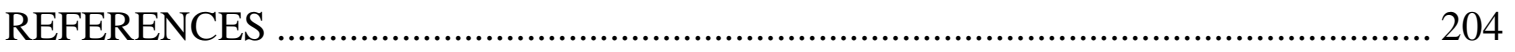

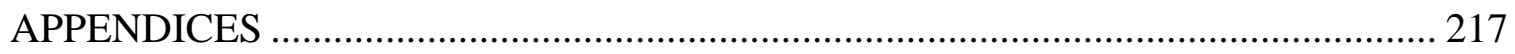

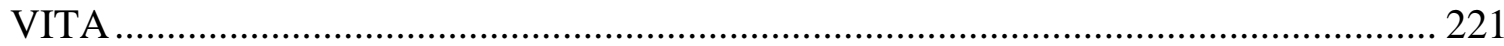




\section{Chapter I: Introduction}

The first time I ever saw Brad was on NBC’s Nightline in a segment entitled “From Ukraine with Love”, which focused upon the romance tour and so-called 'mail order bride’ industry. I watched, fascinated, as Brad's story unfolded: he was a single father from a small town in Pennsylvania and had no luck finding single women in his age group (over fifty five) to date. After years of trying to date local women on internet websites, he came across the website, loveme.com (ran by the international introduction agency A Foreign Affair), and discovered the world of international internet dating. He immediately began corresponding with women in Ukraine and developed a few correspondence relationships with women he met on the site. After a few months, Brad decided to take the plunge and attend a romance tour offered by A Foreign Affair, the industry leader in providing tours. The Nightline episode highlights the ways in which Brad, and the other men attending the tour in Ukraine, experience a boost in their dating currency abroad: hordes of attractive and young women were drowning all of the American ${ }^{1}$ men in attention. Brad, like many of the other men, reveled in their new-found female attention.

The Nightline episode follows Brad throughout his tour experience, showcasing the social events that AFA stages in Ukraine. The 'socials' are large parties held at a local event hall or nightclub, and they feature a highly imbalanced gender ratio favoring the

\footnotetext{
${ }^{1}$ The phrase 'American men' refers to men from the United States. While recognizing that this can be a problematic term, as 'America' also refers to Central and Latin America, I am using the term men used in reference to themselves.
} 
men on tour. Brad met a few women at the social, but the main relationship he traveled to Ukraine for did not end well. After watching Brad's story on television with great interest, I was shocked to see him in the hotel lobby when I arrived in Kiev to observe one of A Foreign Affair's tours. I immediately began a conversation with Brad to find out why he was in Kiev again, and came to discover that Brad was actually one of the AFA tour leaders during my observation time. The tour we were both attending was Brad's ninth with AFA, and he is what I call a 'repeat offender': men who attend multiple AFA tours in a continual search for a mate. While the romance tour industry promotes the notion of heteronormative marriage in order to differentiate itself from the sex tourism industry, many of the repeat tour offenders I interviewed enjoyed traveling and dating new women on a regular basis. Brad enjoyed his tours with AFA so much that he now works on occasion as a tour leader and has begun his own website, A Foreign Bride Guide. While Brad has not yet found the wife of his dreams, he still preaches the romanticized ideal of love promoted by marriage agencies. The ideal of love promoted by agencies is intimately intertwined with the development and democratization of consumption, leisure and tourism. Emotions like love and desire are felt at the individual level, but they are collectively framed, in terms of living the experience, and how that experience is articulated to others (Picard 2012).

Brad's story on Nightline inspired me to research the so-called 'mail order bride' industry and the romance tours that A Foreign Affair conducts in Ukraine, Colombia, and the Philippines. I consider the world of commercialized romantic tours and introductions to be an important site of neoliberal economic recolonizations, while at the same time recognizing the ways in which marriage migration challenges our conceptions of love, 
agency, heteronormative marriage, and sexuality. I seek to explore the international marriage and romance tour industry in terms of two important research questions: In what ways do individual affects and emotions help to (re)produce, and at times challenge, globalized hierarchies of desire that privilege certain gendered, racialized, classed, and sexualized positions? At the same time, how do neoliberal economic processes on the transnational stage impact individuals' emotions and affects, especially in terms of desire, disgust, and anxiety? By conducting a transnational study of three different commercialized romance tour sites, I aim to advance transnational feminist theorizing regarding the ways in which intimate processes shape transnational hierarchies of gender, race, class, and sexuality and vice versa. In addition, I aim to highlight the ways in which whiteness is an ever shifting and changing concept, through discussing many men's attempts to 'whiten' exoticized women they meet on tour. Despite the fact that tourism may seem 'harmless' and a means of cultural exchange, many tourist industries reify existing imperial structures between countries in the Global North and South.

\section{Why Tourism?}

Tourism is a social arena in which the relationship between the physical motion of the body and the emotions subjectively experienced by a person becomes most obvious (Picard 2012). For Picard (2012), tourism is the best field to study people’s articulations of subjective experiences of the world and how they interact with the emotional and cognitive cultures through which their experiences are framed, discussed, and learned. Tourists often experience heightened emotional states while traveling abroad that are considered distant and distinct from their daily routines. Bauer and McKercher (2003) argue, “Tourism represents an escape from one’s normal life, a chance to become another 
person temporarily, or to engage in another lifestyle. Liminality, or the temporary dislocation of the tourist from his or her normal life, explains why tourism, love, sex and romance are so closely linked”. Travel allows people to disengage from their 'normal' day to day existence and expand their horizons regarding romances and sexual experiences that they may normally consider taboo at home and thus, tourists engage in crossing social thresholds that are typically not accessible in their home countries.

The liminal nature of tourism and a sense of geographical distance allows tourists 'free reign' to transgress certain boundaries associated with the proper distribution of affects and emotions in regards to race, gender, sexuality, and class that they would not normally cross at home. Several scholars have discussed the ways in which tourism provides an important space of sexual transgression between men from affluent countries and women from less affluent countries (Cabezas 2009; Enloe 1990; Kempadoo 1999, 2004). Sex tourism itself is a complex phenomenon, as many different forms of touristic sexual encounters exist in the transnational economy, and not all sexual encounters between tourists and locals are clear-cut economic transactions. A large gray area exists in the realm of 'sex' tourism, and many American men are seeking out 'girlfriend experiences' (Bernstein 2007; Sanders 2005) or a local girlfriend to come visit whenever they are on vacation (Brennan 2004). Many sex workers enter into the sexual economy in the hopes of marrying a foreigner in order to migrate. As Sassen (2002) argues, many women have developed new survival circuits and strategies in order to cope with the deepening economic inequality in the Global South. Sex work has become so embedded in social relations that it is often seen as one of the few survival strategies for women in postcolonial societies; sexual labor is often viewed as a supplement to low wages or 
viewed as a more profitable alternative to employment in free trade zone factories, domestic service or other forms of manual labor (Kempadoo 2001, 2004). Transactional sex (Kempadoo 1998) allows for sexual labor to become a medium of exchange, and can include security, intimacy, opportunity, and pleasure, not simply money. Romance Tourism

Pruitt and LaFont (1995) term the phenomenon of women ${ }^{2}$ from the Global North traveling to the Caribbean and Africa in search of sexual relationships 'romance tourism' in order to differentiate women's experiences from 'traditional' heteronormative sex tourism engaged in by men, where money is exchanged directly for sexual services. Women engaged in these 'relationships' do not simply give these local black men money for sex: they engage in 'relationships' with them and tend to buy them gifts, dinners and plane tickets. Instead of being stigmatized as prostitutes, male sex workers call themselves players, hustlers, beach boys, or gigolos, demonstrating that males retain some form of agency in sex work (Kempadoo 1999). Sanchez Taylor (2006, 43) argues against a distinction between American women and men's participation in sexual tourism and instead claims, “female tourists' sexual-economic relationships with local men are predicated on upon the same global economic and social inequalities that underpin the phenomenon of male sex tourism.” White female tourists sexualize, objectify, and fetishize black men's bodies in the same ways white male sex tourists objectify and fetishize black women's bodies (Sanchez Taylor 2001). Thus, an important scholarly

\footnotetext{
${ }^{2}$ Predominately white women seek out exoticized men in the Caribbean and Africa, but not always.
} 
understanding of 'romance tourism' exists that significantly differs from the type of romance tourism that I seek to interrogate in my project.

The term romance tourism is utilized by international introduction agencies to differentiate their services from sex tourism and notions of 'girlfriend experiences'. Many agency websites strive to distance themselves from sex tourism by constantly referring to the women as 'ladies' and the men as 'gentlemen', and by assuring men that these women are not ‘bar girls’ or sex workers (Angeles and Sunanta 2007; Constable 2003). In order to ensure that introduction and romance tours are not construed as selling sex, the discourse utilized by agencies 'classes' up the process by focusing on marriage minded gentleman and ladies. Bud Patterson in his guidebook Foreign Bride 101 warns potential male romance tour participants against simply looking for sex on tour, "Foreign women just don't need us for casual sex. Their culture is full of guys everywhere who ONLY want that, and most of them are younger and in better shape than we are. These women want more than what their men are willing to give them.”3 In Bud's opinion, most women on the website are looking for a more serious relationship and are not looking to engage in casual sex, let alone sex for money. Bud also mentioned to me that Ukraine is by far the most popular tour site.

The popularity of the 'white' Slavic bride speaks to the (re)production of racialized neocolonial hierarchies of desirability within the international marriage market, which privilege lightness and whiteness as beautiful. Men attending tours in more

\footnotetext{
${ }^{3}$ Page 339 of Foreign Bride 101: A “How-To” for Nice Guys by Bud Patterson, copyright 2008.
} 
'exotic' locales still characterized Ukrainian women as the "most beautiful” group of women on AFA's website, but felt that Ukrainian women were also the most insincere. In order to tease out the development of racialized and gendered neocolonial hierarchies of desirability within the romance tour industry, I followed a romance tour with AFA in their most popular tour locations: Ukraine, Colombia, and the Philippines. I posit that romance tours are sites where the global intimate is produced, through individual emotions and affects that (re)create, and challenge, globalized hierarchies of beauty, desirability, and marital acceptability.

Neoliberal economic shifts have impacted intimate relationships in important ways, especially ‘love’ relationships. Many of the American men attending tours feel emasculated, much like Kimmel’s (2013) angry white men, in the current transnational economy that has deprived them of certain privileges that they feel entitled to, such as a 'traditional' wife. Despite the fact that many of the men I interviewed were largely middle class, they still complained about the low currency they experience within their own local dating markets. In addition to feeling as if their masculinity is undervalued in American culture, men on tours argued that women working outside of the home and the 'feminist' movement have damaged 'Western' society. Many American men seek to recapture the masculinity that they feel entitled to by attending tours in countries where they are considered desirable, on the basis of their association with affluence and transnational mobility (So 2006). On the other hand, women in Colombia, Ukraine, and the Philippines have faced the neoliberal restructuring of their economy in different ways then American men. 
Women in all three countries have begun to adopt a variety of neoliberal survival strategies, of which marriage migration is just one option. Women in the Philippines have become the 'global servants of capital' (Parreñas 2001), providing care work in over one hundred countries. Since the regime of the infamous Ferdinand Marcos, the Philippines has focused on creating a migrant labor force that serves global capitals’ needs: most female migrants study nursing or train for other care industries. In Ukraine, many women turn to migratory sex work or 'professional dating' in order to cope with the declining economy. Colombia's continual drug war and implementation of neoliberal economic policies encourages many women to seek out alternative employment options.

In common 'Western' discourses, 'true love' is defined by ideals of untainted intimacy, mutual pleasure, and emotional comfort (Cabezas 2009; Illouz ; Padilla et al. 2007). In the discourses surrounding love, 'true' love has nothing to do with monetary exchanges, and therefore, relationships based upon economic strategy are not considered 'real love'. However, markets, monetary exchanges, and strategic behaviors coexist with friendship, intimacy, closeness, and love. Market transactions do have emotions and many intimate relationships have economic dimensions. The classed nature of the romance tour industry is highlighted through men and women's experiences of economic shifts, and how economic shifts have influenced their notions of love. Love has become a big business in the transnational economy and certain discourses of love prevail in the U.S. and they create a 'democratic utopia of love' (Illouz 1997). The democratic utopia of love Illouz (1997) describes is classed, and its classed nature is intensified by dramatic economic changes. The ideal of love produced by the contemporary market denies the 
importance of class in our choices of a spouse; popular discourse presents physical and intellectual attraction as naturalized preferences and choices.

Since relationships possess economic dimensions, Padilla et al. (2007) argue for adopting a political economy of love theoretical framework in order to examine the way large scale shifts in political economy impact the lived experiences and various practices of intimacy that exist worldwide. In the framework of the political economy of love, intimacy is fundamentally linked to social and economic inequalities. Padilla et al. (2007) demonstrate that love and intimacy are socially and emotionally organized in our daily lives and at the same time, they influence how resources, hierarchies, and power are distributed in the transnational economy. Love is not the only emotion to color people's search for a mate across national borders: the emotions of desire, disgust, and anxiety also play significant roles in shaping romance tour participants' understandings of race, color, sexuality, class, nationality, and gender.

\section{Chapter Summaries}

Since I will be analyzing the importance of affect and emotion in creating notions of race, gender and sexuality in three different regions/countries, I decided to organize my work around different emotional themes: desire, disgust and anxiety. For any work utilizing a transnational feminist theoretical framework, each country must be situated in its proper historical, political, and economic context. Therefore, my dissertation begins with a chapter providing a brief history for my three cases: Colombia, the Philippines and Ukraine. Within each country, I discuss the importance of colonial and neoliberal histories that influenced the development of intimate tourism industries. I then move to 
discussing the ways in which intimate tourism remains an important part of each country's economy.

The second chapter analyzes the emotion of desire and its importance in creating the transnational romance tourism industry. I begin by discussing colonial regimes of control over desire and affect and then move to contemporary colorized hierarchies of desire that manifest in complex and interesting ways within the romance tour industry. Following a discussion of racialized desires, I shift to discussing the manner in which American male tour participants construct notions of a desirable mate and how they construct particular foreign women as fitting these notions better than local American women. Women from Colombia, the Philippines, and Ukraine also desired certain qualities in potential marriage partners.

The third chapter deals with the emotional pair to desire, disgust, and begins with a theoretical discussion of the interplay between these two emotions. Then I move to situating American male tour participant's disgust with their local options in the U.S. in a larger global context of racialized desires. Most American men on tour found the most disgusting aspect of potential American wives to be their appearance: slovenly, overweight, and old. White women from the U.S. are no longer the apexes of femininity: women from countries popular for romance tours are now posited as better wife material than American women, based upon their closer resemblance to 1950's ideals of white femininity. For women in Colombia, the Philippines, and Ukraine, disgust with their local options also prompted their decisions to sign up with introduction agencies. Across all three countries, many women complained that local men were unstable, unfaithful and not serious when it came to relationships. The tenuous economic situation in each of my 
fieldsites made many of my female participants feel that their local men could not provide the financial stability and security they sought.

Many women's disgust and negative experiences surrounding local men prompted them to seek alternative avenues for finding a good husband, but not every American man is considered desirable. In terms of race, many Filipina and Colombian women reacted with disgust to the thought of dating a black man. Women from these countries complained that they were already themselves too dark and, therefore, did not want to marry a darker man. In Ukraine, women reacted with less disgust to black men than 'Muslim' men, but many still considered black men to be in the realm of the 'too exotic' for a potential marriage partner. Many women's constructions of Muslim men had racialized connotations, and most women’s descriptions of Muslim men racialized them as ‘Arab’. Even in Mindanao, where a large Muslim minority population exists, being Muslim is considered an ethnic identity. A number of my female interviewees self identified as half Muslim, demonstrating the racialization and ethnicization of Islam in the Philippines.

The third chapter examines the emotion of anxiety, and delves into various theories of anxiety. I then discuss the anxieties many American men continuously expressed regarding the sincerity of potential marriage partners. Men are consistently attempting to identify potential 'scammers' versus women who they feet sincerely like them for who they were. The concern over scams, is, of course, the paradox of relationships evolving out of romance tourism: many older, and some overweight or unhygienic, men want young, beautiful women to love them for 'who they are' and not the opportunities for a better life that they may provide. Women in all three countries also 
expressed anxiety surrounding moving to a new country and leaving their family, friends, and way of life behind. Many women feel anxious regarding what they will leave behind in their home countries and how life in America will differ from the life they are used to leading.

I will conclude with some final remarks about the importance of emotions and affects in creating global processes and the ways in which global processes influence the development of intimate relationships. Romance tourism is an important window into the global intimate; how intimate processes produce global hierarchies of race, gender, class, sexuality, and nationality and at the same time, how neoliberal global economic restructuring is altering the dating landscape in significant ways by creating a commercialized transnational market for marriage. It is in our intimate daily lives that people 'feel' desire, disgust, and anxiety; these emotions shape how people evaluate potential mates in the marriage market in terms of race, class, nationality, etc. The romance tour industry often reproduces particular notions of gender, race, class, sexuality, and nationality that reinforce neocolonial hierarchies. Global economic processes also influence people's emotions, as wealth and success in the new global economy are considered positive traits that white American men possess. International romance tourism is often promoted by international dating agencies as moving beyond racial, cultural, and linguistic boundaries and the people engaging in tours are portrayed as more cosmopolitan and open minded for looking beyond their own local borders for potential mates. However, they often recreate neocolonial hierarchies instead. 
Chapter II: Theory and Methods

Numerous journalists and scholars (Hughes 2004; Jackson 2007; Lloyd 2000)

have considered the international internet dating industry to be an example of the trafficking of women, where women are literally bought and sold as if they were slaves. 'Mail order brides' ${ }^{4}$ are presented as victims of globalization, women so poor and desperate that they are willing to sell themselves to any man from the Global North. The men looking for brides abroad are often presented in media accounts as predatory males who are seeking women they can control and even abuse, and as losers who cannot find women from their own countries. Numerous scholars have questioned the narrative of trafficking (Bernstein 2007; Constable 2013; Doezema 2010; Mai 2013) that presents sex workers or 'mail order brides' as victims of mafias and pimps that lack agency or choice. Mai (2013) argues that scholars must be careful not to neoliberalize agency by using the word choice: the market operates on the basis of 'choice', therefore scholars must instead discuss decisions and strategies instead of choices. Viewing marriage migrants as victims of trafficking does not recognize the agency of these women in deciding to view international marriage as a potential migration strategy, nor does it recognize that some men may genuinely be looking for a foreign wife and that abuse does not necessarily enter into the equation (Cogua-Lopez 2010; Constable 2012; Johnson 2007; Schaeffer-

${ }^{4}$ I am attempting to deconstruct the notion of a paid-for victim bride, so I will not be using the term 'mail order bride'. Instead I will use the term marriage migrant and focus on the industry of international introductions, which only provide services for introducing men to prospective brides. 
Grabiel 2004).

Many scholars (Angeles and Sunanta 2007; Cogau-Lopez 2010; Constable 2003; Johnson 2007; Luehrmann 2004; Schaeffer-Grabiel 2004, 2006) discussing romance tourism and the marriage migration industry also highlight the importance of race in shaping American men's desires in one particular region or country. The current literature discussing racialization within the romance tour industry has less to say, however, regarding the importance of racialized desires in constructing the industry as a whole in Eastern Europe, Latin America and Southeast Asia for both male and female participants, as well as how these racialized and colorized constructions differ in each regional setting. I will be articulating a theory that advances ideas regarding a process of 'whitening' that American men engage in. A number of scholars (Constable 2003; Johnson 2007; Piller 2007) have recognized that Ukrainian and Russian women’s whiteness is often viewed as a desirable trait. I am adding to prior discussions of whiteness by examining the process of 'whitening' that American men on romance tours engage in to legitimize marrying women in Southeast Asia, Latin America and the Caribbean, who have been historically characterized as "Little Brown Fucking Machines” or LBFMs (Chang 2001; Garrick 2005; Kempadoo 2001; Tolentino 1991). I argue that American men who seek to find a potential bride in Latin America and Southeast Asia 'whiten' exoticized women through emphasizing the qualities that these women share with the 1950's version of white femininity immortalized in the icon of June Cleaver in order to move Latin and Asian women far from the category of LBFMs into the category 
of respectable wives. Most American men are searching for an 'exotic light' woman, one who is not too exotic in skin tone, religion, or location.

Returning to Brad, a repeat client and now tour guide, I argue that his tour preferences and demographic information are typical of the romance tour industry: older, white men who are interested in the exotic Slavic woman. Brad provides examples of the ways that racialized characteristics are considered a matter of personal taste and preference on his website, the Foreign Bride Guide. On the Foreign Bride Guide, Brad breaks down the racialized differences between women from different countries on the basis of their physical appearance. Brad's country of expertise is Ukraine, and he describes the local women in terms of a 'Slavic' look, "Ukrainian women benefit from the Slavic culture. They are often blond (but not always). Green or gray eyes are common. They tend to have graceful figures with long legs. Often they tend to be taller.” In comparison, Brad’s description of Latin American and Asian women is more generic, "In Latin America you will find lovely olive complexions, dark hair and eyes and striking beauty. In the Philippines, it is similar to Latin America, but the ladies are usually shorter and slim. They all look like sisters, with long dark hair.” The differences in physical appearance that Brad discusses on his site acknowledge the ways in which racialized discussions of appearance appear neutral and normalized. Even though AFA offers tours in a number of countries in all three regions mentioned before, Ukraine is by far the most popular tour destination.

\section{The Global Intimate}

I employ a transnational feminist lens in order to disrupt the constructed binary between intimate relationships and globalized economic processes. Transnational 
feminist theorizing engages with the complex and contradictory ways in which these processes structure both individual and collective agency. Therefore, Mohanty (2003) argues that feminist analyses of globalization and capitalism need to begin with the most marginalized communities of women, linking the material conditions of everyday life to larger transnational economic struggles. I argue that the romance tour industry exemplifies the global intimate and the ways in which the intimate is not just limited to the entanglements rooted in everyday life. In fact, the intimate moments of everyday life share an interconnectedness to everyday intimacies in other places and times. Mountz and Hyndman (2006), therefore, argue that the intimate and the global constitute one another in places like the body, the home, and the border. The concept of the global intimate challenges the hierarchy of scale that places the body, the home, and the intimate on a much lower level than the scale of the global or the national. The global intimate is an important conceptual insight into the globalized, but at the same time very intimate relationships, engendered through romance tourism and international online dating services. In the intimate spaces of the home and the body, international relationships created through globalized processes are negotiated and articulated, constantly challenging the imagined binary between the intimate and the global scale.

The intimate, daily non-economic interactions between people all over the world have become organized into new markets. A prime example of intimate markets is romance tourism, where the opportunity to find 'love', however one decides to define love, is a commodity sold on the international market place. Through romance tourism, the relationship between globalization and intimacy is revealed as interdependent and entangled (McKay 2006). Valentine (2006) discusses the fact that growing numbers of 
people live apart but still maintain intimate relationships via the internet. The new forms of cyber intimacy facilitated by the internet allow the romance tour industry to thrive. The internet allows intimacy to stretch beyond national and geographic borders. However, there are important limitations to conducting familial and sexual relations online. While internet technologies can facilitate various disembodied forms of knowing, loving, caring, and even sex, these technologies cannot always act as a substitute for actual physical contact. Therefore, while the majority of AFA's business is conducted via the online dating and correspondence format, those men who are considered 'serious' suitors attend the romance tours to actually meet potential brides in person, to see if chemistry or a 'spark' exists in real life. The theoretical concept of the 'global intimate' captures the importance of affect, emotion, and idiosyncrasy when conceptualizing the global relationships engendered by romance tourism.

When discussing intimate relationships, emotion and affect are an important piece of the equation. For many scholars, affect refers to a body's capability to affect and be affected and in turn (Ahmed 2010; Clough 1997; Seigworth and Greg 2010). I define affect as the motion of emotion, in order to demonstrate the "ways in which feelings can (re)produce dominant social and geopolitical hierarchies and exclusions”(Pedwell and Whitehead 2012). In order to demonstrate the importance of emotions and affect in (re)creating geopolitical hierarchies within the romance tour industry, I will examine the ways in which affect and emotion influence romance tour participants' constructions of the race, gender, sexuality, desirability, and most importantly, marital desirability of each another. 
Recent scholarship has begun to demonstrate the importance of affect and emotion in terms of constructing ideas of race and gender. Race and gender both are identities that are performative ${ }^{5}$, and these performances possess both affective and spatial dimensions (Butler 1997). Hage (1998) introduces a concept of whiteness as an affective 'yearning' for social mobility or citizenship, similar to Saraswati's (2010) theory of desiring 'whiteness' for its affective relation to transnational mobility and cosmopolitanism. Since affect and whitness are often linked together in positive ways, Han (2006) describes whiteness as desired capital, one that attaches to bodies that possess European or ‘Caucasian’ features, such as blue eyes, straighter hair and small noses. Raj (2011: 6) argues, "Whiteness, in particular, becomes a privileged form of desiring capital, enabling bodies that 'pass' as 'White', while marking out bodies which do not. Racial 'others' become produced in the transnational economy of desire as fetishes or repugnant objects.” Caluya (2006) demonstrates that many people’s racial recognitions of other's bodies involve being marked as either exotic (through a fetishizing of certain racial minorities) or sexually undesirable in relation to a discourse of whiteness. Saraswati (2010) argues that while 'whiteness' is often associated with cosmopolitanism and mobility, most Indonesian women utilizing skin bleachers in fact seek to attain ‘cosmopolitan whiteness', not necessarily 'Caucasian whiteness', demonstrating that a multiplicities of whitenesses exist (Kimmel and 2013). Rondilla (2009) agrees that

\footnotetext{
${ }^{5}$ Butler's concept of performativity states that words or signifiers do not simply name things already in existence, but in fact generate and create the things they name. Here is the reiterative power of discourse: that which is reiterated constantly shapes and reshapes reality. Butler discusses the performativity of gender, and how we create and re-create gender norms through our daily performances in her seminal work Gender Trouble.
} 
positive affects and emotions are associated with fair skin in the Philippines. Light skin is termed the affluent skin in Tagalog and is connected with positive values that relate to class, lifestyle, and beauty. Rondilla’s (2009) discussion surrounding fair skin in the Philippines demonstrates that 'lightness', an attainable version of whiteness for Filipinas, is often more desired than Caucasian whiteness itself.

Within the romance tour industry, affective and emotional constructions of both race and gender are constantly being negotiated and articulated by both male and female participants. American men who participate in romance tours often begin exploring the romance tourism industry by searching for Russian and Ukrainian brides, since they are the foreign women who most closely resemble the stereotypical 1950's idealized version of American middle class white femininity. The men who attend tours in other, more 'exotic' locales tend to be frightened away from Ukraine by past participant's horror stories or their own unsuccessful past endeavors in Ukraine. Within the global sex industry, black women are often constructed as oversexed whores that are simply meant for brief and anonymous sexual encounters: these women are not appropriate future wives. O’Connell Davidson and Sanchez Taylor (1999: 45) argue that black women are "not sought out for longer term or quasi-romantic commercial sexual relationships." Instead, most American men are seeking to marry an exotic woman, but one that is not too exotic.

In the political economy of desire, women from Southeast Asia, Latin America and the Caribbean, who fall into the catchall category of 'Little Brown Fucking Machines' (as they are neither white nor African), are placed above women who appear too African or black, as well as lazy, white American women. However, women from 
regions known for LBFMs are still considered as less desirable than exoticized white women, such as Ukrainian women, in the desirability hierarchy of potential wives. O’Connell Davidson and Sanchez Taylor (1999) point out that the phrase LBFM has militaristic and imperialist undertones, as the term originated with American service men fighting wars in Southeast Asia. In contemporary times, the term has spread to include women in the Caribbean and Latin America. Many American men I spoke with on tour in exotic locations pointed out the traditional femininity of women there, and it is through the trope of traditional femininity that men are able to 'whiten' a LBFM into a respectable wife. The men I encountered on exotic locale tours were searching for 'lighter' women that did not possess stereotypically African features, as these women are considered more 'beautiful'.

While race is an ongoing discourse that shapes constructions of beauty and desirability, many scholars have discussed the more nuanced notions of 'color', 'shade' and 'lightness' and their influence upon beauty standards. Nakano Glenn (2009) defines colorism as a preference for lighter skin that leads to the creation of a social hierarchy based upon skin tone, phenotype, hair texture, eye color, and nose size. Skin color is part of a continuum that cross-cuts racial categories and lighter skinned minorities typically possess higher socioeconomic status, higher educational attainments, and higher incomes than their darker skinned counterparts (Hunter 2005). Nakano Glenn (2009) claims skin color is a form of symbolic capital that has actual exchange value and is, therefore, an important asset that furthers people's life chances. The idea that skin color is symbolic capital holds especially true for women, since light skin, and the phenotypical features associated with light skin, are linked to beauty ideals. The beauty queue is on display in 
the romance tour industry, since most of the men engaged in the industry in Colombia and the Philippines seek to find women that do not possess stereotypically 'African' features, such as kinky hair. Men in the Philippines are more likely to desire darker skinned women, because no matter how dark a Filipina is, she remains in the 'Asian' racial category and distanced from blackness.

Hunter’s (2005) notion of the Beauty Queue explains how sexism and racism interact to create a queue of women from the lightest to darkest, where the lightest women get the most resources and the darkest get the least. The lightest women get more access to resources because they are lighter skinned and, therefore, racially privileged, but they also receive 'pretty privilege', since their light skin is also interpreted in our culture as more beautiful. Thus, light skinned women are doubly privileged. The conflation of beauty and light skin is an example of how racial aesthetics operate: lighter skinned people with more Anglicized features are viewed by most in American culture (either consciously or unconsciously) as superior. The conflation between beauty and light skin is most prominent in Colombia, since Colombia’s racial spectrum includes a large number of Afro-descent women that many of my interviewees found unattractive. Many women in Southeast Asia and Latin America attempt to acquire light skinned privileges through the use of cosmetics, skin bleach, and cosmetic surgery because of the conflation of beauty with lightness, (Hunter 2005; Saraswati 2010; Schaefer 2013; Schaeffer-Grabiel 2006; Rondilla 2009).

Rondilla (2009) quotes a 2003 report that states more than two million units of skin-lightening soap are sold annually in the global market. Fifty percent of Filipina respondents currently used skin lighteners and Rondilla argues that the use of skin 
bleaching by Filipinas is not necessarily a move toward whiteness or Europeanness. Beauty ideals in the Philippines are related to East Asian or Chinese beauty standards: pale skin, straight jet-black hair, and large double-lidded, almond-shaped eyes. The hybridized beauty standard Filipinas strive to capture can be considered Asian beauty according to a white imagination. Mixed race Asian women are the new faces of Asian marketing, as they represent a 'relatable ideal' that Asian women can aspire to achieve that is not Caucasian whiteness (Rondilla 2009; Saraswati 2010). Hunter’s (2005) beauty queue posits East Asians and Chinese as lighter, wealthier, and more beautiful than darker-skinned Filipino women. In the past, many Filipinos strived for beauty ideals reflecting Spanish or 'European features': smaller, thinner noses, lighter skin, larger eyes but that now they are looking more towards the Chinese mestizo upper class population and East Asian beauty standards.

Besides seeking cosmetic solutions in their search for lightness, many Filipina women seek lighter partners for marriage in order to lighten their progeny. Therefore, most of the Filipina women I spoke with mentioned to me that they were more attracted to white men than African American or Hispanic men. Filipinas typically looked to lighten their progeny, not darken them, and often felt that they were already 'too dark' to mate with an even darker skinned person. A few of my Filipina interviewees even went so far as to directly cite lightening their progeny as the reason they signed up with the agency to find an American husband. Many Filipina participants in the romance tourism industry desire a form of transnational whiteness that is associated with American men and the lighter skinned progeny that they can potentially achieve through marrying an 
American man, and at the same time, marriage with American men also increases their transnational mobility.

The beauty queue is on display in the Colombian context as well, in both American men's understandings of beauty and Colombian women's understanding of racialized desirabilities. The discourse of Blanqueamiento (whitening), which aims to whiten populations through increasing European immigration, has a long history in most of Latin America. The ideology of blanqueamiento encourages Latin American women to seek lighter marriage partners, to lighten future generations. Bonilla Silva and Dietrich (2009) identify the Latin American color system as a 'pigmentocracy', which orders or ranks groups according to phenotype and cultural characteristics, such as class. They argue that the pigmentocracy is porous: people can move to different strata through various 'lightening’ techniques: marrying a lighter person, having a lighter child, and increasing one's socioeconomic status. Since many parts of the world, even prior to colonization, have traditionally held a preference for lighter skin tones, phenotype features become more of a predictor for social stratification outcomes in the Latin American context.

While skin bleaching as a method of 'whitening' is much less common in Colombia than it is in the Philippines, elective surgical modifications to possess whiter phenotypical features is more common in Colombia. Schaeffer (2013) discusses the way in which many Colombian women seek to improve their desirability quotient in the global market by altering their bodies through plastic surgery. In Cali, the women are more racially mixed than in Medellin, and Schaeffer (2013) observed, Nose jobs and breast implants are all very common in Colombia: some women can even receive public 
funding for plastic surgery. In addition to altering their bodies to 'whiten', many Latin American women are encouraged to find lighter skinned partners for marriage, in order to lighten future generations. By seeking lighter partners, Sue (2009) claims that many Latin Americans ${ }^{6}$ seek to whiten themselves within the mixed race category by avoiding marrying partners with ‘African’ phenotype features. Within the Latin American color continuum, whiteness is still valorized and desired, but typically through a process of racial mixing. The racial mixing process aims to eventually lighten the whole population. Thus, Latin American women involved in romance tourism desire to achieve whiteness through racial intermixing and many of my Colombian interviewees also sought white American men, and at the same time tended to avoid African American men. The women who desired white American men focused on lightening their future progeny. Many women in Colombia are open to dating and marrying 'moreno' (brown) men or Hispanic men, but most would prefer not to marry an African American man.

Within Ukraine, black men are hyper-exoticized. As numerous interviewees pointed out to me, Eastern Europe does not have a lot of Afro-descended people migrating there, nor is there a history of a large African presence in the region. For most of my Ukrainian interviewees, African American men and Hispanic men appear very exotic. Some of my interviewees in the Ukraine felt that non-white American men were too exotic for them, and that the cultural differences would prove to be too much for a successful marriage. On the other hand, more women in the Ukraine were tempted by the exoticness of black men than in Colombia or the Philippines. A number of my Ukrainian

\footnotetext{
${ }^{6}$ In the specific case of Veracruzano Mexicans.
} 
interviewees are more open to Asian and black men than women in countries who felt that they were already 'too dark'. In Colombia, African descended men are not considered exotic, as the color spectrum ranges dramatically in comparison to Ukraine. In the context of the Philippines, many Filipinas did not find so called 'chocolate' men attractive, but a significant undercurrent of fascination with black men exists in many Southeast Asian countries.

In addition to being considered less desirable, dark skin is also equated with nonnormativity. A number of scholars (Stanfill 2010; Weed 1997) argue that both heteronormativity and homonormativity are maintained through their unmarked whiteness. Thus, Ferguson (2000) argues that African-American existence has always been marked as nonheteronormative. Throughout American history, blackness has been associated with nonnormative family structures and perversions. According to Ferguson (2000: 423), “As figures of heteronormative perversions, straight African Americans were reproductive rather than productive, heterosexual but never heteronormative [italics from original].” Thus, blackness and homosexuality have often been subjected to the same types of regulations and exclusions from larger American society, as they are located outside of the space of white heteronormativity and desirable marriage partners.

The relationships engendered through romance tourism are liminal, and often transgressive, in terms of racial barriers (the major exception of course is Ukrainian women), but many men on tour attempt to 'normalize' their choices of exotic women through discourses of traditional femininity. Beal's (1970) essay on being black and female highlights the ways in which race and gender are not essentialist categories, but systems of valuation and devaluation under a capitalist economic framework. The 
capitalist system constructs normative categories and these categories are then racialized, gendered, classed, and sexualized all at the same time. People who do not fit into these norms are subject to marginalization; for example, black people are categorized as sexually nonnormative and are then punished for their perceived transgressions. Through destabilizing the assumption that sexuality, desire, and gender are dichotomous, binary identities, queer theorists challenge the ways in which heterosexuality remains unmarked and under discussed (Butler 1997; Epstein and Johnson 2004; Shah 2012). In order to further discussions of nonnormative expressions of heterosexuality, I queer the romance tour industry, an industry that purports to uphold traditional notions of heteronormativity. Many American men on tour attempted to normalize seeking a foreign bride through discourses of traditional heteronormativity. Thus, men continually pointed to the fact that Ukrainian, Colombian, and Filipina women embodied a more traditional understanding of femininity, gender roles, and heterosexual relationships. Despite American men’s best efforts at normalizing their searches abroad for a wife, it is still a nonnormative expression of heterosexuality, since it encourages crossing ethnic, and often racial, boundaries.

\section{Methods}

I begin my methods section by taking a moment to discuss how I was able to gain access as a researcher to A Foreign Affair. I first visited Thailand in order to begin my research about the romance tour industry, and arrived unannounced at a very small agency run by a British man and his Thai wife. The agency was off the beaten path in Bangkok and very difficult to find. As I waited in the living room of a small house with five local Thai women to see the owner, I began to strike up conversations with the 
women who were waiting with me. After five minutes, the Thai wife of the owner appeared and demanded that I stop speaking to the local women. She immediately wanted to know who I was, why I was there, if I was a journalist, and how I found their office. After explaining to her that I am an academic interested in conducting research, she told me that I would need to speak to her husband in order to gain permission to interview anyone, and he was conveniently out of town. After leaving the office, I felt disheartened and hoped that I would find a company open to researchers within the U.S.

After returning to the U.S., I realized that following only one romance tour company, A Foreign Affair, would be the easiest way to gain access to tours in various countries. I began my relationship with AFA by attending a free 'open house' seminar in Fort Lauderdale. The seminar featured one of the owners of AFA, John, and his Russian wife, and they described to the men in attendance the procedures, potential pitfalls, and logistics of the romance tour experience. Once the seminar ended, I introduced myself and asked permission to attend tours in three locations. John welcomed my interest in the industry and told me that whatever tour I wanted to attend, I could. All he asked was that I come into the experience with an open mind.

Since John allowed me access to any tour site that I wanted to attend, I conducted my research solely through AFA, as it is one of the largest U.S. based international marriage broker companies. Following only AFA tours will help to limit extraneous variables when looking comparatively at women in different areas and allow for the isolation of the impact of regional and national differences on the tour experience. On the other hand, I recognize that my knowledge of romance tourism is situated within the context of only AFA, as I cannot speak to the processes and policies of any other 
romance tour providing company (Haraway 1988; Rose 1997; Stoetzler and Yuval-Davis 2002). AFA is a large introduction agency based out of Phoenix, AZ and is compliant with all International Marriage Broker Regulation Act standards; they have allowed numerous news media, such as Nightline, Lisa Ling and the New York Times, behind the scenes to examine their business practices and romance tours. A new reality television show called Bachelors Abroad on National Geographic features four men attending an AFA tour and their tour experiences, which 'exposes' the realities of legal international introduction agencies and romance tours. I would like to emphasize that AFA is a completely legal, legitimate marriage introduction agency that does not engage in illegal activities, such as human trafficking.

AFA is the industry pioneer in terms of romance tours and began providing tours to Russia in 1995. Since 1995, AFA has led over 435 tours and hosted over 1000 socials. AFA has expanded its tours beyond Russia ${ }^{7}$ to the Ukraine, the Philippines, China, Colombia, Peru, Costa Rica, Thailand and the recently added Dominican Republic. It is important to note, that like any other transnational business, AFA outsources many of its services to local introduction agencies on the ground in each country. For instance, in Colombia, the local office is run and operated by the Arizona office. However, the local office in the Philippines is outsourced to a local Filipino run agency called HLC Lifemates. Within Ukraine, the office in Kiev is run by AFA while the office in Sumy is run by a small local agency. In addition to outsourcing the management of certain tour locales to smaller local agencies, AFA also outsources a lot of its recruiting of female

\footnotetext{
${ }^{7}$ In fact, at the moment of writing, they no longer provide group tours to Russia because of the difficulty and cost associated with obtaining a tourist visa to Russia.
} 
profiles to local agencies. The term 'profile' is how the agency describes each woman who is signed up on the website and I will be using the term in the same manner to describe females participating in the tours, while I will utilize the term participant to describe the men attending tours. Many women who have profiles on the agency websites also work for the agency as translators. Numerous women I met working at the agency in Ukraine and the Philippines also are profiles on AFA's website. However, none of the employees I met in Colombia had any interest in dating American men, an interesting difference. In order to tackle an industry that is truly transnational and multi-sited, I adopt a methodological framework of global ethnography.

Global Ethnography

Burawoy (2000) argues that global ethnography is not an oxymoron; in fact, researchers are embedded in the global processes that they study. In order to conduct global ethnography, the notion of fieldwork has to become flexible in order to adjust to the time-space coordinates of the subject population one is studying. My subject population exists in many countries of the world, but due to limited time and funds, my ethnography includes one site from each region popular for romance tourism. Thus, my work on romance tourism is multi-sited, since it is a truly transnational phenomenon. While Colombia, the Philippines and the Ukraine differ in important ways, all three sites are connected through histories of colonization and the development of intimate tourism industries. Any global ethnography must be grounded in the local histories of each site; therefore, I begin by situating each fieldsite in its proper historical and economic contexts. The method of conducting a global ethnography acknowledges and highlights the mutual shaping of intimate and global forces. Therefore, global ethnography is the 
appropriate methodology to utilize in order to tease out ways in which the global intimate is created in the everyday experiences of romance tour participants.

As a transnational feminist ethnographer, I am inherently embedded in the global processes I am studying and thus, I must discuss my positionality in the field (Moallem 1999; Mohanty 2003). As a middle class white American woman pursuing my education, and in doing so delaying my own marriage and family aspirations, I appear to be most American men's example of what is 'wrong' with American women. Despite the fact that most American men complained about women who shared characteristics with me, they felt strangely comfortable discussing their feelings towards other American women with me. I largely attribute men’s comfort with me as a researcher to two things; I adopted a non-judgmental attitude in all of my interactions with anyone involved in the industry and my position as a fellow 'member' of the tour, and fellow outsider, allowed me into the 'trenches' with the men. The tour in Ukraine was especially grueling, since we took four hour bus rides between three cities in eleven days. In the liminal atmosphere of touring a foreign place, many men develop lasting friendships and bonds and become tour buddies.

While a number of American men on tour considered me a fellow 'comrade' in the trenches of the tour experience, accessing women in each country presented interesting challenges. In Colombia, the language barrier was a serious roadblock at first; over ninety percent of the female profiles in Colombia do not speak English and I do not speak enough Spanish to conduct an in depth interview. However, I was beyond fortunate to have an extremely wonderful and helpful staff working at the Medellin office, and they offered to help me translate for my interviews, as well as suggest women they thought 
would be open to talking to an interviewer. Women who saw me at the socials also approached me interested in who I was, as I clearly stuck out from the rest of the women attending the party. Standing out from the local women helped me even more in the Philippines, where large numbers of local women approached me at the socials, wanting to take photos with me. My whiteness and femininity made me a local 'star' with the female profiles attending the socials, as not many white American women come to Davao. Thus, I had the easiest time accessing female informants in the Philippines, since they were interested in me and spoke English. In Ukraine, I 'blended in' to the larger Ukrainian population, and my status as an American did not help me gain interviews. In fact, I had a difficult time accessing many women in Ukraine to participate in interviews as a cultural reservation towards talking to outsiders ${ }^{8}$ remains in many post Soviet societies. Therefore, while I was able to talk to thirteen women in Colombia and sixteen women in the Philippines, I was only able to interview seven Ukrainian women, another limit to my study.

I began my fieldwork in Medellin, Colombia with a two-week pilot study during April of 2011, where I observed a romance tour and individual dates between American men and Colombian ladies. Seven American men were attending the tour that lasted a week. The tour began on a Thursday with the men's arrival from the airport to the hotel where all tour participants were staying and an orientation at the hotel providing background on how to navigate Medellin and Colombian culture. Friday and Saturday

${ }^{8}$ As a child of Hungarian immigrants, I distinctly recall my parents always telling me to be careful whom I told what to, based upon their own political experiences in a communist regime as children. 
were the days of the main events: the social parties agencies promote as an opportunity to meet literally hundreds of beautiful and available women. Eleven tables were set up for all the male participants ${ }^{9}$ and eight women were sitting at each table. The men went around to each table of women for fifteen minutes. The 'speed dating' ${ }^{10}$ (of course with an imbalanced gender ratio) portion of the evening is followed by a formal dinner and shots of Aguardiente ${ }^{11}$. At that point in the evening, all the men and women are allowed to get up from their tables and dance with one another. Many women leave after the dinner, and after the dancing and drinking begin to wind down, a majority of the men and any women they are interested in getting to know further begin to make plans to go out to night clubs in the area.

The same process is repeated the next night with a different set of eighty to one hundred women. If the men do not find someone they connect with at the socials, they may go to the local office of AFA in each tour city and examine binders full of women's profiles. The men then choose women's profiles they would like to potentially date, and the local office employees call the woman to see if she is interested in a date. By providing all the services mentioned, AFA delivers on its promise to introduce the men participating in these tours to hundreds of women. During my tour experiences, I followed the men and conducted semi-structured interviews with a majority of them, as well as some of the women they dated during the tour. I also conducted a focus group

\footnotetext{
${ }^{10}$ Speed dating is a practice of meeting one-on-one with dates for a few minutes and moving from table to table.

${ }^{11}$ Literally translated as 'fiery water', Aguardiente in Colombia is an anise-flavored liquor made from sugarcane that is popular in the Andean region.
} 
with four employees working at the local agency office. During my pilot field experience, I was only able to collect three female participant interviews, so I returned to Medellin the following July. I spent five weeks in Medellin interviewing men who had just 
finished a tour, more female tour participants and more employees of the local office who worked as translators.

The Colombian tour was the smallest I observed, with only nine men in attendance. Most of the American men participating were white, older than forty, and mid to upper class in terms of socioeconomic position; however, two men were younger than forty, one was working class, and one was from a Hispanic background. The men on tour came from all over the U.S.: Texas, California, Colorado, Georgia, and Florida. In terms of the Colombian women signed up with the agency, most were under forty years old, and many of them already had children from previous relationships. The employees I spoke to at the agency disagreed about the women's class demographics: the most senior employee I spoke to claimed that most of the women are from poor neighborhoods, while the assistant manager argued that a third of the women are poor, a third are professional, and a third are middle class. The majority of my female interviewees finished a vocational degree. Most women in Colombia do not speak English, and most men on tour do not speak Spanish. Therefore, many of the translators and local employees have the linguistic advantage over many of the women signed up. Despite their linguistic advantage, many of the employees in Colombia were not interested in dating the American men on tour at all, a situation unique to Colombia. In Ukraine, on the other hand, many women who worked as translators were also signed up as profiles with AFA.

While the tour experience in Colombia was intimate and small, with very formalized social events, the next tour experience in the Ukraine was a much different experience. I spent four weeks in the Ukraine, following an eleven day long tour that traveled to three cities within the Ukraine: Kyiv, Poltava and Sumy. The Ukraine is 
AFA's 'cash cow', and leads the other countries in the number of tour destinations and dates. Nine cities ${ }^{12}$ within the Ukraine host social parties, and most tours within the Ukraine include at least two cities. Ukraine is a popular romance tour destination in Eastern Europe, based upon the fact that it does not require Americans to obtain a visa for entry (unlike Russia, which used to be the regional leader). In fact, AFA only provides individual tours in Russia and no longer organizes large group tours there. The tour I attended at the end of September 2012 started in Kiev, moved to Poltava, then moved to Sumy, and ended back in Kiev. The group of men I followed was the largest tour group AFA has ever allowed on the tour ${ }^{13}$, with forty male participants from all over the world. Besides American men, the tour included a few Canadian men, an Australian man, a Mexican man, a Polish man and a Norwegian man.

Since the tour I observed in Ukraine was numerically the largest, it was also the most diverse tour in terms of the men's demographics. Forty men participated in the tour, and I was not able to interview all of them (not all of them agreed to participate). Once again, much like the demographics in Colombia, most of the men on tour were white, relatively affluent, and over forty years of age. However, once again, there was some diversity amongst the men; I interviewed two African American participants, two men under thirty, and two men from more humble socioeconomic backgrounds. The women signed up as profiles in Ukraine were also under forty years old, many in Kiev were originally from smaller towns, and not as many women in Ukraine were single mothers.

\footnotetext{
${ }^{12}$ Kyiv, Poltava, Sumy, Odessa, Nikolaev, Mariupol, Lugansk, Kherson, Kharkov

${ }^{13}$ A controversial decision made by AFA that many of the men complained about, since it increased the competition tremendously.
} 
A few of my interviewees had children, but those tended to be women older than thirty, whereas in Colombia, many of my younger interviewees already had children. A large percentage of women in Ukraine speak English, and many of the translators working for AFA in the Kiev office are also profiles. In Poltava and Sumy, however, most of the translators and local employees were not interested in dating the men on tour.

The tour I attended featured three social party events, one in each city the tour traveled to. The social events had a much different feel in the Ukraine than the events held in Colombia. In all three Ukrainian cities, the parties were held at nightclubs and no formalized ‘speed dating’ experience occurred. Instead of a formal dinner, light snacks and bottles of free champagne were offered. Most of the American men abstained from the free champagne and paid to drink beer ${ }^{14}$ from the bars, but would use a champagne bottle to introduce themselves to large groups of women sitting at tables together. The first social event in Kiev was at a nightclub, with nearly fifty men in attendance. Only one hundred ladies attended the social, and many of my male interviewees complained that the event was a "sausage party". After the social and a full day in Kiev for dates, the tour group embarked on a four-hour long bus ride to the small city of Poltava for the next social.

The social in Poltava was also held at a nightclub, but double the amount of women attended. While there were more women in attendance at the social, a number of my male interviewees complained that the women were too young and that too many smoked cigarettes. After the social, the tour group stayed another full day in Poltava in order for

\footnotetext{
${ }^{14}$ The beer was slightly cheaper than bottled water.
} 
men to go on dates with women and then the tour bus drove off to Sumy for the final social event of the tour. In Poltava, some of the men stayed behind to spend additional time with women they met there, going against the advice of the AFA tour leaders. The tour leaders encouraged all of the male participants to attend all three socials, no matter who they met along the way. Of course, some of the guys forgo Bud's advice and decide to skip one or two of the socials in other cities to focus their attention on one woman. The final social event was held in a reception hall in Sumy, a town near the Russian border. Sumy was the smallest town of the tour, and many of my male interviewees complained about the lower class accommodations provided by the tour. During the whirlwind tour experience, and the weeks following, I was able to conduct another approximately thirtyfive semi-structured interviews or focus groups with male and female participants, as well as employees of the local agency in each location.

After the hectic tour experience in the Ukraine, I embarked on a journey to Davao City, Philippines, located in the Mindanao region. Mindanao is the only region of the Philippines with a significant Muslim population, and the Muslim separatist group, the Moros Islamic Liberation Front, has been a major source of political instability within the region $^{15}$. The political instability in Mindanao has led to Davao City’s mayor Duterte becoming well known for implementing the strictest laws and regulations in the country, and for his use of the Davao Death Squad ${ }^{16}$. Within the stricter political and social setting, the tour took on a much more conservative feel. The social in Davao had much

\footnotetext{
15 The MILF is a group fighting for increased Muslim autonomy since the 1960's.

${ }^{16}$ A group involved in vigilante/extrajudicial killings of convicted drug dealers, murders, rapists, etc.
} 
more in common with the tour experience in Medellin: the tour included two social events in one city, the social events incorporated the gender imbalanced speed dating format, and a formal dinner was served. The social event differences in Davao were that no alcohol was served and that numerous singing performances and testimonials played important center roles in the events. The socials in Davao also began with a prayer and the Philippines’ National Anthem.

Nineteen men attended the tour in Davao, and by the end of the tour, eleven were engaged. In comparison, only one couple got engaged on the Ukrainian and Colombian tours I observed. I argue that the high number of engagements occurring in the Philippines is a direct result of the socioeconomic status of many of the women profiles. Most of my Filipina interviewees were already rural to urban migrants, remitting a large percentage of their incomes back to their families in the rural provinces. Similar to Colombian women, many Filipina women were single mothers and had a vocational degree. A majority of the women I spoke to were under thirty years old, but I did meet a few women closer to forty years old. Filipina women were much more open in terms of accepting large age gaps between themselves and their future husbands, so the men on tour there tended to be older than fifty. All of the men I met on tour were white (no Hispanic or African American men), and a few were from Canada and Australia. Many of the employees of the local office were also the most popular AFA profiles in the Philippines and many of the employees date men on the tour.

The increased formality in the social events is largely a product of the Davao office 
manager Halia's ${ }^{17}$ preferences. In both Davao and Sumy, local affiliate companies hired by AFA actually stage the tours. In Davao, the HLC Lifemates office is AFA's official affiliate partner in conducting the tours. Halia runs the Davao office herself, with her family as her support network in management. She stopped serving alcohol at the socials in order to protect young Filipina ladies from making poor choices ${ }^{18}$ and is very involved in the daily decisions of the business. The socials, and the Filipina women participants themselves, seemed more conservative in Davao than in Ukraine or Colombia. The more conservative view of relationships and marriage is demonstrated by the fact that the HLC Lifemates Office takes more of an active role in promoting long-term relationships. Halia offers couples help and support with the Visa process for the U.S., Canada, and Australia. The HLC office is open twenty-four hours a day ${ }^{19}$ and there is a much larger staff catering to client's needs than in Medellin or Ukraine. Halia's involvement in the day-today operations of the office allowed me to reach a large number of interviewees quickly and efficiently. I was able to conduct a large focus group with most of the day shift employees at the HLC Lifemates Office, and I interviewed approximately twenty-five male and female participants. I was also able to interview two couples, and three women who were engaged and preparing to join their husbands (three in the U.S. and one in Australia).

${ }^{17}$ All interviewee's names have been changed to pseudonyms in order to protect their privacy.

${ }^{18}$ Like having sexual intimacy with a male tour participant right away.

${ }^{19}$ The offices in Medellin and in the Ukraine were open typically from $10 \mathrm{am}$ to $7 \mathrm{pm}$. The minimum wage in both countries is much higher than in the Philippines, where numerous interviewees told me the minimum wage is eight U.S. dollars a day. 
Besides conducting interviews, focus groups, and participant observations of the romance tour activities, I began to collect visual and cultural materials that discussed the romance tour phenomenon in the media: various information from agency websites, guidebooks written by other men with advice for 'newbies', newspaper articles, documentaries, and television shows. All of the visual and cultural materials I collected, as well as my observations and interviews from my fieldwork, I consider discourse, or systems of thought, composed by various languages, attitudes, behaviors, and beliefs that systematically construct the social world (Foucault 1971). Through discourse, power is maintained in society, by determining what counts as ‘truth’ and what counts as 'knowledge' (Foucault 1971). According to Fairclough and Holes (1995), the study of how a topic is discussed allows the researcher to examine the ideologies of power contained within various cultural materials. I analyzed the various pieces of cultural material and data I collected regarding romance tourism through the lens of critical discourse analysis, which connects micro-features of discourse, such as syntax, metaphoric structure, and rhetorical devices (in the case of the data gathered via interviews, websites and guidebooks), meso-level factors having to do with production and consumption of the discourse (for example, in the marketing of women ${ }^{20}$, as well as men's encounters with and negotiations of agency marketing), and broader macro-level societal currents (for example, neoliberal economic processes and governance strategies which compel many women to choose marriage migration as a potential survival strategy over other alternatives).

${ }^{20}$ The marketing women employ themselves as well as the marketing utilized by the agency. 


\section{Chapter III: Colonial Genealogies and Legacies of Intimate Tourism}

Alexander and Mohanty (2010) argue that transnational feminist research should interrogate the category of the transnational and what it illuminates, as well as the relations of the transnational to the colonial, neocolonial, and imperial histories that occur on different geographic scales. Mohanty (2003) argues that feminist practices and theories need to be anti-capitalist, anti-imperialist, and properly historicized. Therefore, in order to understand what the transnational illuminates in terms of the romance tourism industry, it is important to discuss the relation of romance tourism to each countries’ colonial and imperial histories, as well as the colonial history of the U.S. Colombia, the Philippines, and Ukraine all share a colonial history, but their individual genealogies and histories have impacted the development of intimate tourisms, and in particular romance tourism, in important and unique ways.

Ukrainian women are often lumped together with Russian women in common imaginaries, and Slavic women have been historically characterized as the world's traveling white prostitutes. The image of the traveling white sex worker has remained associated with women from the region, and is still one of the standard imaginaries used to describe women in Ukraine and Russia. The other discourse surrounding Ukrainian women is of the 'mail order bride' who is looking for an American visa. Unlike the genealogy of intimate tourism in Ukraine and Russia, the development of intimate tourism in the Philippines was largely accelerated during the American occupation of the island. Even after the Philippines gained political independence from occupational forces 
in 1946, a large U.S. military presence remained on the island, camped out at large military bases. The intimate tourist industry in the Philippines developed around the American military bases, as marrying a service man or engaging in sex work with one became an increasingly common economic option. The romance tour industry as a whole largely started in the Philippines, with the publication of pen pal catalogs and the large number of American service men marrying Filipina women. In comparison to both the Philippines and Ukraine, Colombia is a relative newcomer to the romance tour industry, but Colombian women are not new to the sex tourism industry. Many Colombian women migrate to countries like Panama, Curacao, and Germany in order to engage in sex work, as in the past Colombia was considered a dangerous place to travel to for tourists. Now that Colombia has become less dangerous and is open for tourism, increasing numbers of intimate tour industries there are booming. Despite Colombia’s growing popularity in the industry, and that the origins of the industry are in the Philippines, Ukraine remains the stalwart favorite of most American men.

\section{Ukraine}

During the end of the nineteenth century, increasing numbers of white prostitutes in the British colonies caused a moral panic amongst many colonial leaders. The increase in white women becoming sex workers was linked to a new mobility of labor, introduced by technological advances of the time (Doezema 1999). During the moral panic surrounding white prosititution, the discourse surrounding white sex workers ascribed them a white 'slave' identity, since no respectable 'white' woman would 'choose' sex work. Thus, the narrative surrounding white sex workers was that they were victims of kidnap and coercion. However, Fisher-tine (2003) argues that most white prostitutes of 
the time knew they were headed to colonial outposts to perform sex work. He identifies two main routes these women took to the colonies: the Western route led to South America, Rio de Janeiro, and Buenos Aires ${ }^{21}$ and the Eastern route led to East Africa and Asia, with Shanghai, Hong Kong, and Manila as the major points of arrival. White prostitutes were allowed into India from France, Germany, and Italy, but most white sex workers migrated from Poland, Austria, Romania, and Russia. White British prostitutes found in the colonies were punished, and sent home, since they represented a problem for British prestige within colonial society. During the period of Western European colonization, 'Russian' ${ }^{22}$ women were recognized to be 'white' in skin tone, but still were exoticized and considered inferior to Anglo-Saxon women. The General Police of Ceylon ${ }^{23}$ discussed Russian and Polish prostitutes as 'semi-oriental', demonstrating the distance that the British felt from the Slavic 'race'.

Fisher-Tine $(2003,183)$ quotes the Second Financial Commissioner of Punjab as writing,

The prestige of the ruling race is affected by the degradation of its members, especially if they are females. It matters not that the Austrian, Poles and Russian Jewesses who are the victims of the trade are wholly alien to the British race. In the eyes of the general population, the distinction is not recognized. These women, with their white skins, come from the West, whence come the rulers of this country, and the whole European community has to bear the shame of their presence in the prostitutes' chakla.

\footnotetext{
${ }^{21}$ Buenos Aires was at that time the world center of prostitution.

22 'Russian’ implying Ukrainian and Belarussian as well.

${ }^{23}$ Ceylon was the colonial name for modern day Sri Lanka
} 
Interracial relationships between colonized men and 'white’ prostitutes increased alarm for colonial administrators, and led to the sentiments expressed in the following quotation from a colonial administrator in Shanghai, "the prostitution of White women in Asia is the cheapening of our White race. Formerly, to all the Coloured, all over the world, the White woman was a miracle, a goddess, a being inaccessible and intangible. She is becoming an object of enjoyment and sometimes derision, for those same Coloured races”(Scully 1998: 875). Within British colonial discourse, Anglo-Saxon and Western European sex workers were considered to be of a higher status than Russian, Polish, and Austrian sex workers, but Eastern European women were still considered to be of a higher status than local Indian or Chinese sex workers. With the development of the Soviet Union in 1917, the hordes of Eastern European migrants flocking to exotic colonial outposts for sex work largely dissipated. During the Soviet days, sex work largely moved underground and women's mobility to leave the Eastern Block was largely curtailed.

Ukrainian independence from the Soviet Union was announced on August 24 $4^{\text {th }}$, 1991. For the first time in decades, the Ukrainian state had political and economic independence from Russia. However, Russian influence remains strong in Ukraine, particularly in Western Ukraine ${ }^{24}$, where large numbers of ethnic Russians still reside. The linguistic divisions in Western and Eastern Ukraine have paved the way for Putin's invasion of Crimea. With the demise of state-controlled enterprise, Ukraine began economic processes moving towards capitalism, including privatization of state run

${ }^{24}$ The ethnic and linguistic division in Ukraine is evidenced by the 2014 Crimean vote to join Russia. 
enterprises, and the deregulation of foreign investments. Economic liberalization led to major cuts in state provided services, as well as state jobs. Unemployment rates rose dramatically and many older, disabled and 'vulnerable’ populations faced increasing poverty. Incomes dropped and rates of socioeconomic inequality continue to grow. The privatization of the economy at large has concurrently created the individualization of responsibilities that once belonged to the state, a neoliberalization of society.

Development of Intimate Tourism

During the Soviet Era, prostitution was officially outlawed and considered to be a phenomenon of capitalist exploitation, something wholly 'alien’ to the new society the Bolsheviks were attempting to create. The Soviets argued the material conditions of capitalism created the social vice of prostitution; therefore, no material need existed for prostitution to continue. However, sex work existed prior to capitalist economic systems and did not truly end in the U.S.S.R.; it simply went underground. According to a Russian sex worker who worked during the communist system, two types of sex workers existed: girls who would occasionally have sex for money, and the professional women ${ }^{25}$ who served foreign tourists in hotels where only foreigners were allowed to stay ${ }^{26}$. During the Soviet Era, being a professional prostitute in the foreign tourist hotels was a dangerous job, since prostitution was technically illegal. Sex workers had to pay off

\footnotetext{
${ }^{25}$ These professional women were called 'interdevochki'.

${ }^{26}$ From a website called the Courtesan's Diary, http://courtesansdiary.blogspot.dk/2011/01/being-working-girl-in-sovietrussia.html?zx=e637636daaa12d73.
} 
numerous people in the hotel to 'keep quiet', even though many would take the bribe and still call the police on the sex worker.

After the break up of the Soviet Union, prostitution became rampant throughout the former Soviet Republics and satellite countries. Women from these countries began to migrate for sex work as well, and thus, the Russian and Ukrainian woman became known once again as the traveling white prostitute, and similar to the beginning of the century, sex workers from the former U.S.S.R. are found all over the world. Large numbers of Russian and Ukrainian sex workers can be found in Hong Kong, Dubai, Turkey, the countries of the EU, Thailand, Israel, and Malaysia, similar to the locations of Russian prostitutes in the colonies. However, the major difference is that most of these Russian and other Eastern European 'white’ sex workers are no longer intended to serve only white officers and colonial officials. Even during colonial times, elite local men in the colonies could cross racial boundaries by paying to have sex with white prostitutes, and in the contemporary sex work industry, most 'white' sex workers outside of Europe are sought out by men from outside the Global North.

According to a self-identified Asian blog poster on the World Sex Guide ${ }^{27}$ who visited Kuala Lumpur in Malaysia, the opportunity to have sex with a white woman fulfills a deep-seated desire. He says, "I actually travel to Kuala Lumpur often and one of my friends in the hotel industry told me about this place where you can actually find very horny and blonde Russian girls and girls from Uzbekistan. For a Asian guy like me a

\footnotetext{
27 http://www.worldsexguide.com/cgibin/guide/search.cgi?isValidated=Yes;query=russian;catid=\&nh=3
} 
white girl is a dream come true to get laid by. I could not believe it.” Most men from the U.S. and Europe view Russian and Ukrainian women as less ‘enthusiastic' and 'authentically interested' in them. Another blog poster on the World Sex Guide shares his thoughts about Russian and Ukrainian women working in the Czech Republic, "the girls are mostly miserable Russian/Ukrainian ones who don't enjoy the sex as much as the girls in Brazil \& Thailand for example.” Another man describes most Russian sex workers as having as much enthusiasm "as a plank of wood”. One blog poster recommends that foreign men traveling to St. Petersburg should just ask out a normal woman on a few dates instead of paying a sex worker, since the person will get more of a 'girlfriend experience’.

In fact, for men from the U.S., Ukraine and Russia are more popular as romance tour destinations then they are as sex tour destinations. Examining marriage agency websites, Johnson (2007) identifies a paradox: the photographs of the Russian women on many sites are highly sexualized, but at the same time are accompanied by descriptions of their traditional roles as wives and mothers. By featuring discourses of romanticized notions of marriage, while at the same time posting sexualized photos of women, introduction agencies highlight Russian and Ukrainian women’s exoticized and sexualized history within the 'Western' consciousness, but with the promise of this exotic sexuality for only one person: her husband (which could potentially be the men searching on the site). While men feel the 'girlfriend experience' with a sex worker is difficult to find with women from the former U.S.S.R., they do feel that finding a genuine girlfriend, and then hopefully later wife, are easier to find. 
While many marriage migrants are from Asia and Latin America, the most prominent image of the mail order bride is the Russian bride (Osipovich 2005). Constable (2003) argues that after the fall of the Soviet Union, women from the former Soviet bloc surpassed Filipinas in the romance tour industry, as they are often touted as a “superior” choice based on their Caucasianness. Piller (2007) argues that Russian women's main competitive edge is their race: Russian women are exoticized but are at the same time 'white'. Piller (2007) quote a website: “they [Russian women] have a European face but the patience of an Asian.” The same website claims Russian women are “exotic white women who know their place.” Luehrmann $(2004,863)$ argues, "Women in Russia seem to offer all the traditional values men used to look to Asia for, but fit more neatly into the racial hierarchies of the U.S., and may be less recognized as 'mail order brides' when appearing with their husbands in public.” Websites not only focus on Russian women's whiteness; they also focus on their sexuality and appearance.

Taraban (2007) argues Russian and Ukrainian women are the top candidates for American men searching for brides, based on both their traditional values and sexuality. In many agency discourses, Russian and Ukrainian women are constructed as model types that are thin, sexily dressed, and made up. Ultimately, Ukrainian women "take care of their appearance”. Taraban (2007) finds that internet brides are negotiating multiple identities regarding gender; in post Soviet Ukraine, women are expected to be the nurturing mothers rebirthing a nation and at the same time, the discourse surrounding Ukrainian women portrays them as sexual objects. For post Soviet women, their success on websites depends upon depicting themselves as both pre-feminist and hypersexual. With the plethora of sexually available women online, internet brides must distinguish 
themselves by presenting themselves as virtuous (but still sexually appealing) women who are looking to marry; thus they focus on their nurturing qualities. The profiles of Russian and Ukrainian women focus on child rearing, cleaning, cooking, etc. The ads utilize the fantasy of the traditional wife, which focuses on women as beautiful, feminine, and devoted. The Russian and Ukrainian women's combination of sexuality and tradition make for the ultimate fantasy wife for many American men. However, not all men have luck in Ukraine, and a large number of men head to Asia instead to find a bride.

\section{Philippines}

Ferdinand Magellan’s arrival in the Philippine archipelago during 1521 began the era of Spanish interest in, and eventual colonization, of the Islands. The name 'the Philippines' is derived from King Philip of Spain, and the first official Spanish settlement of Cebu began in 1565. Spanish colonial rule in the Philippines lasted over 300 years, and has left a lasting imprint upon Filipino society, culture, and language until today. The Spanish ruled the Philippines as an extension of their colonial holdings in Latin America, and began a Catholic evangelization of native populations on the islands. The archipelago was an important trade and commercial entrepôt for the Spanish mercantile route between China and Mexico (New Spain).

By the $19^{\text {th }}$ Century, the Spanish racial system was strongly entrenched within Filipino society as well, and was based on notions of religious ‘civilization’ and ‘mestizaje’ (blood mixtures), similar to the system of castas in Spain’s Latin American colonies. As in the case of Colombian racial hierarchies, at the pinnacle of the colonial hierarchy were the Peninsulares, people with Spanish ancestry born in Europe. Creoles, 
people of Spanish ancestry and descent, but born in the Philippines, were below the Peninsulares in the hierarchy and often resentful of their limited political mobilities in colonial society. Both of these Spanish 'racial' groups dominated the high political and clergy positions. Local indigenous populations in the Philippines were also called indios, a term adapted from the Americas. The 'mixed' race or mestizo groups in the Philippines differed from those in Latin America, but were based on the same principles. Spanish and indio mestizo mixes were relatively few in number, but they gained economic prosperity as middlemen between indio and European business communities. However, they were largely excluded from society and scorned for their racial impurity (Kramer 2006). The largest mestizo community was the mixture between indios and Chinese, which the Spanish encouraged in order to convert the Chinese to Christianity.

The break out of the Spanish-American war and revolution in Cuba began in 1898 and the leader of the Filipino Revolution, Aguinaldo, declared the independence of the First Philippine Republic. Unfortunately for the Philippines, Spain ceded its final colonial territories to the U.S. ${ }^{28}$ in the Treaty of Paris. It soon became clear the U.S. had no intention of recognizing the Philippine Republic and war broke out between revolutionary forces and the Americans. The Americans defeated the Filipino forces and took colonial control over the archipelago; Kramer (2006) calls the protracted conflict between Americans and Filipinos a 'race war' since American forces racialized entire Filipino communities in their fight against guerrillas. World War II saw the end of American colonialism in the Philippines, first through the Japanese occupation of the

${ }^{28}$ The U.S. paid 20 million dollars for the Islands 
Islands, and then after the war, official political independence from both Japan and the U.S. However, special privileges remained in place for American citizens and businesses until the 1990’s (Martin, Abella and Midgley 2004). Since independence, however, Filipinos have become a globalized work force, migrating all over the world to perform a variety of labor.

The largest migrant flow in the world is from the Philippines, and the state is dependent upon the income migrants remit through legal channels ${ }^{29}$. Thus, Parreñas (2001) calls Filipinas the ‘quintessential workers of globalization’ and the 'global servants of capitalism'. The work Filipina migrants perform, such as sex work, domestic work, nursing, and entertainment work, is patterned upon the Philippines as an export oriented economy. Gueverra $(2006,526)$ argues that the state's continuing support of Filipina women's migration is based upon grim economic realities: $11 \%$ unemployment, 17.5\% underemployment and over a third of the country below the poverty line in 2000 . The state's encouragement of outmigration solves problems of unemployment, as well as underemployment.

The majority of Filipina immigrants migrate to Middle East and East Asian countries $^{30}$, with smaller groups migrating to the U.S., Canada, Australia, and Europe. The most common destinations for Filipina migrants in the Middle East are Saudi Arabia and the United Arab Emirates. The most common destinations in Asia include Japan,

\footnotetext{
${ }^{29}$ The Philippines recently surpassed Mexico to become the third largest receiving country in terms of remittance incomes, behind China and India.

${ }^{30} 50 \%$ of migrants go to the Middle East, $37.8 \%$ to Asia, $7.8 \%$ to Europe and only 1.66 in the Americas (http://www.migrationinformation.org/feature/display.cfm?ID=364) Accessed 3/22/13.
} 
Taiwan, Singapore, South Korea, and Hong Kong. Saudi Arabia, Singapore, Japan and Taiwan all have strict regulations regarding Filipina’s work contracts; for instance, Filipinas are not allowed to marry local citizens, bring their families to join them, or gain legal residency status. Filipina migrants in Singapore are not allowed to marry or reside with citizens. Within Japan, most Filipina immigrants are on 'entertainer’ visas, and Japanese constructions of these performing artists focus on their sexuality (Tyner 1997). Filipina's status as migrants in Taiwan is synonymous with being poor, uneducated, and uncivilized (Cheng 2003). Numerous scholars have discussed the fact that many Filipina migrants attempt to marry local men in order to secure more permanent resident status, laying the groundwork for a thriving economy based upon intimate tour industries (Lan 2003; Law 1997; McKay 2003; Piper and Roces 2003).

Development of Intimate Tourism

Law (1997) and del Rosario (2005) connect the development of the contemporary sex tourism industry in the Philippines to its history of American colonialism and militarism. In the city of Olongapo, near Subic Bay Naval base, 12,000 registered and 8,000 unregistered ‘hostesses’ were available for American servicemen (Hall 1996). Angeles City, which was next to Clark Air Force base, was a notorious and infamous prostitution center for American and Australian men. The Clark base closed in 1992, after the eruption of Mount Pinatubo destroyed most of the base's infrastructure. O'Rourke (2001) posits that American men view Filipina women as 'sexually available', due to the Philippine's history of military sexual colonialism. The U.S. Ambassador to the Philippines, Harry Thomas Jr., created a wave of controversy in 2011 when he claimed that nearly 40 percent of male tourists traveling to the Philippines are traveling there for 
sexual adventures. Prostitution in the Philippines is technically illegal, but most law enforcement turns a 'blind eye'. A report by UNICEF claims the sex industry in Philippines is the fourth largest source of Gross National Product, as well as ranked fourth in terms of child prostitutes ${ }^{31}$. The Philippines, while still a popular destination for sex tourists, is largely eclipsed by the sex tourism industry in Thailand in terms of Southeast Asia and is now known more for migrants and mail order brides. Angeles and Sunanata (2007) relate common stereotypes of Thai and Filipina women to the different ways in which Filipina and Thai women are racialized: Thailand has become the signifier for sexuality and Thai women the signifier for prostitutes while the Philippines and the Filipina have become the signifiers for the domestic worker and mail order bride.

The sex work industry developed near the U.S. military bases, but has grown steadily even after the bases officially closed. In the Philippines, I encountered a large number of older white men from the U.S. and Australia dating significantly younger girlfriends. The large age gaps between the white men and their local Filipina dates are entirely normalized within society, even though most of those same women would not date a local Filipino man over fifteen years her senior. The lack of ageism Filipina women display when choosing a potential foreign mate is a major draw for the intimate tour industry, and a number of men mentioned it as a motivating factor for visiting the Philippines, "Yes it's all commercial but most Filipinas have a unique ability to make an old fuggin' machine feel he's really loved. Amazing also how they seem to have no aversion to being intimate with a man old enough almost to be their great-grandfather. No

${ }^{31}$ Behind Thailand, Indonesia and Malaysia. 
I'm not ashamed, what else is there at this age? ${ }^{32}$ ” Numerous men posting in online sex tour forums discussed how easy it is to meet women in the Philippines, and how local women will often be open to dating a tourist, if he pays for her dinner, etc.,

It is easy to meet chicks there. I am 44 years old and have a beer belly but in Cebu, I was Brad Pitt. There are many girly bars but its not necessary to go to one. Just go to the mall. Any mall. Spot a pretty girl and ask for her cell number. You'll get it. Guaranteed. Ask her if she would like to have a coffee with you. She will. And I mean goddessesses. Not skanks, these girls are tired of poverty and are more than willing to share their time with you in hopes of romance, which will get them out of their dismal shacks. They are nice sweet girls who dream of a better life, and they will be as good to you as you are to them. Even buying them a T shirt makes them happy. Like everybody else, I like to fuck, and most of the ladies are happy to oblige if you are good to them. No payment was necessary: they enjoyed eating daily, swimming at my hotel, and eating out with me. But they want to fall in love. Be careful. They are easy to fall in love with!

Most men involved in the sex tour industry are trying to avoid marriage, but a number of sex workers in the Philippines hope to find men seeking the 'girlfriend experience', who will potentially marry them or send them money from abroad.

Many American men know that women who seek out foreign men for dating or sex work often are interested in getting married and leaving the Philippines, and they use their knowledge to get the best 'service’ possible, “ Look for 9-9.5:ers [out of a 10 point scale] who also have nice attitude and are looking for someone who can take them away from the $\mathrm{Ph}[$ ilippines] and get married. They are the absolutely best because they will give you $100 \%$ of everything they have, sex all the way you want and can take, and in all and every way, try to make you fall in LOVE with herself.” The men posting on the forum could not stop raving about the fact that even older American men have a high currency within the Philippines’ dating market. While Ukrainian women are often

${ }^{32}$ http://www.worldsexguide.com/guide/Asia/Philippines/ (accessed 3/26/14) 
described by men on the forum as cold, much like sex workers in the 'West', Filipina women are thought to be more sincere, "I can only assume that Western guys have generally treated the local girls well and with respect, because most of the ones I met were friendly and trusting - not hardened at all.” The preceding quote demonstrates the ways in which Filipina women are considered to be more caring and 'real' sex workers than Ukrainian or Russian women.

As Angeles and Sunata (2007) point out, Thai women are more associated with sex work than Filipina women, who are more often associated with care work. The distinction between Filipina and Thai women is explained by one of the posters on the sex world guide online forum,

Even though Thai women seem more attractive, they don't speak English as well and I don't think any match a Filipina in heart. They seem to get into your blood. Especially if you're American. There is a huge disparity between the working girls and good girls. The good girl will take care of you. She'll negotiate for you like it was the end of all life and is genuinely on your side. During crisis, she will assume control of the situation and almost seem to protect you and she will be your partner. Sex is unbelievable but she will have a curfew. Even if she is 30 years old. The bar girls are more dependent on you and accustomed to sleeping all day and staying up all night.

Here, the poster distinguishes not just between Filipina and Thai women, but also between 'good girls' and 'working girls'. Like most discourse on the sex tourism forum, men continually praised women who provided more of an intimate connection than simply performing the sex act, demonstrating that most men are indeed seeking a semiemotional connection while engaging in sex tourism. Davao is a smaller city in the Philippines and is a destination 'off the beaten path', even for many sex tourists, “Anyway's there was a good time to be had in Davao, and because there are not many Caucasians at all in this off the tourist track city, you will get plenty of friendly 
approaches and eye contact from the local girls.” Similar to the situation with Ukrainian and Russian women, Filipina women are more popular as potential brides than short term sexual encounters.

Filipinas have the longest history of marriage migration out of the three sites, with the development of paper catalogs during the 1980's of Filipina pen-pals and potential brides (Tolentino 1996). Constable (2003) explains that Filipina women are popular potential bride choices with American men since they speak English and are more familiar with American culture than other Asians. Constable (2003) also observed that photos of Filipinas on romance agency websites tended to be more 'prudish' than Eastern European women's photos, since they are often scantily clad and in seductive poses. The fantasy of the Filipina woman is more aligned with fairy tale notions of romance, where the representations of Filipinas depend upon their innocence and respectability. Constable (2003, p. 96) argues, “Like the Disney Cinderella, prospective Filipina brides are often represented as poor, innocent young women who deserve to be rescued from menial labor and shabby clothes by way of marriage to a Western hero prince.” Instead of focusing on their sexuality, many websites describe Filipina women as petite, slender, feminine, pious, hard working, and respectable. On the other end of the desire spectrum, men associated Colombian women with a passionate sensuality.

\section{Colombia}

The Spanish began the exploration of the New World in the Caribbean, thus the Caribbean coast of contemporary Colombia was discovered early. Spanish explorers founded the cities of Santa Marta and Cartagena in 1525 and 1533 respectively. Colombia became a part of the Viceroyalty of New Grenada, with Bogota becoming the 
capital of Spain’s colonial possession. During Spanish colonial rule, the indigenous population was decimated from exposure to European diseases. With the dwindling indigenous population causing slave labor shortages, the Spanish Empire turned towards importing African slave labor. Early Spanish colonial policies did not focus on familial migration and creating a settler colony. The crown instead focused on converting the native populations to Christianity and amassing large amounts of wealth through constant exploitation of natural resources. Controlling the racial intermixture between white, indigenous, and black populations became an important focus of the colonial state, which aimed to maintain hierarchies of superiority based upon race, color, and sexuality.

Under the Spanish colonial system, an ethnically hybrid society developed in Latin America, unlike anywhere else in the colonial world. In order to regulate a racially diverse society, the Spanish imperial government established a racial hierarchical system. At the top of their system were the Peninsulares, people born in the Iberian Peninsula. During colonialism, only Peninsulares were allowed to hold the highest imperial posts. Below the Peninsulares were the Creoles, Spanish people born in the colony. Before Spanish women migrated to the colonies, the male colonizing Spaniards intermixed with women from indigenous and African slave populations. The mixed race populations created through various racial intermixing were categorized and called castas. A complex system of racial categorizations evolved over time in the Spanish colonies, and the most common racial mixtures were mestizo (white and indigenous) and mulatto (white and 
African) (Montalvo and Codina 2001) ${ }^{33}$. The mixed race castas were higher within the racial hierarchy than the indigenous and African slave populations.

By the $18^{\text {th }}$ Century, colonial populations were no longer distinguished by race but instead were distinguished by raza (lineage), which included specific 'calidads' or qualities. Carrera (2003) argues, “Calidad represented one’s social body as a whole, which included references to skin color but also often encompassed, more importantly, occupation, wealth, purity of blood, honor, integrity, and place of origin.” In the castas system, the calidad of mulatto was not only associated with dark skin, but also included notions of being debased morally. On the other hand, the calidad of Spaniard included light skin and lofty moral attributes. Despite the fact that most of the population was racially hybrid, the social stratification system of the 'sociedad de castas' was still based upon constructed notions of racial difference. Wade (1993) demonstrates that in the castas system, the one certainty that existed was that to be black or indian was bad, and to be white was good. Even after independence, Colombian society still utilized a discourse of blanqueamiento, or 'whitening', to discuss the ideal population of the nation.

Wade (1993) argues the policy of blanqueamiento represented Colombian progress by highlighting and romanticizing mestizo populations through the rhetoric of mestizaje, which became a neutral moral ground for the mixing of indigenous, African and 'white' populations. By encouraging European immigration, the Colombian state attempted to 'whiten' the population through racial mixing. Colombian nationalists argued that through constant racial mixing, eventually indigenous and African genetics

${ }^{33}$ Other common casta: Zambos (1/2 indigenous and $1 / 2$ African) 
would fade away and disappear. However, as Wade (1993) points out, every lightening is at the same time a darkening, and many lighter people discriminate towards mixing with darker people. Therefore, a mestizo or whiter nation is not possible to achieve if discrimination against African and indigenous populations continues to exist. Indigenous and African populations remain at the bottom of the racialized hierarchy within a ‘mestizo' national framework, and African is considered even lower than indigenous. The colonial casta system and the post-colonial nationalist rhetoric of whitening have left a lasting impression upon racialized hierarchies in contemporary Colombia. Racial hierarchies are evident as well in the geographical locations of indigenous and African descendent populations, who typically live in the lesser-developed Pacific regions of Colombia versus the more mestizo populations of the mountain highlands. Development of Intimate Tourism

Sex tourism is growing by large amounts in Colombia, where laws are relatively lax regarding sex work. In Colombia, sex work is legal and the country is often referred to as the 'Thailand of Latin America', a reference to Thailand's ${ }^{34}$ association with sex work. According to a blogger on the Thai Visa Forum ${ }^{35}$, Colombia shares three important traits with Thailand for developing a booming sex tour industry: a comparative advantage over other surrounding countries in women attractive to 'Western’ sex tourists, an internal culture of male chauvinism and prostitution, and the government's permission for the sex tourism industry to thrive. No official statistics exist regarding the numbers of

\footnotetext{
${ }^{34}$ Both Thailand and Colombia have taken issue with the media spreading this view ${ }^{35}$ http://www.thaivisa.com/forum/topic/292752-developing-colombias-sex-tourismindustry/ (accessesd 3/16/13)
} 
women involved within the sex industry in Colombia, but conservative estimates place the number of sex workers in the tens of thousands ${ }^{36}$. Cartagena, with its location on the Caribbean coast, is one of the most popular sex tourist hotspots, with many human rights groups discussing the availability of child prostitutes ${ }^{37}$.

Most scholars that have discussed Colombian sex workers in terms of migration: in Curacao (Kempadoo 1999), in Spain and other parts of the EU (Oso Casa 2010), and Japan (Méndez 2013). However, as increasing numbers of sex tourists head to Colombia directly, more scholarship has turned to focusing on child prostitution in Cartagena (Mayorga and Velasquez 1999) and Bogota (Ritterbusch 2013). The growing popularity of Colombia as a sex tour spot is demonstrated by the 2012 international scandal between a sex worker in Cartagena and a CIA employee. Colombia has been growing in popularity as a sex tour destination, as it has been deemed as 'safe' for most American travelers in the major urban centers. However, a few posters on the world' sex tourism still characterized Colombia as dangerous and Colombian women as scammers, “The woman just wanna green card to come in our great country. Soon she get the paper she will disappear it happen to me so guys be aware. Look behind you who is follow[ing] you and make sure not to go girls apartment. Someone may pop up on the way, take your money, beat you up; you lucky if they won't kill you. Not safe anymore [in] Columbia.” While some men commenting on the forum highlighted the dangers of traveling to

\footnotetext{
${ }^{36}$ http://colombiareports.com/opinion/from-the-editor/23526-colombias-35-million-sextourism-commercial.html (Accessed 3/20/13).

37 The age of legal consent is 14 in Colombia
} 
Colombia, most men focused instead on Colombian women's beauty and their 'caring' abilities in term of sexual and emotional labor.

One poster on the forum simply raves about Colombian women's beauty, “To all the men who enjoy the fruits of Latin America, I highly recommend Colombia - especially Medellin... the most beautiful women in the World are here!” Many of the men on the forum discussed their desire for more emotional care labor than simply performing a sexual act for money,

Just romance them and there is no need to negotiate prices. [I met this girl at the club] She even sat on my lap for 4 hours in a packed car all the way back to Santa Marta, and that night after dancing we went at it all night. Then I flew her with me back to Bogotá \$200 roundtrip, and I didn't mind buying a few clothes for her. We were like newlyweds. Night and day, anything and everything, and she even cooked and cleaned for me

The previous poster not only mentions that his intimate interaction with a sex worker was similar to that of a newly married couple, but also highlights that men do not necessarily have to pay a sex worker to find company in Colombia. The idea of not paying for sex work is a common topic on the forums regarding Colombian women and Filipina women. Despite most men's positive assessment's of Colombian women’s appearance and emotional care, there were some men on the forum who commented on Colombian women’s weight, "First off, I had high expectations of seeing amazing women in Colombia, but was a little disappointed. In general, not as hot as Brazilians and some others. Lot more fat chubbies down there like here in USA than I expected. Anyway, regardless of hot or not, they are all very friendly, and know what you want and like.” Comments regarding women being 'too chubby’ rarely exist on websites devoted to Ukrainian or Filipina sex workers. 
The romance tour industry in Colombia has also seen a large boom in recent years; Colombians account for 10\% of fiancée visas to the U.S. and have since 1999 (Cogau-Lopez 2010). Romance companies differentiate themselves from sex tourism by "classing up” the industry through using the language of marriage and focusing on romance instead of sex (Schaeffer-Grabiel 2004). Colombians are the largest Latin American group applying for fiancée visas to the U.S., and Colombia is the most popular destination within the region of Latin America, leading Peru, Costa Rica, and the Dominica Republic in terms of men who visit, and the number of romance tours offered. According to the journalist William Storr" ${ }^{38}$, "The country is emerging as one of the biggest new players in a $\$ 2$ billion international marriage brokering industry that has long been centered in former Soviet states and was virtually unheard of in South America 10 years ago.” AFA offers tours in three Colombian cities: Cartagena, Medellin, and Barranquilla, whereas for other Latin countries they only offer tours in one city.

Cogau-Lopez (2010) contrasts the stereotypical perception and portrayal of Asian, and to some extent Russian women, as timid, quiet, servile, and immersed in traditional structures of courting and marriage to the portrayal of Latin women as spontaneous, talkative, cheerful, and very sensual. Many websites refer to Latina's 'hot' and 'spicy' nature and focus on their love-making skills to differentiate them from Asian and Ukrainian women. American men on the vacation tours described Latinas as faithful, passionate, hard working and committed to family, unlike American women. Most of the women in Colombia are racially mixed, from the working class and less likely to have

${ }^{38}$ From an article published in the Telegraph, May $21^{\text {st }} 2013$ 
internet access. Since beauty is a form of social mobility in Colombia, many women turned to plastic surgery to attract men on the tours (Schaeffer 2013). Female tour participants in Cali, Colombia tend to be more dark-skinned and working class than the women who attend tours in Medellin. In Schaeffer's (2013) study, Colombian women had less access to the internet and thus, were more focused on meeting males at the social events. Women are investing in their bodies through cosmetic surgery in the hopes of 
finding a foreign man, demonstrating how women use beauty to willingly transform themselves into marketable "products".

\section{United States}

Typically, when scholars discuss the U.S., the term postcolonial is rarely ever utilized. The U.S. shed British colonialism early within the development of decolonization of the Western Hemisphere and in fact become one of the major imperial powers of the contemporary era. Ray and Schwarz $(2000,165)$ describe the contradictory position that the U.S. occupies in the postcolonial imagination, "Interestingly enough, it is the U.S., of all the "postcolonial societies" around the world, in which we find perhaps the most dramatic example of turning the colonial relationship on its head. Post-colonies are obviously capable of becoming oppressor states, but none has been quite successful at this as the U.S.” A number of scholars (McClintock 1992; Frankenberg and Mani 1993) have scoffed at designating the U.S. as a postcolonial site, but King (2000) argues that the postcolonial label encompasses important concepts associated with internal movements of resistance towards American imperialism, such as the Civil Rights Movement, etc. Singh and Schmidt (2000) claim that the U.S. can be considered the world's first postcolonial and neocolonial country. The U.S.'s early move for independence from European powers, it still maintained many of the defining features of European colonial networks, such as the color-line.

Most scholarship regarding postcoloniality has been Eurocentric and allows the assumption of a lack of post coloniality Kaplan (1993) argues that American historiography often claims that no American empire exists, but she challenges the 
resilient paradigm of American exceptionalism and critiques the United States' noted absence from the postcolonial study of imperialism. The common narrative of American history as a noncolonial power, unlike Europe or the Soviet Union, denies the clear colonial presence the U.S. has imposed in Cuba, the Philippines, Puerto Rico, Guam, and now in Afghanistan and Iraq. In addition to American military interventions globally, Sharpe (1995) argues that racialized minority populations experience economic marginalization within the U.S. Instead of naming the U.S. as postcolonial, Sharpe (1995) states instead that we should define the 'after' of colonialism and how U.S. relations to former colonies are often neocolonial.

The development of the romance tour industry in the U.S. has focused on satisfying middle class white American men's desires for a younger, exotic woman, demonstrating the ways in which American hierarchies of gender, race, class, and sexuality are reproduced. Many men trace their decisions to search for foreign brides to the development of feminism in the U.S. They argue that the middle class, white American women they would normally want to date are too busy instead focusing on their careers and material possessions. The romance tour industry caters to the disappointed American man by providing him an opportunity to find love, demonstrating the privilege that men have in society, since no concurrent commercialized mail order husband industry exists. Within the American racial system, whiteness still is associated with beauty, intelligence, hard work, and affluence and thus, it is not surprising that many American begin their searches for a foreign wife in Ukraine, where women are considered 'white'. 
Within the international romance tour industry, the United State's complex history as both postcolonial and neocolonial country largely influences the experiences of women who do eventually migrate to the U.S. So (2006) argues that Ukrainian women have an easier time ‘blending in’ with their white American husbands than women from the Philippines or Colombia, who are more likely to be viewed as 'mail order brides'. Therefore, many American men couch their search for an international bride in the more exotic locations as a search for a more traditional woman, with better family values. By focusing on foreign women's superior family values and femininity, American men seek to normalize their nonnormative search for a foreign bride. For American men who are bringing home women from areas typically associated with 'Little Brown Fucking Machines', the discourse of traditional femininity can 'whiten’ these women into 'normative', if not superior, potential wives. 
Chapter IV: Desire for the Exotic Light Woman and a Transnational Brad Pitt

Desire is often understood as the spark that lights the fire of intimate relationships. Most of us consider desire to be a deeply intimate and personal emotion: my desires are my own and no one influences what I find a desirable. Sexuality and romance are inherently linked to desire, cementing the impression that desire is indeed an intensely individualized experience. However, numerous scholars have challenged an individualized view of desire, and instead have discussed the ways in which desire is influenced by society and social structures. The romance tour industry highlights the ways in which individual articulations of desire are influenced a great deal by transnational conceptions of race, class, gender, and sexuality. Within the romance tour industry, desire is the main emotion that is highlighted on blogs, websites, and in tour guides. The romance tour industry is dominated by various discourses of desire that are gendered, sexualized, racialized and classed, and a number of the American men I interviewed reproduced these discourses.

I argue that American men on tour desire what I term the 'Exotic Light': women who are exoticized, but at the same time removed from the 'too exotic' of blackness. A large number of American men begin their journey into the romance tour 'world' by traveling to Ukraine, in search of a white, but still exotic, June Cleaver. If men don't have luck finding a bride in Ukraine, they typically head towards more exotic locations, like Colombia and the Philippines. AFA also conducts tours in China, Thailand, Dominican Republic, Peru, and Costa Rica. Despite the fact that other commercialized tour agencies are spreading out to even more exotic locations, like Ethiopia and Nigeria, mainstream tour agencies like AFA are still not moving to places in Africa. American men have 
developed clear geographic preferences for finding brides that are often based in ideas of race, class, and sexuality. The geographies of mainstream, commercial romance tourism often differ significantly from the geographies of sexual tourism, which are more 'open'. Sexual tourism is largely available in nearly every country in the world, but is most popular in former colonial sites associated with the pornotropics, such as cities in Asia, Africa and Latin America/the Caribbean. Despite the fact that American men will engage in sex tourism in most countries of the world, the women they decide to bring home and marry often come from a much narrower group of countries, which are predominantly located in Southeast Asia, Latin America/the Caribbean, and Eastern Europe. Women from all three regions fall into the 'exotic light' category.

Women in Colombia, Ukraine and the Philippines that are registered as AFA profiles also articulate racialized, classed, gendered and sexualized conceptions of desirability. Most women articulate their ideal as a transnationally mobile Brad Pitt: blonde, blue eyes, tall, mobile, affluent, and relatively young in age. Within the transnational marriage market, American masculinity is often associated with affluence and whiteness, providing many older white men currency that they have never experienced before in their local dating markets. Even older and less physically attractive American men on tours receive a ton of female attention. Women in all three countries, on the other hand, are used to fighting for the attention of local men and a competitive dating market. The desire for love and intimacy is central to the romance tour industry, and is an important social emotion. 


\section{What is Desire?}

Desire is a social, rather than individual project (Stoler 1997; Young 1995). Stoler (1997) goes as far to argue that desire is not a biological drive that has been repressed by society, but is instead a mechanism of control through which society specifies certain racial, gendered, and classed locations. Desire permeates the infrastructures of society by creating collective group fantasies. The intimate realms of desire are where racial and gender classifications were, and continue to be, both defined and defied (Hall 2004). Ideologies regarding class, sexuality, gender and race are key components of defining what it meant to be a productive and reproductive member of the nation. During colonialism, sexual desires underwrote most of the European conquerors' race theories and ideologies (Abrahams 1998; Hall 2004; Howell 1998; Levine 2004; Stoler 2002; Wilson 2004; Yegenoglu 1998; Young 1995). Thus, sexuality is a critical transfer point of power. Colonial authority rested upon educating the proper distribution of sentiments and desire through regulating morality and intimate relationships (Stoler 2006). Nocentelli (2008) argues that early interracial romances taught European men and women what and how to desire: that is how to perform and distribute affect in ways that are both gender specific and racially appropriate. The colonial state designed its educational institutions to domesticate the sexual desires of children and hopefully influence them to pursue appropriate desires later in life. It was during the colonial development of proper racialized desires that beauty became a criterion of racial classification.

Savigliano (1995) argues that a political economy of passion has been juxtaposed to, and at the same time intertwined with, economies of production that are described in 
materialist and ideological terms. An imperial circulation of feelings, desires and affects gave rise to emotional capital, 'passion', which could be consumed in the form of exotic cultures. Exotic cultures were represented as 'mysterious', 'untamed', 'wild', 'primitive' and 'passionate'. During colonial times, prostitution became institutionalized within large colonial cities all over the world (Hong Kong, Bombay, Buenos Aires, etc.), since prostitution was considered part of the 'economy of nature'. Colonial administrators assumed it was 'natural' for soldiers and male colonial adventurers to fulfill their sexual urges with sex workers, even if they did not publically promote prostitution (Levine 2004; Leupp 2003; Tambe 2009). Sex work ‘vice’ zones became racially segregated, based upon the race of the client and the worker, in order to regulate the intimate contacts between colonizer and colonized (Fisher-Tine 2003; Levine 2000; Scully 2008).

Sex tourism remains a thriving industry in Asia, Latin America/Caribbean and Africa; the former colonial porno-tropics are now sexscapes of desire (Brennan 2004). In the current economy, a growing population in the Global North desires and demands travel that involves sexual activities. Kempadoo (2004) points out that our current conceptualizations of sexuality, sexual desires, and ideas regarding love continue to be deeply informed by the specific cultural and social histories of colonialism and capitalism. According to Brennan (2007), sex and romance are more than simply sites of comfort, pleasure, and intimacy: they are also sites of capitalist production and consumption. The commodification of 'otherness' in the capitalist market, and particularly in the tourist economy, enables racialized bodies to become the sites of both indirect, and often times direct, consumption. Elements of desire, power, sexism and racism combine in many tourists' quest to consume an 'authentic' other (Mullings 1999). 
Many new sexual-affective relations are structured by the transnational tourism industry and the sexual exchanges tourists engage in across interracial and international boundaries often reinforce existing international racial hierarchies and inequalities. Tourism, as an industry, is infused with masculine ideas about adventure, pleasure and penetrating the exotic (Enloe 1990). Tourists' extraction of affect and passion are fundamental parts of the travel and hospitality industry (Cabezas 2009).. Romance tourism combines the intimate realms of sexuality with ideologies of love and marriage in order to create a profitable, global industry. The romance tour industry builds upon longstanding affective economic relations and moves them from the realm of sexual fantasies and desires to the realities of marriage and migration. Desire, sex, love, and money intertwine in everyone's intimate relationships. Within the Caribbean, Asia, Africa and Latin America, racialized hierarchies, based upon colonial categories, have been institutionalized into the sex industry.

Sex tourism depends upon the exoticization of the other's bodies and the corresponding desire to experience and consume those bodies. American men's (as well as men in other parts of the Global North) sexual taste for the 'other' reflects a desire for a high degree of control over the self and to see others as racial, sexual and engendered beings (O’Connell Davidson and Sanchez Taylor 1999). Men interested in sex tourism feel that prostitutes in the U.S. are too cold and obviously motivated by money, while Asian, Latin or Eastern European women hide the monetary aspect of the relationship better. The men and women involved in searching for a foreign spouse are shaped by various cartographies of desire, formed through intersections of culture and migration. Many American male sex tourists explained the attractiveness of foreign women in terms 
of satisfying conventional sexual desires but, more importantly, that foreign women also provide nurturing. Kempadoo (1999) argues that many male sex tourists from the U.S. seek women abroad, since they feel women at home enjoy excessive power within society. For many men in the U.S. (and a number of other countries), the newly feminine power in society undermines traditional male authority. Therefore, a number of men feel that they must reaffirm their masculinity by exerting control over women in other countries. Kempadoo (1999) claims that through intimate tourism, many American men attain a sense of control over their sexuality and at the same time, assure themselves of their racial and cultural privileges.

While racialized and colorized desires characterize both the romance and sex tour industries, there are important differences in the types of women men seek out for transactional sexual relationships versus long-term marriages. American men, as well as other men from the North, tend to seek out casual sex relationships in any part of the world, but the romance tourism industry, which is geared at marriage, is much more geographically localized. As mentioned earlier, the geographic regions that serve as the most popular sex tourist spots, as well as romance tour destinations, tend to be in Southeast Asia, Latin America and the Caribbean, reflecting long standing colonial legacies. The three regions mentioned prior are the home of Little Brown Fucking Machines, and 'brown' women are the most ideal 'exotic' women to bring home to the U.S. as wives (behind Ukrainian and Russian women, who are of course thought of as 'white'). Women from all three regions are presented as superior wife material to American women, since they still possess a more traditional understanding of femininity: foreign women take better care of their appearance, typically are open to dating older 
men and prioritize the men in their lives through performing various forms of emotional and reproductive labor. Many American men involved in the romance tour process claim that foreign women resemble an idealized version of 1950’s middle class white femininity.

\section{Desiring a Foreign June Cleaver}

American men desire foreign women who possess traits associated with white femininity from the $1950{ }^{39}{ }^{39}$ and men's desires are showcased through their reworked ideas surrounding race and color. White, middle class women are no longer at the top of the desire hierarchy for a certain section of American men, since they are no longer feminine enough and have become too 'masculinized' by feminist ideas of gender equality. American men are seeking women that still possess the stereotypical 1950’s idealized 'traditional' white, middle class femininity, and the emotional labor 'good' wives provided men back then (beyond just housework). American men construct foreign women from certain geographic regions (Eastern Europe, Latin America and Southeast Asia) as 'exotic' women that still possess the nostalgic vision of 1950's femininity that they desire. Latin American, as well Eastern European and Southeast Asian women, are naturalized in the romance tour market as having the proper cultural grooming that has made them more traditional, feminine, docile and better mothers (Schaeffer-Grabiel 2006). In American male participant's opinions, foreign women are everything American

\footnotetext{
39 That image is captured in the television character of June Cleaver. She exemplifies 1950's suburban, middle-class femininity. Her work is the work of the home, and she is always dressed in a feminine manner, cooking dinner in her pearls and high heels.
} 
women no longer are, such as: beautiful, petite, devoted, religious, obedient, submissive and sexy (Piller 2007).

For my male interviewees, middle class white women from the more 'traditional' era of the 1950's represented the height of femininity and what it meant to be a 'good' wife. Most of my male interviewees constructed foreign women as superior to contemporary American women, in terms of providing care to their husbands and family and not prioritizing a career outside of the home. Russian and Ukrainian women approximate men's 1950’s ideal the most, as their 'whiteness' makes them resemble June Cleaver more than Filipina or Colombian women. In addition to prioritizing family life, Russian and Ukrainian women are thought to resemble June Cleaver in terms of her feminine appearance: thin, fashionable, sexy and made up. All of my male interviewees, no matter which tour they attended, thought Slavic women were so beautiful that they could easily pass for models. For some American men, however, rumors of Russian and Ukrainian women’s coldness and 'scamming' nature made more ‘exotic' women appear as a better potential marriage partner. Many of the American men seeking brides in more exotic locales engage in a process of 'whitening' these women by highlighting attributes these women share with the idealized vision of 1950's femininity they seek.

How men define and approach what beauty and femininity mean to them varies across all three countries. In Colombia, many men focus on the feminine way women dress and their 'curvy' bodies, with a special focus on the derrière. Fernando told me Colombian women’s “curvaceous bodies are amazing.” Many men in all tour locations focus on the feminine way Ukrainian and Russian women dress and how stylish they are, but tend to discuss these women as thin, sexy, gorgeous model types. According to Kyle, 
a man I met on tour in Medellin, "Ninety percent of the women on the Russian thing are just ...they got this gorgeous movie star twenty three year olds who could be models, even beyond models and movie stars. Like absolutely perfect, you know?” Men in the Philippines tend to define Filipina's femininity in terms of their petite body sizes and more conservative fashion sense. While men in the Ukraine and Colombia focused on the sexy way women dressed, men in the Philippines were often looking for a more demure, conservative girl next-door type instead of a 'sex bombshell'. Collin, who attempted dating a woman in Russia before attending the AFA tour in Davao, felt that Filipina women are more 'wholesome' and 'sweet'. The different ideas of femininity and beauty my interviewees expressed are based upon racialized hierarchies that place Ukrainian and Russian women at the apex of desirability within the political economy of desire. Desiring Educated Slavic Supermodels

The tour I attended in the Ukraine stopped in three cities and forty men participated in the tour, the largest tour AFA has ever conducted. The tour was so large, in fact, that a number of the men complained there was too much competition and not enough personalized attention (in terms of setting dates). When I asked one of the AFA owner's brothers, Wayne, why the Ukraine was the most popular tour spot AFA offered tours to, he answered:

Without sounding racist: they're [Ukrainian women] white. I wrote to Jeb [Cebu office manager] and Halia, this is a niche market. So you're not going to get as many people to come here [Philippines], even though the girls are beautiful and probably just as loving and caring and maybe even more so, as far as family oriented. Still, it's just a niche market. Same with China. Same with Latin America. 
Wayne was one of the few people I spoke with that identified Ukrainian women's

whiteness as the reason for the Ukraine's dominance and popularity within the romance tour market. Brad, a repeat tour offender and also part time employee of AFA, described the reason for his interest in Ukrainian women as based upon their resemblance to June Cleaver and her whiteness,

I mean, it's just, they [Ukrainian women] have this blonde, blue eyed - they dress to kill, and they're just so ladylike. I tell you what, it's a lot like dating June Cleaver from Leave it to Beaver. I can see them wearing pearls making borscht with an apron in the kitchen. They really value that. Funny thing. You know, you'd walk to a restaurant and you order borscht. 'Oh this is really good', and then every woman I ever went out with, she goes, 'I make it better'. Every time! You gotta love it!

Most men did not bluntly identify race as the motivating factor for attending a tour in the Ukraine. Instead, the men phrased their interest in Ukrainian women over Latin or Asian women in terms of personal taste and preference. When I asked Brad ${ }^{40}$, what do you think it is about the Ukraine that draws most of these men here over other tour locations, Brad answered, “The women! I think that you have to have, you've [the researcher] already been to Latin America, so, you know, it has to be your taste. Or an Asian woman, it has to be your taste. You're going to Philippines. You'll see.” Many of the AFA employees also linked racialized desirabililties to questions of personal taste and preference. Both agency employees and Brad link men's decisions to attend tours in more 'exotic' countries to issues of taste and individual preferences, but as the 'beauty queue'

${ }^{40}$ Brad is a very open individual. He has participated in a television special about AFA shown on Nightline, in a documentary about romance tours in the Ukraine and in the National Geographic upcoming program Bachelors Abroad. He told me I could use his real name in this research but I still have chosen to give him a pseudonym. 
(Hunter 2005) demonstrates, ideas of beauty, desirability and attractiveness are socially

constructed and influenced by discourses of colonialism and capitalism.

The connection between class, race, and nationality are exemplified in a quote

from the AFA tour leader in the Ukraine, Bud. He examines how American men’s class

status often affects their choices of where to attend a romance tour,

Most of the men who are going to the Philippines want to meet somebody who is ok with the broad age realms, somebody who they view as not likely to be university educated, with very, very traditional marriage and family values. People who come to Ukraine, I think, they expect university educated women who are professional, obviously very intelligent - not that the women anywhere else aren't - but sophisticated, and sophistication is important to some men - to have a conversation. Your average CEO or corporate vice presidents. It's gonna be hard to go to the Philippines and find somebody who can really have a, you know, good conversation with on this level, when it comes to accounting and math, those kinds of things. So, I think guys are looking for themselves. So, I think most of the guys who are going to the Philippines are probably not university educated, white-collar professionals. In Latin America, I think typically you'll see, what you see in Philippines, I think, most of the guys who go to the Latin America are going to be blue-collar guys. You get a few white-collar guys, but you typically get young blue-collar guys going to Latin America. And, it's interesting, a lot of the guys going to Latin America are either Latin American themselves or they have something that they...with the culture, you know, they are native or they were married to a girl from Panama or something like that. In many cases it's familiarity with the Latin culture which drives guys to that culture.

Here, Bud links Ukrainian women to a more educated, 'higher' class status that is largely based upon her 'whiteness'. He characterizes most men attending 'exotic' tour locales in terms of class status: they are blue collar, working class individuals who are not necessarily seeking intelligent women. Bud argues that most men are 'looking for themselves'. Since most men participating in romance tourism are white, it is not very surprising that many men go first to the Ukraine. No matter which tour I attended, and whether or not my male interviewees actually 'liked’ Ukrainian women, they all considered Ukrainian women to be beautiful and educated. American men on tour did not 
think Ukrainian women were just ordinary beautiful: they all thought Ukrainian women were model beautiful.

I met Greg on tour in Colombia, but he had already been married to a Russian woman and attended a tour in the Philippines prior to our meeting. When I asked him what his Russian wife looked like, he told me, “Oh yeah. I mean my Russian wife was...beautiful. Drop dead beautiful.” As mentioned earlier, Kyle felt that the Ukrainian and Russian women on the website were model beautiful, but he also thought the photographers the agency used were more professional in the Ukraine. Tim also mentioned the professional, and often times highly sexualized, photos of the women in the Ukraine, "You ever been to the website and see what the girls put on there? The Ukrainian girls have some really hot pictures on there.” Many men also commented on Russian and Ukrainian women's world-renowned beauty. Mel explained to me, “It’s funny. People I know around the world know the beauty of Ukrainian women, people know the beauty of the women. All the models in Europe come from Russia, Ukraine. I mean this area for whatever reason, you know, they are just...beautiful. Victoria’s Secret girls are from here.” Men’s constant references to Ukrainian women’s model like appearance reflects the stereotypical construction of these women: tall, thin, blonde and blue eyed.

The fact that not a single one of my male interviewees questioned the attractiveness or beauty of Russian and Ukrainian women demonstrates that women from the Eastern Europe region are considered desirable since they represent an 'unmarked' body associated with global beauty. If these women can truly be models, it is because they possess the same characteristics associated with standard notions of 'white' beauty, 
but with a slight 'exotic' flair. Many men explained their choice of attending tours in the Ukraine to me by telling me they preferred the 'Slavic' look, a code word for not just white, but often fair. Alec, an eye doctor, explained to me on the bus from Kiev to Poltava that he attended the tour because he was into the 'Slavic' look, "I mean countries around the world that AFA goes, like the Philippines, South America. I wasn't interested in going there. I am not attracted to those women. I am more into the Slavic and Swedish look. Very fair, light eyes, light hair.” Jared, a younger man from the South, also told me he was into the 'Slavic' look and was not into the Latina or Asian looks. A couple of my interviewees also linked their interest in Ukrainian women to a past Ukrainian heritage in their families. Paul, who was under thirty, even learned Russian before he attended the tour, in order to feel a stronger connection to his heritage.

Even though all ${ }^{41}$ of the men I interviewed deemed Ukrainian women beautiful and sexy, Ukrainian women's beauty did not necessarily translate into desirability for marriage. A good number of the men I spoke to in Colombia and the Philippines had previously attended tours in the Ukraine and had become disillusioned in one way or another with the potential for finding real relationships there. At least five men I met on tour in all three countries had previously been married to a Russian or Ukrainian woman (though not necessarily through an AFA tour experience). The clear preference that many American men declare for Ukrainian women is part of the reason Wayne can argue that the Philippines and Colombia are niche markets; men typically begin their search for a foreign bride searching for an exoticized white woman in the Ukraine. Some of the men

${ }^{41}$ Literally ALL. Not one man I spoke considered Ukrainian women to be anything but beautiful. 
who had been to the Ukraine for tours and not experienced luck in terms of finding a potential bride, moved to more 'exotic' locales, like Colombia and the Philippines, next. Many American men argued that Ukrainian women are 'too cold’ to be a good wife. Desiring a Sensual Sofia Vergara

Colombia and the Philippines are considered 'niche markets' by AFA and their niche status is demonstrated by the much smaller amount of men that attend tours in both countries. In Colombia, the tours tend to average ten participants and many men attending tours in Colombia have a link to Spanish culture. In Colombia, most American men are searching for women that exemplify stereotypical mestizo Colombian women, like Sofia Vergara or Shakira. The website www.latin-wife.com describes Colombian women in the following manner, "Colombian women are well known world wide for their beauty and sensuality.” Agency constructions of Colombian femininity often include a curvy (but still thin) body, a sexualized nature, a penchant for high heels and sexy clothing, as well make up and long hair.

Greg quickly distinguishes the woman he met in Colombia from the American girlfriend he left behind in terms of a fashionable femininity or "girly-ness", "She’s [Colombian woman] always classily dressed. Everyday she goes to work she's got some different thing on, some different outfit. Her shoes and outfits and jewelry always matches. She’s a girly-girl or whatever.” Kyle also describes Colombian women as desirable in terms of their physical appearance, "Well, they dress like there’s no tomorrow. Everyone, but not every one, but most of them are very good..like they put on makeup like a makeup artist would put on makeup. They never really look bad so they 
rely on that, looking really great.” Many of my male interviewees constructed Colombian women's femininity and desirability in terms of their fashionable and sexy appearance. When I asked a set of brothers from Texas, who were 'repeat tour offenders' attending a tour in the Philippines, which of the many countries they visited had the most desirable women, they both answered Colombia. Matt based his decision on Colombian women’s feminine appearance, "You see those girls riding around on those scooters, riding around with her hair tied and a pair of red stilettos like this high, that's damn cute no matter where you are.” However, even though these men felt Colombian women were the 'hottest', Matt felt Colombians were an unrealistic choice because, "Well, it’s just that they don’t speak a lick of English.” Both Matt and his brother Tim agreed that Colombian women were the most attractive out of all the Latin American tour destinations and they were not the only ones; Colombian women's beauty within Latin America is a consistent theme I heard speaking to other men who had toured multiple Latin American countries. Thus, it is no surprise that Colombia is the most popular intimate tour site for the region, as Colombian women are well known for their beauty.

Men's choice to attend a tour in Medellin versus other cities often had a racial and color basis. Salvador, a Cuban gentleman from Miami, disliked women in Cartagena because, "To me, Cartagena is the worst. They were a bunch of hustlers. Number one, they are hustling you for money. It’s just awful, it’s filthy, you know when I went to their party, they [women tour participants] are all dark, most of them are black!” He felt girls in Cartagena were too dark and told me, "The women were all dark! No, no, no! I will never go back!” Mel also discusses the differences between women from varying Colombian cities by focusing on the women's education and appearance, "So a typical 
girl here [Medellin] might be a little more educated than some of the girls in other cities, speak some English versus none, but many girls in Cartagena and in Barranquilla are a bit more nice but girls here are much prettier.” Salvador summarizes his viewpoint of racialized differences within Colombia by saying,

You go to Barranquilla and its not like that [only black women like Cartagena]! You see many mixes. With all due respect to them, I would rather have Barranquilla, I like the women there better than the women in Cartagena. And, as far as being polite, you can get that here. The most beautiful women are here in Medellin.

My male interviewees consistently placed women from Medellin (Paisas) at the top of the racialized beauty hierarchy within Colombia based upon their 'whiter’ appearance and association with 'whiter' qualities, such as being educated and professional, as well as speaking some English.

The American men attending the tour in Colombia typically did not desire indigenous looking women either. Kyle labeled women with features that looked more indigenous as less attractive and highlighted Colombians' links to European influences,

Anyway, I really didn't know much about the Latin women and I guess sort of misjudged South America, like many Americans do. They think its kind of like Mexico but actually this whole area, once you get past Mexico and most of Central America, where the Aztec Indian influence was, and you have the real dark skinned people...actually South America has a lot of German influence and Italian and a lot of Spanish, where it's really European...it's like Europeans that speak Spanish and the reason they don't speak much English, from what I understand, is the history.

Kyle's quote demonstrates that darkness and indigeneity are associated with negative qualities and unattractiveness, while attractiveness is linked to notions of whiteness and European-ness. Fernando also linked European-ness to desirability and beauty when describing Argentinian women (who are known for having a 'whiter' appearance), “The 
women I met in Argentina had very pretty faces. Very Europeanized. You can find blondes there.” Men may be engaged in a process of whitening Colombian women to become acceptable marriage partners, but they are also engaged in a simultaneous process of exoticizing them.

Some of the men who choose to attend tours in the Ukraine and the Philippines, however, do not appreciate the curvaceous body type. Marley explained why he chose the tour in the Ukraine over a tour in Colombia, even though he had traveled to Colombia previously and enjoyed it immensely, by referring to Latina's bodies, "The problem is a lot of the Colombians are thicker and hippie. They have a big ass and boobs.” Besides not appreciating Latina body types, some men felt they were too 'spicy' and 'hot tempered', echoing stereotypical portrayals of Latin women in American popular culture. Collin told me he thought Latina women were beautiful, but that they did not possess the modesty he was seeking in a wife, "I looked at them, they're beautiful, but they didn't seem to have that shyness. I mean, Carnivale and all that, and some of those bathing suits they're almost wearing.... Modesty is not a big thing there.” The spicy, fun loving Latina is constructed in opposition to the more demure and conservative Filipina.

Desiring the Exotic Girl Next Door

The Philippines is another 'niche' market and their niche status is evidenced in a number of my interviewees' stories regarding what drew them to tours in the Philippines. Many of these men attended a tour in the Philippines based upon cultural exposure; many had friends or acquaintances with a Filipina wife or they had dated a Filipina in America. Dan mentioned his past experiences with Filipino culture and visiting the Philippines because of his Filipino friends as the main motivation for finding a wife there, "My 
friends are Filipino and I know the culture so well. I have been here three or four times just visiting the Island, not even looking for a girl.” Through an intimate friendship with Filipino people, Dan became acquainted with, and appreciative of, the Filipino culture. From there, it was only a natural progression for him to search for a potential mate in the Philippines. Jake also mentioned a happy Fil-Am ${ }^{42}$ couple he was friends with as inspiration for his tour attendance, "I've always liked them [Filipinas], and I had a friend that dated a young Filipina, he was like 52. He met a woman from the Philippines and is so happy.” Most of my male interviewees that attended a tour in the Philippines first traced their interest in Filipina women to intimate relationships they were already familiar with.

Carl had dated a Filipina in America, and his past relationship inspired his search for a woman from the Philippines, "I got interested in Filipino culture through a girl I met in the U.S. and I dated her for one or two years. And after I dated her, I kinda figured I would pursue finding another Filipino.” A young Australian man, Corey told me that his exposure to a lot of co-workers' Filipina wives inspired his tour participation, “A lot of guys have Filipino wives, and they just have really good families.” The intimate relationships Dan created with Filipino culture and the other successful couples he saw created the desire to potentially find a mate in the Philippines for a lot of the men I met on tour. Many of these men felt Filipina women's conservative, girl-next door femininity made for an ideal wife and long-term relationship partner.

${ }^{42}$ Shorthand for Filipino American. 
In terms of 'personal preference', many men linked their interest in Filipina women to the 'Asian' look; petite with long dark hair. Carl, who actually has recently married the Filipina girl he was engaged to, told me his initial interest in the AFA website could be traced back to his attraction to Asian women, "Obviously I am attracted to Filipinas. Physically, I am just attracted to Asian women.” Even though I met Jerry on a tour in Colombia, and he had attended numerous romance tours in the Ukraine, he constantly highlighted that he is physically attracted to Asian women,

Asian women I think as far as Asian women go, let me figure out how to word this, so as far as Asian women go you have guys that find them absolutely gorgeous but I know a lot of guys that Asian women just don't do it for them. Whatever it is. I happen to find them gorgeous. For me, I absolutely adore them. And in Asia, just as a tourist, you are a rock star!

Most of my male interviewees considered Filipinas beautiful based upon their petite, feminine appearance, tan skin, and long hair. Marley argued Filipina’s main physical asset is their size, “ I think they have really beautiful girls, they are small, they are beautiful that way.” Employees like Olivia at the local agency office told me that the most popular women are, "Typical Filipinas, petite. Yes, with the exotic long hair!”

Filipina's petite sizes are linked to a more conservative girl next-door type of beauty versus the model beauty ascribed to Ukrainian women or the sexpot type of beauty ascribed to Colombian women. Travis, a veteran of the Iraq war who lost a limb during his service, explained to me that he was not looking for the 'model' type. His main concern was to feel comfortable with the woman he was intimate with,

You know, and in all honesty, as much as like I want a pretty girl, I don't want somebody so far above me, that it's like I'm always trying to keep up, you know. And I really don't want that all model style, because, you know, I'm not be...uncomfortable with that, I'm not gonna take them back...you know, because 
I'm uncomfortable, you know. You know, I'm not becoming jealous like just naturally because I'm getting out of where I feel comfortable.

Travis wanted to feel secure in his relationship, and therefore, unlike many men who desired Ukrainian and Russian women, Travis was not interested in the model type of woman. He wanted a pretty woman, but not so pretty that he would need to worry about her finding another man.

Many of the employees of HLC told me that darker skinned Filipinas are more popular than light skinned, mixed looking Filipinas. Many of employees find men’s preferences to be ironic, as men's idea of beauty is the opposite of their own understandings of beauty. Denny, the manager of the HLC Office, told me, "Mostly they [American men] like the darker skinned girls. If they see it’s a light skinned, forget it.” Within Filipino society, beauty is constructed in terms of lightness and Anglicized features, and mixed Asians are celebrated for their increased beauty (Rondilla 2009). The owner of HLC, Halia, described how the beauty queue in the Philippines is based upon ideals of lightness,

Everyone wants lighter skin. A lot of skin bleaching is famous here. Whitening, because they want to be lighter. They want to be lighter, probably because they think, well in the eyes of the Filipinos a lighter skinned person is attractive. The boys also want the lighter skin. Filipinos like the lighter skin women in the Philippines. So if you are darker, you are below the list of attraction. Like here, with your skin like this, men will look at you, like oh my god, she will be my girlfriend and pretty. Lighter colors are the pretty colors in the Philippines.

American men's understandings of what made Filipina women sexually appealing and beautiful were the opposite of local Filipino's understandings, which many of the employees found to be ironic and slightly humorous.

Halia discusses her understanding of the ironies regarding American men’s 
different notions of beauty in the following quote,

Now the American men, in fact I have one guy who was like Halia I want to meet somebody really exotic. I want her more darker because I don't want to bring somebody back there who is of the same color, our color in another country. And he wants the girl to have a little rounded nose. Flat nose or little rounded nose. I can't imagine what people wants. Another guy came here and said I wanted somebody who’s Chinida. Look for someone with slanted eyes.

She mentions that men's inversion of the Filipino beauty queue is based upon American men's search for an exotic Asian looking woman to bring home. While many of my Filipino interviewees characterized 'darker’ women as the most desired by American men, how Filipinos define darkness is significantly different than how many Americans define darkness. The disconnect that exists regarding what is 'dark' demonstrates the subjective definitions people employ when discussing color. The different understanding of 'dark' explains why my Filipino interviewees consistently described the most popular women as 'dark'. Riley told me that Filipinos consider themselves to be Moreno/a, while they consider people of African descent to be 'chocolate'. While some of the very dark Filipina women are popular with American men, most men are seeking a 'morena' wife, similar to the situation in Colombia.

In order to ‘whiten' Filipina women, and construct them as representatives of the 1950’s femininity that many American men idealize, most of my male interviewees focused on Filipina's sweetness, innocence, and conservatism ${ }^{43}$. The Filipina is constructed as the ultimate sweet, girl next door. Bud Patterson, in his guidebook ${ }^{44}$,

${ }^{43}$ Based upon the Philippines’ reputation for a strict Christian society. Divorce and abortion are both illegal.

${ }^{44}$ Foreign Bride 101: A Guide for Nice Guys by Bud Patterson 
writes, "Filipina women are widely considered some of the most attractive women in all of Asia. They are sweet, feminine, family oriented and generally of high morals and traditional Christian values.” Many of my male interviewees echoed Bud’s assessment of Filipina’s sweetness and Christian values as important for a prospective bride. Lyle, a divorced man from Virginia, told me he chose to attend the tour in the Philippines because the culture is conservative and Filipinas are, "So sweet, so innocent." Filipina women's sweet approachability is often a constructed femininity that is the anti-thesis of the model-type femininity ascribed to Ukrainian women. Matt commented on Filipina's friendliness in general, while discussing why Filipina women made for better wife material than Chinese women (who he felt were unfriendly).

Even though many male interviewees found Filipina’s conservative upbringing and sweet demeanor attractive, a few of my interviewees felt Filipinas were just too poor to be sincere. Greg, who attended a tour in Colombia and the Philippines, felt the dire poverty situations many Filipinos faced to be problematic for finding a sincere relationship. A number of my male interviewees also professed not to be 'into Asian women’, linking attraction back to ideas of individual taste. Kyle explained he was not into the 'Asian look', but still could appreciate Asian women’s beauty,

I, myself, am not attracted to the Asian women Asian women are... well once you see a lot of them and get used to that difference, you appreciate the beauty that they do have. Filipina girls are very cute and very nice and family oriented but they are like petite. Five one is like tall. I actually dated a girl and she was like five two and she said she liked me because I was tall. Her dad was tall and he was like five seven.

In order to appreciate Asian women's beauty, of course, he must first get used to the different way an Asian woman appears. A number of my interviewees found Filipina’s 
demure, girl-next-door appeal desirable, but Kyle felt that these traits made Filipinas too immature, "They [Filipinas] are a little giggly and it kind of seemed like while they were very bright, they were a little immature.” A major deterrent to finding a Filipina bride for many men is providing remittances to the women's families left behind. Kyle told me, "They [Filipinas] are very motivated but the negative is - you marry the daughter, you marry the family.” Numerous male interviewees in other countries told me that the need for financial support made Filipinas less desirable.

\section{Desiring Transnationally Mobile Brad Pitts}

Women from Eastern Europe, Latin America, and Southeast Asia have throughout history been objects of desire for white, colonizing European and American men. Colonial discourses and narratives ascribed the title of world prostitute to Eastern European women, and at the same time ascribed the identity of "Little Brown Fucking Machines" to women in Southeast Asia and Latin America. The colonial history of desire has influenced the development of sex tourism as a major part of the contemporary economy in all three of the regions mentioned. Male sex tourists from the U.S. portray women from home as cold and sexually inferior to women in these sexualized geographies (Cabezas 1999; O’Connell Davidson and Sanchez Taylor 1999). Within typical male sex tourist discourse, white skin is devalued because of its association with civility, and is therefore, considered less sexual than more exoticized skin tones. Women in all three tour regions are constructed as not only sexually superior, but as more feminine as well, since they cook, clean and provide emotional labor to men. In many American men’s opinion, foreign women perform proper femininity, unlike American women. 
During the colonial period, and much of the contemporary period, women from Eastern Europe, Southeast Asia and Latin America have been portrayed as objects of desire and were/are rarely allowed the opportunity to express themselves as desiring agents. However, recent scholarship regarding both sex and romance tourism includes women's desires, hopes, anxieties and unique perspectives regarding their experiences (Brennan 2004; Cabezas 2009; Constable 2003; Johnson 2007; Kempadoo 1998; Schaeffer-Grabiel 2004, 2006). In terms of correspondence marriage, Constable’s (2003) seminal research on marriage migrants examines the desires of both Filipina and Chinese women signed up with internet pen pal agencies (as well as the American men who correspond with them). Within Asia, American men are imagined as more modern, powerful and attractive. Constable discovered that many Chinese women felt foreign men would be more accepting of partners with prior divorces or older women who had never been married. Chinese women tend to imagine American men as less controlling and more romantic, open and expressive: some even feel American men are more educated, cultured and intellectual than Chinese men. Filipina women in Constable’s study described foreign men as handsome and kind. Many Filipina women mentioned that foreign men were able to look after their wives and remain romantic after being married, unlike Filipino men. For many Chinese and Filipina women, American men’s ability to care and provide for them is inseparable from ideas of love, and the care provided by American men allows many women to look past typically ‘disgusting’ characteristics, such as old age, bad health, or a poor physique.

Schaeffer-Grabiel (2006) examined the desires of female romance tour participants in Guadalajara, Mexico and Cali, Colombia. She found that female 
participants of romance tours in both tour locales view American men as providing a more stable lifestyle, with increased opportunities, as well as a more egalitarian household. Similar to women in Asia, women in Latin America highlight similar desirable qualities when describing their ideal mates. While most Mexican women described local men in Guadalajara as "macho”, many of them felt that American men respect women who are strong and successful. Schaeffer-Grabiel (2004) demonstrates through her interviews that Mexican female tour participants imagine American men as tall, slender, well dressed, and light skinned. The physical characteristics Mexican women derided in local men often correspond with ideas regarding education, culture and professional status. Thus, issues of skin color, and all of their links to ideas regarding class, status, and beauty, are just as important for women involved in the romance tour industry as they are for American men.

Johnson (2007) demonstrates that race is very important for Russian women when discussing the desirability of various American male suitors. Many of the Russian women she interviewed underlined the fact that they were interested in 'European' men, a term indicating Caucasian, since they also used the same term to describe white American men. Often times Russian women used the term ‘Christian' as a signifier of whiteness in Johnson's interviews, since 'Christian' in the Russian context is tied to nationality and race. Johnson (2007: 85) quotes a survey of Russian women that indicates 85 percent want to find a white man, 10 percent would consider an Asian and for 5 percent the race of the man does not matter. Fourteen percent of Russian women on the website Johnson examined explicitly stated they were only looking for white men. As the recent scholarship on marriage migration and romance tourism demonstrates, women 
from all three bride exporting regions desire American men for similar reasons and tend to imagine them as racially white.

Women that I spoke with in all three tour locations stressed three important characteristics as desirable in a potential husband: serious, financially stable, and faithful. In terms of age, appearance, and race, some trends appear across all three field locations but a degree of variation exists in what women find desirable, based upon their nationality. Predominantly, however, Colombian, Ukrainian and Filipina women tend to imagine American men as a financially stable, transnationally mobile Brad Pitts. Why Brad Pitt? For most women abroad, Brad Pitt physically represents a ‘typical’ American man: blonde hair, blue eyes, and tall in height. Jessie, an interpreter in Colombia who has worked at the agency for five years, explains what most Colombian women find desirable when seeking an American or other foreign man,

Most of them want a white man. Like I would say all the girls want a Brad Pitt. That's not going to happen. So they're expecting look-wise white men who are in their twenties or thirties or in their forties. There's a lot in their forties. But the younger ones, want a guy under 40 , white guy, stable, financially stable, oh yeah, and the financially stable part is really important because most of them are not stable. Most of them are living in the [favelas], in the rough neighborhoods. The ones you see like in the mountain, neighborhoods that are really high up. Remember when you went to Saint Elena? Most of them live in those types of neighborhoods. Most of them are middle to lower class, they don't earn that much money. Most of them are single mothers. A lot of single mothers. And a really, really small amount of them are professionals or in college, working as yers and dentists. But usually the girls are middle to lower class, they work in factories or as secretaries, so they want someone that's financially stable.

While Jessie is describing Colombian women's desires, women from Ukraine and the Philippines also often described 'hot' men in terms of a Brad Pitt-like physical appearance. Jessie describes Colombian women's expectations of American men in terms of whiteness, but more importantly in terms of class. Many women desired whiteness in a 
potential American husband for the financial affluence and economic stability that transnational whiteness represents. Many women’s struggles with their own financial stability inspired them to consider looking outside of their country for a potential mate. Financially Stable Brad Pitts

Jessie mentions that while most Colombian women are expecting a semi-young, attractive white man, what matters more to most women is an American man's financial stability. The desire for financial stability became a reoccurring theme in my discussions with women in the Philippines and Ukraine as well. Nadja, a Ukrainian translator who was also engaged at the time to an American man, put her concerns over financial stability in the following way, "I am looking for a guy with money and stability. Why would I leave my home country to be poor? I can be poor here!” Missy, one of my Filipina interviewees, explains her desire for meeting an American man in terms of American men’s financial stability, “Actually, I am looking for American man because he's so..., maybe he has some stability.” Elisa, a Colombian woman, told me that notions of American financial affluence and stability are a common discourse in Colombia, "I have heard that foreigners are more sure of what they want, more stable, and that's what I want to find out.” When I asked Kristina, a translator in Kiev, about the motivations of Ukrainian women for finding a foreign man, she mentioned that most women were looking for financially stable men that could support their family,

Mostly, of course, this is, wealthiness, money, unfortunately. But, most of them want to meet a man, because they are so disappointed with the men here. They want a real man, a real father to their children. They are looking for support. Cause a lot of girls, who are presented in the agency, they are divorced, and mostly have children. They're taking care about their future, and they want their children to have a good father. 
Many Ukrainian women feel unstable in the Ukraine because of the major economic changes that have occurred since the collapse of the Soviet Union.

The extreme wealth gap in the Ukraine is hard to ignore: Bentleys are a common sight on Kiev streets and the major shopping district includes all the major European design houses. Nadja mentioned, “If you don’t have money, you are a nobody in Kiev.” The extreme wealth gap is a relatively recent phenomenon in Ukrainian society. During the Communist Era, most citizens were relatively equal in terms of access to apartments and consumer goods. The immediate years after the transition to capitalism brought numerous financial crises to the region and created financial instability for many families. Nadja once again explains the Ukrainian standard of life in terms of poverty, "Ukraine is a poor country. All our salaries are like miserable. They are really small, it's not enough to live, just to survive. Not all people [live this way], but almost, the best majority of people, they have small salaries and it's difficult to live. You can buy food, pay some bills, that's it.” Kristina also characterizes the average Ukrainian's lifestyle as poor, "Here the average when you see a level of life, it's pretty low.” The recent financially unstable years, and the persistent economic problems of capitalism, continue to inform Ukrainian women's search for foreign husbands. According to Sandra, one of the local agency office managers, the typical woman in Ukraine is, "taking care of, thinking about her future, she wants her children to be wealthy. She's thinking that it's great to date a foreigner, that it's easy.” Many female tour participants view marriage to a foreign man as the easiest way to find financial stability.

The extreme wealth gap between the elite and the rest of society is a relatively new phenomenon to the Ukraine, whereas in Colombia, the extreme wealth gap 
developed under Spanish colonialism, but is being tempered by the growth of a small middle class. As Jessie pointed out in her earlier comment, a large number of the women searching for an American husband are from financially unstable backgrounds: many of the women live in 'favelas ${ }^{\text {}} 45$ and do not work professional jobs. However, the assistant office manager Xiomara described the current economic backgrounds of the women in Colombia as more mixed, "I think it's like 33\% are from poor backgrounds, 33\% are from professional backgrounds, and the other $33 \%$ are stable.” The managerof the office told me, "Like they can find ladies which lives maybe in poor neighborhoods, but you can also find teachers from college, professional. So, it's like a mix.” The growth of the middle class in Medellin is leading to an increasing amount of middle class and professional women searching for a potential foreign husband. The owner of AFA told Kyle, after he had a negative tour experience in Costa Rica, that Kyle could find professional women in their mid 30's in Medellin.

Even though women in Colombia are increasingly associated with professional, middle class status, they are still seeking an American man with financial stability. Xiamora told me, "Most of them [women] are looking for serious relationship for sure, someone who's honest, someone who already knows what he wants in life and like some guy to be established, like be economically established.” Most women wanted to ensure that when they left Colombia, they would not have to face financial hardship. A number of my Colombian respondents focused more on personality characteristics, such as sincerity, stability, and honesty over a man's appearance. Carolina explained her focus on

\footnotetext{
${ }^{45}$ In many cities in Latin America, poor people are pushed into neighborhoods high in the mountains that are difficult to access.
} 
personality over appearance to me, “I am not really interested or worried about a man’s physical appearance. I want to find someone who is respectful, someone who is sincere and someone stable.” Isabella described her desires for a husband in similar terms, “Someone sincere and stable.” Colombian women continually imagine American men in terms of a transnational affluence that can potentially translate into future economic stability for them. Colombian women are not the only ones seeking out financial stability; many women in the Philippines desired a man with financial stability as well.

The wealth gap in the Philippines, largely established during Spanish colonialism as well, has remained consistent due to the extreme corruption exhibited by the modern state (Presidents Marcos and Arroyo are a few recent examples). A major wealth gap and issues of poverty are the most evident and extreme in Davao City in comparison to the other tour locations I attended. Most of the American men stayed on the property of the hotel, unless they participated in organized tourist activities. Many of the men were disturbed by the poverty facing them in the Philippines. Mickey described his intense confrontation with poverty beginning the moment he left the airport,

From the moment I touched down, until now? It's been like, two different tracks of the same train. Two rails. I'm seeing that the lifestyle of the people when I rode in from the airport - there's the world of Marco Polo [hotel] and then there's the tour. There's two separate things going the same way. I knew there would be a culture shock, but I didn't realize to what a degree of, how poor it would be. I came from the airport to here, and that was a pretty stark first impression. This is like an oasis.

Greg called the Philippines “Third World” and "trashy”, while Neil also mentioned the shocking poverty he saw on his way to the hotel, "A lot of these girls, come from, you've seen the poverty here, I mean. When I got off the bus to go to the hotel, [I had] no idea 
how poor it was. We're not talking down on your luck, we're talking ruinous poverty.” The crushing poverty facing many rural populations in the Philippines leads to a dependency upon migrant remittances, both internally and internationally, and has paved the way for relationships between young Filipinas and older foreign men to become increasingly socially accepted (Constable 2003; Parreñas 2000, 2001).

Many of my female interviewees in Davao are internal rural to urban migrants and are already responsible for supporting their families through remitting money. I spoke to a few interviewees that had worked as OFWs abroad in Saudi Arabia and the United Arab Emirates. Many of the women I spoke with commented on supporting their families: their parents, siblings and/or children. They often live in boarding houses, since they cannot afford their own apartments on the average wages paid to workers in the Philippines. Most of the women I spoke to send a large portion of their income back to their families in the rural provinces. A number of Filipinas told me that their families did not mind, and even at times encouraged, them to find a foreign husband. Missy explained to me that her mom encouraged her to sign up with HLC, "My momma said, go in America, go find someone American because you know that they think that its just for money." Missy also told me that she is the eldest in her family and it is her responsibility to remit money home, "I am the eldest. I have to help take care of my parents. For me, it's your responsibility. If you are eldest, it's your responsibility to help them. Your responsibility to help them.” Ultimately, Missy hoped to find work abroad in the U.S., since real economic opportunities do not exist for her in the Philippines,

I want to go to America just to find a job. Before you go to another country, you need to find a job. You have to reach age 23 so I have to wait two years. If I am 
23 right now, I am not here. I better go to other parts of Asia. I don't know, it's just so very hard to work here in the Philippines, small money. Most of us here living in boardinghouses.

Riley characterized the situation of most Filipina’s lives as sad, “It's sad because people are poor.” The extreme economic hardships faced by many of my Filipina interviewees manifested in their desire to find someone stable.

A young Filipina employee of the HLC local office, Lily, was dating a Filipino man her age when the tour started. Her relationship changed dramatically after meeting the man she was assigned to as a 'buddy' ${ }^{46}$, since he developed an immediate crush on her. After a few days, Lily began to develop reciprocal feelings for Matt and decided to dump her Filipino boyfriend. Lily linked her decision to end her relationship with her local boyfriend in order to date Matt to Matt’s stability, “Then Matt has his 3 children too. I can see that Matt is more responsible at the same time he’s stable. Yeah, compared to my boyfriend. And he showed me a lot of kindness, sweet; goodness and he surprise me a lot.” Zia, who also worked at the local office, told me that she believes Filipina women tend to look for older foreign men, rather than young men, because of older men’s stability, "Because for me, that guy [young man] is not stable. He cannot take care of the family.” Many employees of the HLC office traced the large age differences between many Filipina women and their American boyfriends/husbands in terms of desiring a stable family life. Wayne, the owner's brother, reiterated Filipina’s supposed preference for older men, “Actually, even when they’re [Filipinas] dating guys who are

\footnotetext{
46 The HLC office in the Philippines was the only office that used a 'buddy' system. Each man is assigned a buddy from amongst the employees of the local office. The buddy is meant to help him navigate the tour and dating experience.
} 
fifteen to twenty years older, its because they're stable, they're much more responsible, providing for the family." While financial stability is a large focus of many women on the tour, the desire to find faithful and honest men also plays an important role in women's constructions of different American masculinities.

Appearance does not Matter, or Does it?

Romance tour agencies proclaim that looks do not matter to the women participating in tours; these women are looking for good men that will support them and remain faithful. To a large degree, I found that to be true in my discussions with female tour participants: women do seek men who are financially stable, faithful, honest, sincere, and caring. However, physical appearance does matter to a number of my female interviewees in every tour locale. Many Ukrainian and Filipina women discussed the fact that men in the U.S. looked significantly younger then their local counterparts. The office manager Katya in Sumy explained that American men’s youthful appearance is an enticement for female participants,

Sometimes we explain them that men look much younger their age, but they can't believe, because they see our men of this age and they are completely different from men abroad of this age. For example, a forty-five years old man from the U.S.A., he may look completely different from Ukrainian man of this age, because, I think or many ladies think that men from abroad they take care more about themselves. When you overcome a generation gap, if you meet a man here and you have like 10 years difference, he can look much older.

In the Philippines, the office manager Denny explained the extreme age gaps between Filipina women and foreign man to me by pointing out that American men take care of their physical appearance, "Mostly, the American men, they look young. They do not look their age.” Alexis also described her admiration for American men's youthful experience, “Men from the U.S. look young. Very young compared to Ukrainian.” Even 
though many women praised American men's relatively youthful appearance, not every American man is considered to be desirable and attractive. Racialized ideas regarding desirability permeate female participants' considerations in all tour locations.

Ukrainian, Colombian and Filipina women create racialized hierarchies of desirability in a similar manner to male participants. Many of my female interviewees' desires look towards whiteness as a signifier of transnational mobility and affluence. Many women I interviewed in all three locales desired a white, American man, but clearly not all American men are Caucasian. Despite the fact that not all Americans are white, most Filipina, Colombian and Ukrainian women imagine Americans in terms of whiteness. According to Kristi, an employee of the HLC agency, "Sometimes they don't care if it's a German, as long as it's white they will say it's American. For us, if it's white, it's American.” The stereotypical image women possess of an 'American' is based upon the fact that most male participants in any tour locations are older white men. The lack of differentiation between American and European man is present in Ukraine as well. Kristina, a translator in Ukraine, told me that Ukrainian women do not make big distinctions between white men from the North, "Oh, actually mostly, don't care or get the difference. Don't care if from Europe, don't care when it's United States. When they hear English, they think yeah, this is American. They don't realize that this guy can be from England, Italy, that one from Germany, this one is Portuguese.” Employees working for local agencies in each tour location discussed the fact that most of the men participating in the tour are white men, and that most female tour participants are expecting to see white men. Within women's considerations of desirability, American 
men's association with whiteness, affluence and mobility move them to the apex of the desire hierarchy.

Many of the Filipina females who sign up with the HLC Lifemates office in Davao desire a lighter appearances for themselves, not just the men they desire to date and potentially marry. Missy constantly discussed her desire for lighter skin, and the phenotype features associated with whiteness (small nose, light colored eyes, etc.). When I asked her if she utilized skin bleaching soaps and lotions, she responded:

Yeah [I bleach my skin]. I am not brown. But if I spend time in the sun, I get brown brown. Very tan. I don't like. I like this skin, having a pinkish thing. [pointing to my skin]. I wish I had pinkish lips, blue eyes. Other Filipina use contact lens just to have blue eyes. You should be glad that you have that! You know the cat eyes? Green? I like those. I like your eyes a lot, my eyes look like they are black.

Many women in the Philippines use skin bleaching lotions and soaps in order to achieve and maintain lighter skin tones. Even though Riley does not use skin bleach creams, she explained to me why other women do, "Most of the Filipina want to be, it’s like you will gain a level of respect and popularity if you have white skin. If you are, it's like because if you are white people will see, she's from rich family, from money, she's a really respectable woman, she's a lot. So that's why Filipina wants to be white. Just like me, I love to be white but I never am. I am always this color, dark.” Some of the female employees at the HLC Lifemates office discussed their avoidance of the sun in relation to remaining light. Protecting her skin is so important to Missy that she does not like the beach near her family’s home, “It’s not good for my skin, the beach. For my skin, I don’t like that. I don’t want to go brown, brown, brown. I want white, white, white.” Besides 
skin bleaching, many women look to 'whiten’ themselves through marrying an American man and producing mixed race progeny.

The most popular actors, actresses, and models in the Philippines are of mixed race descent. Mixed Filipinos are considered to be more beautiful, based upon their 'different' racial background. Young women, like my interviewee Mary, desire a white American man because, “I want a white baby with blue eyes! I can’t marry a man darker than me! My children will be black. I want my children to be lighter than me.” Thus, many Filipina women engage in a dual process of lightening: lightening their own skin with bleaching products and lightening their future progeny through intermarriage with a white American man. When I asked Missy what type of man she was looking for, she responded, “A white man! I like white men.” Missy linked her desire for American men to desires for phenotypical features associated with transnational whiteness, such as blonde hair and blue eyes. Missy tells me, "I’m more attracted to American people because they are tall, they are white, have a nice nose, nice eyes, blue eyes. I really like it. Blue eyes and nice nose, not like mine.” American men who possess these features feel desirable, a feeling many of the men do not experience within their local dating market. Tom puts his feeling of increased desirability in terms of possessing white features, "This right here is a secret world. Filipinos are just good people. They just think we're the bomb. Little nose and the green eyes and stuff. Well this girl, she's thirty three or thirty four, took a hold of my nose and told me, I want your nose.” Even my male participants understand that their whiteness, and the phenotype features associated with their whiteness, is one of their main advantages in the global love market. 
Colombian women are also looking to lighten or 'whiten’ themselves through plastic surgery and to whiten their future progeny by marrying someone lighter. Schaefer (2013) argues that Colombian women in the city of Cali alter their bodies through plastic surgery in order to use their bodies as a tool for social and physical mobility. She argues that cosmetic surgery in Colombia has become a normalized part of everyday life, since it often provides women access to the rewards of beauty: success, mobility, and the neoliberal agency of choice. I also observed in my fieldwork that a number of Colombian women in Medellin utilized plastic surgery to alter their appearance, in the form of nose jobs and breast implants. Though skin bleaching was not mentioned by any of my Colombian interviewees as commonplace, plastic surgery is considered to be just another normal beauty enhancement. Women in Colombia continually focused on increasing their position in the beauty queue by surgically altering their phenotype features to look more 'European', demonstrating that lighter, more Anglo looking women are at the front of Hunter's (2005) beauty queue. Besides investing in their bodies as a 'pliable' commodity (Schaeffer 2013), Colombian women look to marrying lighter American men in order to lighten their future children.

The desire to lighten one's children can be linked to long-standing discourses of racial mixing and blanqueamiento ${ }^{47}$ that have been popular in Latin American countries for centuries. Thus, many of my Colombian interviewees expressed their desires for tall, white men with fair features, which is evidenced by Josephina's descriptions of what she’s looking for in a man, "Tall, not too skinny, not too dark, brown and white men.”

${ }^{47}$ Please refer to chapter three for a detailed discussion of the Blanqueamiento philosophy and process in Latin American history. 
Kari, a translator for the agency, kept telling me she preferred blonde, 'whiter' looking men, "I like blondies!” While many women imagine American men as stereotypically Caucasian, many still find 'brown' or 'moreno' men attractive and are open to dating, or potentially marrying, a brown man. Elisa claims that she is open to men of any race but prefers men with an olive skin tone, “I like tall guys with olive skin. I don’t have a real preference for white or black." While Elisa did not mention a specific preference for a white man, she did prefer a man with an olive skin tone. Olive and brown skin tones are considered more acceptable within the Colombian racial continuum of skin tones than dark tones or features associated with blackness. As Jessie pointed out, most of the women are searching for Brad Pitt, and he exemplifies stereotypically white, 'Anglo' features.

During interviews with employees of the local Medellin agency office, I focused on the demographics of the men who attended the tours in Colombia. All the employees I spoke with acknowledged that most of the men attending the tour are older ${ }^{48}$, middle to upper middle class white males, similar to the demographic in the Philippines. A few Hispanic and black men attend the tours in Medellin, but they are a small segment of the male romance tour population. Caren, a translator, told me that while white men are the norm for tour participants, 'moreno' men can find success, "Usually in these tours, white men always come. But last time a Filipino had a lot of dates, [he was] popular.” A number of Colombian women expressed concern over dating African American men, but were open to dating Hispanic or other 'moreno’ men. Sofia began dating Jared, a South

\footnotetext{
${ }^{48}$ Mostly over 40, and a large percentage of the men on tour are over 50 years old.
} 
Asian man with brown skin, and things began to get serious quickly. She explained to me that she didn’t mind dating him, since he was Moreno and not negro in color. The desire for increasing lightness and whiteness evident in the cases of the Philippines and Colombia is not present in the case of the Ukraine; however, similar racialized hierarchies of desirability are also being (re)produced there.

Ukrainian women are now considered 'white' in terms of both race and color ${ }^{49}$, so they do not focus on attempting to 'whiten' or 'lighten’ themselves through cosmetic procedures or intermarriage. Instead, their concern over race and color has to do with 'difference'. In much of the post Soviet world, it is not common to see local people of African descent. When I asked my Ukrainian interviewees about racial issues in Ukraine, they told me that the population is relatively heterogenous and Slavic, especially in smaller towns. My female participants continually characterized Asian, Muslim, and black men as 'exotic' and 'different'. Even though suitors associated with exoticized difference excited and enticed some Ukrainian women into dating for a short time, most often times these relationships did not develop into marriage. My Ukrainian interviewees consistently considered black or Muslim men to be 'too exotic', unlike white American men, who are considered 'exotic', but not too exotic to marry. Bud, the tour leader in Ukraine, mentioned that the number of African American male tour participants in the Ukraine is relatively small,

Most of the times they [African American men] choose to go to the Philippines or to Colombia for whatever reason. When they do come on our tour to Ukraine, they are typically pretty successful. We find that educated black men do pretty

${ }^{49}$ The racial situation described was not always the case: Eastern European, especially Slavic people, were considered a 'lesser' white than Anglo Saxon British colonizers. 
well here. Non-educated black men may struggle sometimes in the courtship process. But, yeah, if they for whatever reason most of the time are gentlemen of color come to it, he decides to go to Philippines or Latin America.

Bud's explanation of the racial dynamics in each tour location clearly links American men's race and class status to their tour destination choice, and classifies the men on tour in the Ukraine apart from men in the more racially 'exotic' locales based on education (which is often linked to ideas of class).

A majority of my Ukrainian interviewees considered African American men too exotic for marriage and they are typically looking to find white American husbands. At first, many of my Ukrainian interviewees did not focus too much on potential husbands' physical appearance. Once issues of race and color came up in the conversation, it became clear that the racial component of a man's appearance did matter. Ludmila described her ideal mate in terms of whiteness, "Yes, race is important for me, only a white man.” Elena mentioned that she was looking for a white man that was not too large in size, "I need to see him, I'm sporty and would not like a man burdened with excessive weight. No more, no less. But preferably white!” Many employees of the local agency commented on the fact that it is difficult to get women out on dates with African American men. Kristina described how she began a friendship with one of the African American men on the tour, since not many women would agree to date him. She explained to me that the older generations in the Ukraine are simply not used to nonSlavic populations, and thus, many women cannot imagine bringing home a nonwhite fiancé to their families.

While the majority of women I spoke with in all three countries found African American men to be too exotic for marriage, there is a small minority very open to dating 
black men. Another translator/profile in Ukraine, Ilona, is dating an African American man from Miami, but discussed her concern about bringing him to her small hometown in rural Ukraine, since not many people of color ever visit her town. She thinks he is attractive and interesting, so she is open to dating him, but recognizes that there will be certain obstacles they have to overcome as a couple in order to get married. When I asked the manager of the Kiev office if African American men have luck finding ladies to date, she replied "Not that much, but some of them do.” I met two African American brothers on tour in Kiev, and they were able to connect with some of the ladies and find dates. It was their third tour, so they did not seem to think finding a date in Ukraine was hard, but as Bud pointed out, both of these men are highly educated. In the Philippines, Denny, one of the office managers, mentioned to me that African American men can find dates and potential brides in the Philippines, but they just cannot be as picky as the white American men. The managers in Colombia also pointed to the possibility of a woman dating an African American, but said that it is not the typical case.

The common desire for a white husband across all three of my tour sites demonstrates that female tour participants are also (re)createing neocolonial hierarchies of desire. In female participants' hierarchy, white men are still at the apex, since they continue to be associated with affluence, mobility, and attractive physical features, such as light skin and eyes. Contrary to popular media discourses that present these women as 'desperate' to leave their countries, my research demonstrates that women signed up with tour agencies are indeed discriminating in their choice of husbands. They may not discriminate in terms of age and beauty, but they are discriminating in terms of race, color, class, and religious background. 


\section{Chapter V: Disgust and a Move to the Transnational}

According to the esteemed philosopher Immanuel Kant, what makes an object (or a person) abhorrent and disgusting is precisely its (or their) outrageous claim for desirability. Throughout human history, a fascination with the disgusting has existed, even though most critical theories have focused on desire versus abjection in the past. However, disgust is as important to intimate relationships as desire is. It is only through the articulation of disgust that people begin to discover what they desire. The inherent tension between these two 'opposite' poles of the emotional spectrum is the way in which individual 'tastes' are formed. A number of American men explained to me that 'exotic light' women are their 'type', and many women I interviewed also explained that their type is a transnationally mobile Brad Pitt. People that fall outside of the desirable category are discussed in terms of disgust, and abjection. Much like desire, disgust is also a socially constructed emotion, even thought it feels intensely personal.

Men on tour described most of their local dating options in the U.S. with disgust. According to the men on tour, American women have become too masculinized to be desirable: they are overweight, underdressed, and too focused on their careers. The same men, on the other hand, discussed foreign women in terms of desirability, because of their more feminine appearance and traditional family values. However, not every foreign woman is desirable and commercialized romance tourism mainly thrives in the former Soviet Union, Southeast Asia and Latin America. Noticeably, women associated with blackness are often left out of the commercialized romance industry and a large number 
of white American men I interviewed often discussed blackness in terms of disgust. While black bodies and sexualities are considered desirable for sexual encounters, they are non normative and are therefore, repulsive for marriage. Romance tourism allows white American men on tour to resolve their sexual attraction to exotic nonwhite women in Asia or Latin America through feminizing and 'whitening' them. Ukrainian women, Colombian women, and Filipina women often discussed their local dating options in terms of disgust as well: men who are unfaithful, immature, and financially unstable. In addition to articulating disgust towards many of their local dating options, a large number of women in all three countries also discussed men associated with blackness with disgust, demonstrating that many of these women are indeed not desperate enough to marry any man simply because he is an American.

\section{What is Disgust?}

Like desire, disgust has important embodied manifestations. Rozin and Fallon (1987) identify four bodily reactions to disgusting experiences: a characteristic facial expression, an appropriate action (distancing oneself from that which is disgusting), a distinct physical manifestation (nausea), and a characteristic feeling state (revulsion). By adopting a definition of the disgust experience, Ahmed (2004) argues that we can demonstrate the 'weightiness' of feelings and how they physically imprint upon our bodies. Thus, Tyler (2008) points out that the communication of disgust relies heavily on metaphors of embodied sensation, needing the imagery of foul tastes and rancid smells. Miller (1997) argues that disgust is always a response to something, since we do not feel disgust in the abstract, and therefore, disgust is dependent upon contact: "it involves a relationship of touch and proximity between the surfaces of bodies and objects" (Ahmed 
2004: 85). The offensive object must be close enough to us for us to feel disgust, and thus, disgust acts as a contact zone. The contact of disgust causes our bodies to recoil and we begin physically distancing ourselves from the offending object, situation, person, etc. In essence, to be disgusted is to be affected by what one has rejected (ibid: 86).

Throughout history, many artists and philosophers have argued that desire and disgust are conjoined affects and often interplay exists between these two extremes (Young 1995). However, Ngai (2005) argues that the constant pairing of desire and disgust demonstrates that the two affects have an asymmetrical relationship, as disgust is a structured and an antagonistic emotion, while desire is amorphous and vague. Accordingly, she argues that disgust is never ambivalent about its object, unlike most other feelings. Disgust takes on urgency and specificity, while desire can often be vague and ambivalent. The language of repulsion is more limited and narrow than the language of desire, demonstrating that even the language surrounding these two emotions is asymmetrical. Despite the asymmetries between desire and disgust, they both play an important role in (re)producing transnational hierarchies of race, class, gender, nationality, and sexuality.

By solidifying boundaries between bodies and objects, disgust maintains and creates political power relations. Tyler (2008) claims our embodied reactions of repulsion reveal wider social power relations. Disgust ranks and orders bodies in hierarchies, through assessments of inferiority and superiority that rank certain others below or beneath the subject (Ahmed 2004; Miller 1997; Tyler 2008). Miller (1997) goes as far as to claim that the work of disgust is to hierarchize the entire political order through constituting claims of superiority. Disgust reactions want to include others; therefore, one 
can argue that it is a sociable emotion, which can be used to create group unity within hierarchies (Ngai 2005). To name something as disgusting is performative, since the ascription one assigns to an object also generates the object that it names (Ahmed 2004). Butler (1993: 20) defines performativity as, "the power of discourse to produce effects through reiteration.” Thus, to understand current discourses of disgust in terms of hierarchies of race and gender, it is important to explore the development of racialized and gendered disgusts during colonialism and the ways in which they contribute to group unity.

During European and American colonial expansion, colonial administrators utilized the emotion of disgust in order to maintain racial boundaries between the colonized and colonizer (Stoler 2002, 2006). Disgust is an aversion to something, or someone, which is perceived as 'dangerous' because they have the power to contaminate, infect, and pollute through proximity and contact (Miller 1997). While Ngai (2005) describes disgusts' asymmetry to desire in terms of the expressions of both affects, the relationship between desire and disgust is particularly intertwined within the construction of colonial sexualities and ideas surrounding the contamination and pollution of racial boundaries. Disgust towards other races often was expressed through fears of miscegenation and the mixing of races, which was thought to lead to contamination and degeneration. Unlike other forms of disgust, sexual disgust may be the ultimate temptation to transgression (Dollimore 2001). Miller (1997) contends that the disgusting can be alluring, especially if the object of disgust is taboo or prohibited. Young (1995) furthers Miller's argument by stating that disgust always bears the imprint of desire, in order to mask the symptoms of repressed sexual desires. Dollimore (2001) counters that 
disgust is not always an expression of repressed desire, even though it often is. The complex relationship between disgust and desire characterized both American and European colonial encounters with various 'Others'.

The pull between repulsion and desire creates ambivalence towards racialized 'Others'. The fraught and tense relationship between illicit desire and repulsion is an important narrative that underlies discussions of both colonization and globalization (Lowe 2006). Colonial discourses created an aestheticization of race, in which whiteness began to be associated with hygiene. The linking of hygiene and beauty to race is a process that began in the 1700 's and during that time, beauty became a criterion of racial classification (Stoler 1997). Links between sex and race developed further in the nineteenth century through widespread fantasies of blackness as attractive yet dangerous, since blacks were considered threateningly fertile (Young 1995). British geneticists in the Victorian Era eroticized the native 'Others' of the colonies, but at the same time denounced them as 'disgusting', 'repulsive', and 'hideously ugly' (Lowe 2006). The exhibition of Sara Bartmann and her 'excessive’ Hottentot genitalia were pathologized under the gaze of European medical science, but at the same time were sexualized and eroticized (Abrahams 1998). Black women were considered the lowest human species in the evolutionary chain, because of their excessive sexuality, and according to colonial rhetoric, black women were so bestial that even their own men preferred white women to them (Abrahams 1998; McClintock 1995). Concurrently, black men became the embodiment of the sexualized beast, which working class white women could not resist. Through these discourses, blackness became associated with fecundity and hypersexuality, and it still remains the case in contemporary discourses. 
An irreconcilable conflict exists in colonial narratives and discourses between desire and aversion: the idea that sexual desire for the 'other' is a 'natural' impulse was never questioned, even if it was couched in terms of abjection. Since white women were entrusted with ensuring the racial purity of the nation, white men could not allow them to be penetrated by 'dark savages' or to express their desires for 'other' men. White male colonial administrators put severe restrictions on white females' sexual agency during colonialism in order to protect the purity of white identity (McClintock 1995; Yuval Davis 1997). However, they often did not apply these same stringent rules to themselves, because of male privilege. During early colonial settlement and exploration, interracial unions between white men and native women represented a danger to racial purity and cultural identity, since the colonizing men could not only be contaminated with disease though sexual relations with a native, but they could also contract debased sentiments and immoral ideas (Stoler 1997b). This was resolved in the U.S. with anti-miscegenation laws. Marriage provided legitimacy to unions that were simply meant for sexual urges, as well as to the progeny that resulted from these marriages. Racial miscegenation, or racial 'pollution', became a major concern of colonial administrators, since the mixed progeny from interracial unions could potentially seek access to European privilege (Stoler 2002) McClintock (1995) and Levine (2000) both contend that the new lands Europeans and Americans colonized became the 'porno-tropics', places that became representative of illicit sexuality, fecundity, and sensuality. Manderson (1997) argues that Asia (as well as other former porno-tropics) still represents an “illicit space”, or adventure zone for Westerners, where sexual taboos are open for transgression. Sexual taboos are open for transgression in many former colonial sexscapes (Brennan 2004). Men seeking sexual 
relationships in the porno-tropics of the Caribbean want to escape the 'demands' of 'liberated' American women through fantasies of 'hot' Latina women, while still maintaining traditional understandings of gender roles (Brennan 2004). Dominican women, as well as many other women in the Global South, are constructed as both sexually superior, and more traditional, than American women, since they cook, clean and 'take care' of their men. Through their emotional labor, Caribbean women are considered to perform proper femininity and racial sexuality in the eyes of many American sex tourists (Cabezas 1999). Ultimately, the eroticization of women in the Global South presents them as sexually desirable and primitive at the same time, demonstrating the deep intertwined expressions of desire and disgust.

In contemporary sexual tourism in the former colonial porno-tropics, black bodies continue to be represented as primitive, closer to nature, and hyper-sexualized (Cabezas 2009; Kempadoo 1998, 1999, 2001, 2004). Thus, darker skinned people in the Caribbean are typically employed in low level service positions or in highly sexualized entertainment positions. Even though women of color in the Global South have a long history as the object of American males’ desires. Many sex tourists consider black and brown women desirable and erotic, but don't view them as long term potential wives or domestic partners. Within the romance tour industry, an aversion to blackness for marriage continues, expressed through discourses of disgust and abjection, on both sides of the industry. On the other hand, 'brownness' and racial hybridity are deemed as attractive and desirable, representing the best of both worlds. 


\section{From June Cleaver to Roseanne Barr}

When American men are discussing their disgust with the typical American woman, they are often implicitly referring to middle class, educated white women ${ }^{50}$. Men on tour associate middle class white women with the feminist movement and all the problems that they associate with feminism. American men are disgusted by women's lack of femininity within the U.S.; women no longer "take care" of themselves and they “let themselves go”. American women are portrayed in numerous international dating guides as disgusting, over weight women. Women in other countries are considered more beautiful for reasons relating to body size, appearance, fashion and make-up. Kay (2008, 35) argues in his guidebook that, "First, women from countries with a lower economic status tend to walk a lot. They also usually eat less fried and high caloric food than Western women. These two factors alone ensure that foreign women are generally in better shape than their Western counterparts.” Davis (2009) argues that, “They [foreign women] continually work on their looks. They dress well and tend to stay fit.” According to Roosh V (2010, p. 17), "You will find a good amount of chubby girls [in Colombia], but not massive cows like in the States.” In one of Roosh V’s online blogs, “42 Things Wrong with American Women”, the number one reason is that American women are fat. American women no longer possess a feminine appearance according to the authors of these guides. The portrayal of American women as lacking in femininity in comparison to

\footnotetext{
${ }^{50}$ Working class white women and minority women often worked outside of the home before middle class and affluent white women joined the public workforce outside the home. Thus, the image of the 1950's housewife does not reflect their experiences and histories.
} 
women from other countries is a common theme I found in guidebooks and on the websites, as well as with my male interviewees.

The American men I spoke with that are involved in the romance tour industry are disgusted by a perceived lack of femininity within the U.S.: many of my male interviewees argued that American women no longer "take care” of their physical appearance and have "let themselves go", much like the guidebook authors. Throughout the romance tour industry (as well as the sex tour industry) discourses, American women are portrayed in terms of a disgusting appearance: they are over weight slobs that dress in sweats and sneakers, with no makeup. According to Roosh V., American women lack other important feminine qualities, besides small body frames, and these include: they don't know how to cook (reason number 7), they cut their hair short (3), they rarely wear high heels (36), and they don’t know how to be sexy (13). A lot of disgust directed against American women is directed at their physical appearance, and in particular, their weight. Besides discussing American women’s overall lack of feminine appearance, a number of my interviewees found older American women to be particularly disgusting and unattractive.

According to Tim, “The worst thing about being a man my age is the women. If you take an older woman anywhere, all you hear is I'm cold, I'm cold, Are you cold? I'm cold! I'm just about freezing to death. Then it's I'm hot! That's all you hear. Premenopausal stuff. And it ain’t there. It’s just nature working. It’s just ridiculous.” Tim’s disgust with menopause indicates that he feels women his own age will not have the libido necessary to keep him satisfied, in addition to having constant mood swings and complaining about the temperature. Tim also felt that the women he had real 
opportunities to meet through domestic online dating ${ }^{51}$ were only women in his age bracket,

Well first of all, in America, really and truly, I don't think a man, I mean I'm a successful man without a doubt, but even that, like ok for instance, me and Jerry joke about it. Like we are both on match.com. The women that contact me on match.com, they're fifty years old, or more. They tell me I think we have a lot of common and we should talk and I think what in the hell would we have in common? (Laughs). The quality of women I really like is mid 30's but very few of them out there, really, they like me because I got money, that's the way I see it."

Jerry, his tour buddy, agreed with him and mentioned, “And they look seventy! That's why I am here and roughly the same thing as Tim, like I should maybe spend more time looking in the mirror, typically don't spend any time looking in the mirror, but when I sit down across the table from a fifty year old woman, I see an old woman.” Even though men recognized that they were no longer young themselves, they still sought younger and physically attractive women.

Jerry told me that he tried dating American women, "You know I tried dating some women my age, fifty to fifty five years old, and we had nothing in common. I see an old woman; I have no children and I certainly don’t have any grandchildren so their conversation revolves around their grandchildren and that's all they can talk about. It just seems like they have no other interests.” Mel characterized the dating scene in Florida in much the same manner that Tim and Jerry characterized the dating scene in Texas. He told me, "The point is, for us in Florida, dating and being single in Florida is the absolute pits. Absolute pits. Women our age don’t take care of themselves, they’re bitchy, whatever and think they're the shit. You take any of these women here [Medellin] and

${ }^{51}$ Through websites like Match.com or Okcupid.com 
stack them up against American women, there is no competition.” The common

consensus amongst my male interviewees is that American women over forty are disgusting and undesirable, since many no longer take care of their physical appearance and are only interested in talking about their children and grandchildren. On the other hand, most men over forty felt that women younger than themselves in the U.S. were completely uninterested in them. Americna men's feelings of undesirability within their desired dating market (younger women) prompted their search for a woman abroad.

Tom, another man from Texas, complained about how he often was made to feel like a 'pervert' by young women in his hometown,

I mean, I go to a 7-11 or a convenience store and there's a girl there, twenty six, cute girl. I try to make conversation with her and she looks at me like I'm a freaking pervert. I might not be dressed like it right now but I'm a fucking millionaire. And you know what? This girl at the store, you look at me like I'm this beneath you. And then I see the next time I come in, I see you as this chatty Kathy with the guys living down the street, driving a twenty year old car, with earrings that leave a big hole in the side of your head. And you treat me like I'm just a bully, you almost want to mace me.

Tom's brother, Mark, felt that he was invisible to most of the American women he was attracted to, “I mean, I can’t even get a women to look at me in the United States. Not the ones I'm looking at.” Mark then explained a story to me in order to summarize his opinion of American women,

I'll tell you what. I live in a town of one hundred thouand people and twenty miles away is another one hundred thousand, but I work in North Dakota and where I work is a town of twelve thousand and there's probably fifty thousand there now. I can't even get a woman to look at me. I went out with a group that I work with, a couple of guys' wives and sat with them at a table and a girl is flirting with me under the table, first time a woman's looked at me in four years and I'm sitting across the table from her husband. So what does that tell you about American women? 
Many of the men over forty that I interviewed felt jaded with American women on two fronts: many of them were divorced and many felt undesirable to younger women in the U.S. market. While many men focused on issues of American women's slovenly and disgusting appearance, most men were disgusted by the state of gender relations within the U.S. and the increasingly unfeminine behavior of American women.

Problems with Femi-Nazis

The lack of femininity in American women's appearance troubled many of male interviewees, but more men were troubled by issues they felt that feminism has wrought in greater society. A large number of the men I spoke with felt that women should have equal access to education and be treated with respect. However, a majority of these men felt that the women’s movement had gone past seeking equality to alienating men from the picture entirely. Brad, a repeat tour offender in the Ukraine, explained his feeling of alienation to me,

I think there is a notion, part of the problem is, in part there's feminism...Look, I believe in equal rights, my god do I believe in equal rights. Totally. I paid for my daughter to get a degree in women's studies. A woman should be paid, to get exactly the same rights as a man, there should be no difference whatsoever. That's ridiculous. Because of your reproductive system? So I believe in that. But at the same time, there's a certain aspect of feminism that, pardon me, is like, ok, you don't need a man? Sorry, and what am I supposed to do? Buy a dog? So there's that. There's also the divorce rate, scares me to death. I'm afraid to get married again, to an American women. I'm afraid. I thought I was doing it right. It's easy, it's like, oh, you don't like my cooking, I can find another man. There's more men than there are women in America, slightly.

Many scholars studying the phenomenon of commercialized romance tourism also discovered that American men seeking brides abroad characterize American women as too feminist and independent (Constable 2003, 2005; Johnson 2007; Schaeffer 2013; 
Schaeffer-Grabiel 2004, 2006). The antifeminist rhetoric utilized by men on tours is often the same rhetoric utilized by many conservative ‘angry white men’ (Kimmel 2013) when they describe their discontent with modern women and feminism. Mel argued that the problems with feminism stem from the fact that our society makes women behave like men to advance in the job market,

In the United States, our society forces women to behave like men and here it's a woman's thing to be feminine. Women in the United States have forgotten how to be women and feminine. And I am saying that without being chauvinistic, and I don't want someone at home naked cooking me dinner before I get home every night. No. But you know, I want a partner, not... I don't want a challenge when I get home. I have a very stressful job and I have challenges all day long. I want a partner. But in general the major differences are, so in the US the women they rebel, and here, they are happy being women, they are happy to have a man who is loyal. At best when you do other internet dating sites, or whatever, they have thousands of profiles so you look for women near your age or someone close to where you are and you look at a profile and there's this long list of wants and essentially it just comes down to, bitch, bitch, bitch, and now I know why you are still single. I know why you are not married, you are never going to find a husband and even if you do why does he want to date you. Why are you so hot?

Mel and Brad's comments are representative of how most men participating in romance tours feel. Many local AFA employees, like Kari, told me that American men characterized women in the U.S. as no longer 'loving' enough, “They only say that American girls don't want to have a serious relationship, don't settle down, in their physical appearance they are fat and lazy, and they are not loving.” Diana, who had just started translating for AFA, told me that men are no longer the priority for American women, "What my client told me is like the, when you got married with an American woman and have kids, this girl only matters the kids. It's only worry about kids, so the relationship disappears, they become just like room mates - pay the bills, take care of the kids, but the relationship doesn't work.” Disgust with local dating options is not limited to 
American men. I met men on tour with AFA from Australia, Canada, Mexico, Norway, Germany and Poland and they all explained to me that the women in their country had become too masculinized and spoiled. However, none of my interviewees referred to feminists using the term feminazi, but perhaps men refrained form using the term because of my class, gender, and racial position as a potential feminist.

On the other hand, when exploring travel guides and blogs dedicated to finding women abroad, narratives of masculinized feminazis and how the feminist movement is inherently emasculating circulate more frequently. Roosh V. argues in his blog, “Traditional Gender Roles Create Feminine Women”, that, “Traditional gender roles are opposed to the uglification, masculinization, and slutification that enablers advance in Western society today.” The common discourse of increasingly masculinized women in the U.S. translates for Roosh V. into women increasingly having sexual relationships in a masculinized way. Roosh V. argues that, “Today, the modern feminism movement can be boiled down to one thing: allowing Western women to be fat sluts. They are fighting for the right to look as ghastly as they want, while being able to ride one-hundred cocks without being judged. They have condoms in their drawers because they expect to have random sex with strange men.” Roosh’s argument resounds with disgust towards American women's appearance and sexuality. While crude and offensive, his argument is an undercurrent of thought in travel guides written for men willing to travel abroad for sex or romance. Roosh V., and men of a similar mindset, also link the rise in American women's promiscuity to the hook up culture prevalent in the U.S., "Nightlife venues give average women near unlimited choice and attention, causing a sharp degradation in her attitude, warmth, and even her appearance.” Once again, not many of my interviewees 
traced their decision to find women abroad to American women's promiscuity in a direct manner, but the undercurrent of women having too much choice and currency within the dating market did emerge in my own discussions with American men on tour.

Bud, the tour leader in Ukraine, identified a number of reasons why AFA attracted increasing numbers of American men. He identified the gripes that many of male tour participants voiced regarding American women's spoiled nature, career obsession, and lack of traditional family values, and then linked them to larger processes of major changes in conventional gender roles. Bud also mentioned the fact that men struggle to find good marriage partners in a culture that has such a multitude of marital options for women,

I think, what's wrong with the American men is also wrong with American women, and it isn't like you got all population of perfectly fine men who struggle to meet good women. I think, sometimes, you know, the marketing of these kinds of services projects that is completely wrong. I think, in our culture we just got away from traditional family and some people have no problem with that; I think we kinda got obsessed with isolation and independence from the opposite sex. So, you know, however independent you are, the stronger you are, all these messages about that. And I think, there are guys...still wanna find somebody who will throw up a traditional family role, and that doesn't mean they are looking for women who will be subservient in any way, some guys are, but I just think they want somebody who will.....and do what is instinctively natural for him, the family or try to...the family, protect the family, provide for the family. And you know, in America we have a situation where it's pretty much equal numbers as far as many women are concerned. Women who are available for relationships, who are looking for commitment in marriage and find somebody very...you just turn a lot of them, there are some, of course, but not a lot; and the ones who are out there, they obviously take your time and find somebody who they think is the best available person for them, and a lot of guys are just struggling to meet somebody and compete.

Bud critiques the individualistic narratives prevalent in American culture today, and argues that they are responsible for the decline of the traditional family. An increasing 
number of American women are, in his opinion, too focused on independence from the opposite sex. Since a large number of American women are independent and have a lot of choices, the local dating pool of available women for American men who seek out a more traditional wife is relatively small. As Ben points out, most of these men are struggling to compete for the attention of women available in their small local dating pools.

Many guidebook and website authors who characterize feminists as problematic feel that the feminist movement is emasculating men in the U.S. through encouraging women to compete with them in the job market. Henry Makow, who wrote a journal regarding his experience dating younger women in the Philippines, argues that women in the U.S. and Canada are too liberated; they let feminism challenge ideas regarding their 'natural' roles within the heteronormative family as caretakers. As Makow (2000) elucidates further, "Women are not brought up to serve husbands and kids anymore." American women have pushed their career and educational agendas ahead of their service to their families, and he finds American women's new priorities to be disgusting and problematic. Kay (2008), a romance tour guide writer, argues feminism has ruined American women by making them adopt 'male' behaviors, such as being assertive, aggressive, selfish and unemotional. In a survey, American men seeking potential brides abroad characterized American women as liberated, selfish, aggressive, and materialistic (Piller 2007). The problematic 'male' behaviors that men associated with feminism is a reflection of the fact that the qualities many women have adopted are qualities associated with successful business people, demonstrating the continuing gendered nature of the business world. The disgust surrounding feminist women who act like men pushes certain American men to desire women outside of their national realm. 
According to Constable (2003), the segment of middle class American men seeking to marry women from outside of the U.S. do so for two main reasons: middle class American women have become too career-oriented or they are considered too pampered, lazy, entitled and materialistic. The two contradictory views of American women that Contable's interviewees expressed (women as both lazy and career driven) were often blurred together and I found my interviewees expressed similar sentiments as well. Men considered feminism to be the root cause of middle class white American women’s spoiled, materialistic behavior and lack of traditional family values. Besides masculinizing women, work and a career outside of the home mean that a woman's husband is no longer her top priority. As I argue in the previous chapter, American men are seeking the emotional labor of prioritization and want to feel like the number one priority in their wives' lives, even ahead of the children. Thus, women who place their careers first elicit disgust from a number of my male respondents. Almost all of the men I spoke with considered American women to be spoiled because of their increasing consumption habits, their entitled expectations, and their lack of service to the family. Spoiled Brats

Marley summed up most of my male interviewees’ sentiments regarding American women’s spoiled nature in his comment, “American women want it all. Nothing you ever do is enough.” The increased opportunities for material consumption available to most middle class white American women has made them focus more on material acquisitions as a priority, and my male interviewees argue that the focus on materials is a detriment to their husbands and families. American women's increased materialism directly challenges men's ideal of a proper heteronormative marriage, in 
which women prioritize their husband's happiness over simple material consumption. Matt discussed his opinion regarding American women's spoiled behavior with a tale about his female manager,

My supervisor, she's been dating this guy for 9 years. He finally pops the question, she says yes, so he gives her the engagement ring, she looks at it she thinks, I'd like to take it back. So he takes it back, and brings a second engagement ring. So he gives it to her, and she says I don't like it, take it back. So he brings a third engagement ring, this one she says is ok, so she accepts it. Does that sounds normal to you? Can you understand how that would make a man feel?

The story Matt describes above reflects Marley's comment that American women are never satisfied. Women's constant exposure to the consumerist culture of the U.S. tainted their femininity by placing material consumption above service to others (most importantly service to the family). Justin discussed how he felt isolated and undesirable in the Orange County area of California, and considered the reality show Housewives of Orange County ${ }^{52}$ to be representative of the local female population in his dating market,

Oh, boy, you know, at sixty five, well, you know, I just came from Orange County, Orange County housewives. Right down the street from me and, you know, they're not interested in me, you know, very interested in money, I guess, but there's nobody that I was interested or would be interested in. I had a very hard time to be there just to make a connection, I wasn't good at it, it didn't happen. And I tried hard.

The housewives' spoiled and opulent lifestyles, which are glamorized through reality television, disgusted Justin and thus, he was looking for love in the Philippines.

Justin was not my only interviewee to link larger social processes to American women's spoiled behavior. Mel, for instance, took society in general to task regarding the consumerist culture that pervades the U.S.,

${ }^{52}$ A show that depicts wealthy housewives of Orange County and their opulent lifestyles. 
Women who are there [South Florida] look at us and see that we have a decent day job and a nice house and all that. The materialism and superficialness that our society preaches to us, that you can't be happy unless you have this and all the bs in the news to distract us from real problems, so let's focus on the Paris Hiltons and distract from the fact that there's tons of people dying all over the place and wars around the world and you can forget about it.

Many of my male interviewees complained that the consumerist culture made American women only focus on a man's material possessions, and not on the actual person that he is. A significant number of men would tell me that American women only cared about the amount of money that he made at his job and the type of consumer lifestyle that he was leading. Henrik, a man who turned his romance experiences in the Ukraine into a side tour guide business, explained to me that he was simply sick of the way American women focused on issues of money immediately, "They [American women] get to you first on every date; the first two questions are, what do you do and what kind of car do you drive? When you hear that question on every date you are on, it is kind of frustrating.” A number of men I spoke with echoed Henrik's complaint that the women they dated locally are too preoccupied with a man's financial situation and material possessions to truly prioritize their husbands and families down the road. American women are placing too many demands upon their significant others, while foreign women are thought to be satisfied with a stable home life.

Kay (2008) argues that not only are American women spoiled, they are also entitled and selfish. Kyle described middle class women in the U.S. as being spoiled by their fathers, like children, “American women are like give me the long term because I'm not worried about today; I have it taken care of and if it's not I'll call daddy and that kind of thing”. Tim argued that women in the Philippines were more humble and capable wives, 
since American women are too out of touch with the reality of poverty, "You bring one of these girls home and take an American women down there and drop her off, and send her to one of the shanties or slums that they got here, it's like they couldn't make it. If you took their phone away from them, that their parents pay for and stuff like that, they wouldn't know what to do.” The common narrative regarding American women's thwarted maturity levels is linked to an indulgent society that no longer values hard work and humility. Jerry agreed and linked American women’s spoiled behavior to being too career-driven, “As far as my opinion of American women, as wrong as it probably is, ask anyone we know if I am wrong. They're spoiled, they are way too career-driven when they are young and when they are older all they want to care about is children and grandchildren.” As Constable (2003) argues, many male interviewees characterize American women as materialistic, shallow, spoiled, and entitled, but at the same time consider them to be too career-oriented and focused on work outside of the home. While men's views may seem contradictory, they actually are not. My interviewees considered working outside of the home to be selfish, since taking care of their family and husband should be a woman's priority instead.

\section{Career Women}

Henrik explained to me that American women's focus on their careers outside of the home made them challenging to date, "I find them [American women] more and more challenging to date. They are really preoccupied with their careers and conquering the world.” The men on tour feel increasingly frustrated with middle class American women who put their career ambitions ahead of their family and consider women's ambition to be evidence of American women's selfishness; the men I spoke to want to be the number one priority in their wives' lives. Many of the men I met are retired and seeking women 
that will want to travel and spend time with instead of working a job. Kyle discussed his desire to be accompanied while retired, “But again, I’m in a unique position since I don't have to work. Three times a year I will go somewhere and work for a month and work on some project. I wouldn't want someone who came to the United States and have to work”. Even though many men sought professional women who were not desperate to leave their home countries, the men I spoke to ultimately did not expect the women they married to work outside the home.

In fact, work outside of the home was associated with problems for Kyle in previous relationships. Kyle lives in Atlanta and feels that career pressures are especially salient there, "Atlanta is a real business town so all the ladies there beyond their 20's are real career oriented and they just work a lot of hours and have a lot of travel so when they would come home, they wouldn't want to go anywhere or do anything because they were tired." Women's work outside of the home simply prevents them from prioritizing their husbands. Thus, most of my interviewees did not want their foreign wives to work a full time job, as working would distract them from providing their husbands with care and attention.

Tim traced the problem of spoiled American women to the fact that society tells women that they can have it all, in terms of having both the career and the family life, Well, they've been told so long they can have everything, you know that they can have the career, they can have the family. And then they're working on their career real hard to be successful, which everybody wants to be successful. Then they get that and at 40 they want to start a family. It's bullshit. You've missed your window of opportunity on the way up as you're looking for it on the way down, and they're dating 27 year olds and they're 45 . Then you got the high school sweetheart and prom queen and all she ever liked was the bad boy football player or the motorcycle rider and now she's got 3 kids and he's off doing whatever or in prison or something. Now she's looking for a good guy to be a 
provider. Well, now its somebody else's turn to do it.

According to Tim, American women are fooled into thinking that they can have both a successful career and a healthy family life at the same time. He feels that by 40 , most successful, career-oriented women have missed their window of opportunity to have children, since men their age are divorced with kids, and looking for younger women. He also mentions that American women who are young and attractive tend to pursue the 'bad boy' and look later in life towards finding a good 'provider'. By then, Tim argues, it is too late for these women to find a good provider like himself, since their beauty has faded and they are saddled with another man's kids. Tim's opinion is representative of the complaints many male interviewees had regarding American women’s desire to have it all, in terms of career and family.

The American male population I spoke with on tours characterized their opinions of American women in terms of disgust with American women's physical appearance: American women are not just unattractive, they are fat and dress manly. Besides possessing what these men considered to be a disgusting physical appearance, American women in industry discourses also possess disgusting personality traits, such as being spoiled, materialistic, and overly career oriented. The men I interviewed, as well as guidebook and website authors, traced American women's increasingly masculinized appearances and behaviors to the spread of feminist ideals. Men like Brad recognized that women should be respected and receive equal pay, but felt that current feminism goes too far by encouraging women to disparage men. Some men went further and argued that feminism has destroyed American culture and the American family by making middle class white women so disgusting, that they are considered unfit for marriage. The disgust 
these American men feel with their local dating options prompted them to search for potential mates abroad. However, while most foreign women were considered to be more desirable and better wife material in other countries, the men I interviewed in all three tour locations tended to describe blackness in terms of disgust. While many men from the U.S. desire black women from the Caribbean and Africa for short-term sexual encounters, a much smaller group of these men actually marry black women. Marriage requires taking a forbidden and taboo desire for blackness and legitimizing it to the larger society. Thus, many of my interviewees described women associated with blackness in terms of non normativity and instead desired women associated with racial hybridity.

\section{Blackness at the Bottom of the Marriage Queue}

The colonial tension between desire and aversion in regards to black women's bodies continues in the contemporary sex tour industry throughout the Caribbean and Africa. However, these same destinations are not as popular for romance tourism. In fact, AFA only began romance tours to the Dominican Republic in 2013. The transnational racialized beauty queue of women is reproduced daily within the romance tour industry, and is clearly visible when examining which tour destinations are the most popular (as mentioned before, it is Ukraine). During my discussions with men on tour in Ukraine, their desire for white women is an undercurrent that is expressed in terms of their personal preferences for the 'Slavic' look (which is code for light eyes and hair). Most of the men on tour in the Ukraine did not discuss race explicitly, as it was implied that they were interested in white women when they discussed their preference for the 'Slavic' look. However, race and color became central concerns for the men on tour in Colombia and the Philippines. 
The racial composition of American male participants in Colombia is significantly different than the tour populations in the Philippines and the Ukraine. As mentioned in Chapter three, the spatial order of Colombian society is extremely racialized. The racial spatial order can be seen in the geographic segregation of different racialized populations within Colombia, with most 'whiter' populations living in the Andean cities and most Afro-Colombians and Indigenous Colombians living in the Pacific Coast region (Wade 1993). The coastal cities of Barranquilla and Cartagena are also home to large numbers of Afro-Colombians, as Cartagena served as one of the major slave ports in the Americas. Thus, in popular imagination and discourse, Medellin is associated with whiteness more than the other Colombian tour cities of Barranquilla and Cartagena. A number of my tour participants traced their decision to attend a tour in Medellin over tours in coastal cities to issues of race, and in particular, blackness. A Cuban gentleman from Miami, Salvador, disliked women in Cartagena because, "The women were all dark! No, no, no! I will never go back [to Cartagena]! Women in Barranquilla and Medellin are beautiful, but the women in Cartagena are too dark.” Salvador continually denigrated the romance tours in Cartagena based upon the racial composition of the female tour participants.

Salvador characterized the city's populace as hustlers and expressed a disgusted form of shock at the blackness of the female tour participants, as if he was scandalized by their blackness, "To me, Cartagena is the worst. They were a bunch of hustlers. Number one, they are hustling you for money. It's just awful, it's filthy, you know when I went to their party [social event], they are all dark, most of them are black!” Fernando mentioned that he had heard from many people that Cartagena was known for black women, and he attributed women’s racialized appearance to Cartagena's coastal location. The city of 
Cali, which is located in the interior of Colombia, is also known for its racially mixed inhabitants. Schaeffer-Grabiel (2006) observed that many women participating in a romance tour in Cali changed their hair color and utilized plastic surgery in order to make their bodies pliable, in order to embody qualities associated with desirability (larger buttocks, breasts, etc.). Schaeffer (2013) notes that twenty percent of the Cali male tour participants were African American (which is an unusually large percentage in the industry). On the other hand, the tour I attended in Medellin did not have many African American participants. Only one African American man attended the first social event of the tour and did not return for the rest of the events. The racialized differentiation between women from Cali in comparison to women from Medellin is found in one of the few guidebooks written about Colombia. According to Swenson (2010), "Personally I do not like Cali so much due to the dirt and grime. However, the sleaze factor adds to the thrill of the hunt. On average girls in Cali are less pretty.” Most of the women in Medellin, on the other hand, are described by various characteristics, such as professionalism, that demonstrate ideals of cosmopolitan whiteness (Saraswati 2010), in addition to their 'whiter' physical appearance. Besides racial differentiations within Colombia, many men on tour differentiated women in Colombia from other Latin American women.

Kyle told me that he did not enjoy his first tour experience in Costa Rica, as the women there are, "not professional. Most of them were on welfare." His experience in Coast Rica was so disappointing that he called the owner to complain. John Adams recommended Medellin to Kyle, since he was looking for slightly older, more professional women. Kyle explained the difference between Colombian and Costa Rican 
women to me in the following manner, "Well the ladies here are just ... as far as the ladies go, they are beautiful and professional and educated. Even the ones that don't speak much English seem to have some type of job here that keeps them going whereas in Costa Rica it seemed like they just don't work there.” Within the previous quote, Kyle is reproducing hierarchies between women from Costa Rica and women from Colombia: Colombian women are educated professionals, while Costa Rican women are unemployed and lazy.

Even though Latin America has a diverse racial makeup, most men on tour are searching for mestiza women that resemble Sofia Vergara or Shakira. Women of African or indigenous descent do not fit the mestiza ideal of the Colombian woman. A Canadian man who moved to Medellin, Kelin, began to utilize AFA's dating services and had very strong opinions about why Colombian women are the best within Latin America. Kelin explains, “I don't like the women in the Dominican Republic, Cuba or Costa Rica. They are too dark for me. Women in Cartagena are too tan and dark too. I like the women in Medellin.” Kyle told me that his friend thought he was crazy to look for love in Colombia, since his friend thought that most Colombians were black, Everybody's who seen the pictures thinks whoa! They think there is real attractive women [in Colombia] and it surprises them. One of my neighbors said I thought all Colombians were black. I said its not true. You know what he was basing it on? Because he saw their soccer team and it was all black and I said it looks like an American basketball team.

Xiomara also mentioned that many men come to Medellin in particular to find 'lighter' women,

Maybe because there are a lot of black girls [in coastal cities like Cartagena] and they want to have a girl like in the middle, with tanner skin. Yeah, and that kind of girls [coastal girls] are too dark and they [American men] don't find them 
attractive. Medellin is famous for having beautiful girls. So, I don't know if they get curious about it, "I want to find a Paisa, cause she is the prettiest of Colombia," whatever, they come here.

Xiomara's quote demonstrates the ways in which spatial articulations of race and beauty are the norm in Colombia, and that women in Medellin are considered to be more beautiful and desirable because they are lighter than women on the coast.

Kyle also labeled women with features that looked more indigenous as less attractive,

Anyway, I really didn't know much about the Latin women and I guess sort of misjudged South America, like many Americans do. They think its kind of like Mexico but actually this whole area, once you get past Mexico and most of Central America, where the Aztec Indian influence was, and you have the real dark skinned people..actually South America has a lot of German influence and Italian and a lot of Spanish, where it's really European...it's like Europeans that speak Spanish and the reason they don't speak much English, from what I understand, is the history.

Here, Kyle 'whitens’ the Colombian women he’s interested in marrying by simultaneously highlighting the European influence in Colombia and the physical distance from the indigenousness associated with Central America and Mexico. He also likened the Colombian women he met in Medellin to women you would see in the U.S., once again 'whitening' them by association. Kyle points out that the women he knows in Colombia do not have the dark skin, and he also compares Colombian women to Italian women,

The two women I know or three that I know from there don't look like..they look like very attractive Americans. They don't have the dark skin, well one of them is a little bit dark and the other two if you saw them you would think they were from Charlotte or Dallas or something. The Latina women are really a bit like the Italian women, although a little bit more accessible like their features are a little softer but they still remind me of the Italian women. 
Both quotations from Kyle demonstrate that racialized hierarchies influence the development of the political economy of desire, and within these hierarchies, women with African or indigenous appearances are at a disadvantage in the market compared to lighter women.

Dark is not Black

Since Colombian women belong to a varied and wide ranging racial spectrum, the American men on tour there often discussed blackness within terms of undesirability and nonnormativity for marriage. Many American men are trying to 'normalize' their exotic choice for a wife, and thus tend to seek racial hybrids who can be 'whitened' into superior marriage partners. In the Colombian context, blackness and darkness are equated with one another. However, the link between blackness and darkness does not hold true in the Filipino context, since darkness is disassociated from African roots and heritage, unlike the darker Colombians. Filipinas are assigned to the Asian racial category and are largely disassociated from blackness. Therefore, within the Philippines, men can choose darker skinned Filipina women and still consider them as 'exotic light' within a global perspective. Dark skin is not always associated with blackness, particularly in Asian contexts. Many of the local employees commented at length about the fact that most American men looking for a wife in the Philippines are seeking out the most stereotypically ‘Asian’ looking women. When I asked Olivia, a local AFA employee, about the type of woman most popular with American men, and she replied, "A typical Filipina, petite.” The local AFA office in Davao has a weight limit of fifty-five kilograms for women that sign up, which demonstrates the important link between Filipinas and petite size. 
While men in Colombia expressed disgust towards the darkest women in Colombia, the men on tour in the Philippines did not find darker skin to be disgusting. Halia, the owner of the local Davao office, explained to me that most men are looking for very 'Asian' looking women, as they are considered 'exotic',

Now the American men, in fact I have one guy who was like Helen I want to meet somebody really exotic. I want her more darker, because I don't want to bring somebody back there who is of the same color, our color in another country. And he wants the girl to have a little rounded nose. Flat nose or little rounded nose. I can’t imagine what people wants. Another guy came here and said I wanted somebody who's Chinida. Look for someone with slanted eyes.

A number of employees at the local Davao office kept telling me that American men on tour in Davao preferred darker skinned women. Vic told me, "Yes, they like dark Filipinas with the exotic long hair! Mostly they like the darker skinned girls. If they see it's a light skinned, forget it.” Most of the local employees I spoke to agreed with Vic’s assessment, and argued that most American men are looking for darker skinned, exotic women in the Philippines. Halia told me, "I should say they like dark colors here. The darker the color, the more the guys think she is exotic.” Zia explained men's desire for darker skin as part of the reason men came to the Philippines, “The majority [of women] that they [American men] like are darker. Because if they want white, they can just stay in the States. Or go to China, or other countries because here, the majority here are tan, dark, dark color.” At first, American men’s desires to find the most exotic women in the Philippines seems to challenge my argument regarding men’s desires for the exotic light.

However, American men view Filipina in different racialized terms than Colombian women. While Colombian women can be associated with blackness, women in the Philippines are not. In the Philippines, the 'darkest' women will still not be 
considered ‘black’, since they are racialized as ‘Asian’. In addition, how my Filipino interviewees defined 'dark skin' is relative to the color continuum within the Philippines and does not necessarily reflect other definitions of darkness and blackness. Many people in the Philippines considered themselves to be ‘too dark' and many women would avoid the sun, in order to maintain lighter skin colors. Even American men on tour in the Philippines recognize that part of the attraction of the industry in general is the simultaneous processes of exoticization engaged in by both men and women, evidenced by the following quote from Jamey, "Just like they are very exotic to us, so we are exotic to them. I like black eyes, dark hair, they like blue eyes.” Women in the Philippines, Colombia and Ukraine all looked for foreign men because they often had become disgusted with their local dating options.

\section{The Trouble with Local Masculinities}

Women in Ukraine, the Philippines and Colombia all discussed the local men in their locations in terms of disgust. Within Ukraine, the most common narrative and discourse surrounding local men is that they drink and smoke too much, in addition to having multiple girlfriends at a time. Elena explained to me that infidelity is a major problem in both Russia and Ukraine, "In Russia, most men are disrespectful to women. Many gigolos, unfortunately common. For the last fifty years, many women are psychologically discouraged. I would like an American man, even though I do not speak much English.” Elena points to the fact that the post War generation women in the former Soviet Union have been suffering with local men. In fact, one of the major discourses promoted by many romance tour agencies is that a serious shortage of men exists in the former Soviet Union. According to the FAQ section of the AFA website, "In Russia, for 
instance, there is a serious shortage of Russian men due to a combination of war and the very low average male life expectancy ${ }^{53}$. Alcoholism is also a very serious problem affecting many Russian males. A poor economic environment causes many men to shun the responsibilities of a wife and family.” Julissa, a young translator, confirmed that the shortage of men in Ukraine is a major factor in the international dating market, "Also, the statistics we have here are that, it seems like, there are 4 girls and 1 boy for them. It's about all those wars, all those genocides by Stalin, and all those awful people from the USSR, and that's the reason.” The numerical shortage of men in Russia causes serious relationship problems, particularly in the form of infidelity, since men have "many more options”.

The sheer numerical advantage men in the former Soviet Union wield over the dating market is mentioned by the agency, and by many women signed up as profiles, as well as many translators. Julissa explains that since Ukrainain men have so many options in choosing a girlfriend, they have become incredibly lazy and unfaithful,

When you're smart, intelligent, and you have good work, mostly you don't have a boyfriend, because he is a jerk. He's a fucking lazy jerk. He sees that, ah I am great, as far as if he's cute, he's a jerk, because he knows it and he can pick her her her her. He's just like, hey girls, I am here, who's the first, who's the first. I hate that. They know that they are all like dominoes. That's the reason when the girl is alone, and a foreigner seems not so bad when there's jerks here who are drinking, smoking, lying on the sofa and doing nothing.

Alina had a more tempered view regarding Ukrainian men. She explained to me that there are good and bad men in the U.S. and in Ukraine, but the overabundance of women in Ukraine makes it difficult to find a faithful and serious man. As she points out, "Yes,

${ }^{53}$ The average life expectancy in Russia is age 64, but one quarter of Russian men will die before the age of 55 . According to CNN, vodka is the main culprit. 
too much, it's the main [problem], yes, too much beautiful girls, too much beautiful girls and there is no men.” Most of the women I spoke to in Ukraine traced local men's infidelity and lack of seriousness to the overabundance of choice they have in the dating market. Thus, many women felt that competition for local Ukrainian women is especially fierce. The richer the local man, the more he is associated with philandering and having a bevy of women to choose from. Ilona simply states, "Many of them are not serious.” In addition to a perceived lack of seriousness, many women commented that most Ukrainian men are not responsible when it comes to providing for their families, and that many try to avoid child support payments. Katya told me, "Most of men don't do it [pay child support]. They just escape from the lady, so sometimes ladies just support children and herself.” Ultimately, many Ukrainian women claimed their decision to look for an American man is based upon ideas that American men will be in better physical shape, more financially stable, and more serious/faithful in relationships.

Many American men restated the agency discourse surrounding the population imbalance in Ukraine in order to justify Ukrainian women's interest in them. Duncan stated, “There’s just too many ladies there. The men are just outnumbered. In other words, what men there are there aren't very good men to hook up with.” Since an overall shortage of men exists in Ukraine, most of the 'good' men have already been snatched out of the marriage market. Duncan argues that whatever men remain in the marriage market are not the best options because of the general shortage, reaffirming why many Ukrainian women would be interested in looking for men abroad. According to the tour leader in Ukraine, Bud, “The guys here in Ukraine who want to get married, they meet somebody younger.” Bud once again cites the shortage of available men as the reason 
Ukrainian men can be picky when it comes to marriage. He argues that most men will date the youngest and most attractive Ukrainian women on the market, leaving large numbers of women over the age of twenty five single. A number of American men on tour in Ukraine also pointed to the fact that the large gender imbalance in the population leads Ukrainian men to be unfaithful, since they have so many options in the dating market, a complaint that many women and American men also leveled at local men in Colombia.

In Colombia, a large number of my female interviewees perceived local men as financially unstable, irresponsible, and adulterous. When I asked Sofia what drew her to sign up with AFA, she explained to me, "Because I want to meet different people. Someone different than the assholes I meet here. They are dogs! They are not serious. They are immature. Or maybe I just found the worst but it seems to be a trend.” In fact, most of the women I interviewed in Colombia complained to me that most local men are not serious about having long term, monogamous relationships. Isabella traced her desire to join the agency based upon her perceptions of American men as more 'serious' than Colombian men, "One of the reasons I wanted to sign up with the agency was the difference between Colombian and American men. American men are more serious and Colombian men are just looking for fun.” Carolina reiterated Isabella’s sentiment and also links Colombian men to 'fun', "The thing with Colombian men is that they don't really want to have a serious relationship. They just want to have fun.” A number of women mentioned 'fun' or 'partying' as a major issue that younger Colombian (and sometimes older) men seem to have. Even Caren mentioned that most Colombian men party until their thirties, "They are just like men under thirty, until they are like thirty five 
or something, and they only think of partying with their friends.” Local men’s partying lifestyle is often associated with infidelity and instability by Colombian women.

Elisa linked partying and going out to have fun with financial instability, "They [Colombian men] all work, they all study, they all drink and go out. I have heard that foreigners are more sure of what they want, more stable, and that's what I want to find out.” Most Colombian women explained to me that they are looking for a serious and faithful man, who is devoted to his family. They did not associate seriousness, faithfulfulness, and stability with local men. The desire to find a 'serious' man drove many of the women to sign up with AFA. Alejandra considers herself to be one of these women, "The men here are not very serious. I have friends who want something else, but it’s just that they [Colombian men] want only to have fun. I really want a serious relationship. I may not express it often but I really want and am really interested in finding someone, finding something serious.” Jolyn, as well as a number of other women, referred to local men as ‘dogs', “Ugh! Yes! They [Colombian men] are dogs! [Laughs]. I think American men will be more faithful and respectful than Colombian men.” Xiomara explained that most women think American men are less likely to be dogs, "The first thing is that American guys like more serious relationship than Colombians do. That's what they [Colombian women] think at least." Caren argued that Colombian women have become incredibly strong because of a lack of 'good' men, "Women here are stronger, because guys here like the majority are all like, “Actually I'm the man of the house and I don't do anything”, and the girl works. Men here are not really for relationships.” American men on tour often repeated these characterizations of local men. 
Mel explained to me that Colombian women are interested in American men because Colombian men are considered unstable,

Yes often they [Colombian men] don't make enough money, or spend the money drinking or gambling. But these could just be generalities about people but you had the question about Colombian women and he answered the question. I have talked to many women over here and from many other countries, and it's the same thing. They are not loyal, they are unfaithful, they are dogs, they are this and that.

American men often reproduce the discourses surrounding local Colombian men as unfaithful in order to justify Colombian women’s search for an American husband. For American men, it appears logical for Colombian women to pursue foreign dating options when local men are unstable and unfaithful, easing American men's anxieties regarding potential scams. Therefore, discourses surrounding Latin men’s infidelity and financial irresponsibility elevate white expressions of masculinity, which are considered 'rational' and 'stable'. Mel describes the stereotypical Latin man as unfaithful and unstable,

Because, all Colombian women, and you've heard it all week long, don't like Latin men. They all think they cheat on them, that they lie, the typical Latin male has three women in his life. He has the wife, the Madonna, who's home with the children, he has the mistress, who takes out to dinner and screws, and he has the fbuddy. All Latin women know this. They hate that about their guys and the guys typically can’t hold down steady, stable jobs. Seriously, I mean, over here women are like, they're not really, guys don't really respect them.

By characterizing Latin masculinities as inferior, American men feel reassured that Colombian women's attraction to them is based upon real discontent in their local dating markets and not desperation to leave Colombia.

In the Philippines, like Colombia, women mentioned issues of seriousness and fidelity when discussing local men. Debbie told me she joined Lifemates in order to find a more serious man, 
But I think that foreign men is a serious person, unlike the Filipino who is not. They cannot be in a relationship with one woman. I have experienced that. In a relationship with a Filipino, they can't be faithful. So I decided that a foreign man will treat you nice. Most of the boys here in the Philippines do that so that's why I decided to look for a foreign man.

Once again, my female interviewees linked a lack of seriousness to infidelity. Zia told me that cheating is a major problem in the Philippines, since a population imbalance exists between men and women, much like in Ukraine, "Because there's a lot of women. The population of women here is more than the guys. So the guys can have 2 or 3 girls at a time.” She also told me, “There’s a lot of good looking men here. You just can’t trust them.” A number of women in Colombia, Ukraine and the Philippines link local men's lack of fidelity and seriousness to problems with family stability and support. Lindy, at the time, was having a hard time finding local men she felt could help support her, "It's very hard to find out here Filipino guys umm...to love you and umm...take good care of you and your family. I don't know. I’ve tried before but it's not working.” Despite Lindy’s interest in finding a foreign man, she has since married a local Filipino man. While some Filipina women mentioned problems with local men as the reason they came to Lifemates, much like women in Colombia and Ukraine, an important number of women mentioned they did not necessarily have issues with Filipino men.

Isis told me that, “Ah Filipino has no problem. I think umm...in my part is...what I’m looking for is more mature. A family figure guy.” While Isis says that she has no problem with Filipino men, she is implying that many local men in her age group are not mature enough for a long term, committed relationship. Lily, an employee of HLC, started dating Matt. The comparisons she made between Matt and her local Filipino 
boyfriend focused on themes of maturity. Even though her local boyfriend had a child, he was not involved in raising the child and Lily felt his behavior was extremely immature. Most importantly, Lily felt that Matt would provide her with more stability and increased opportunities. She ended her relationship with her local boyfriend to pursue a serious relationship with Matt, but unfortunately they have already broken things off. Despite local men's association with immaturity and instability, a few women mentioned to me that they are 'better lovers' and more 'romantic'. When I asked Missy if she preferred Filipino or American men, she told me, "For me, Filipino man. In terms of sex, American people is too rushed. Filipino is very good at going slow. There is a romance. They do a lot of things. In America, it’s too rushed." Riley also mentioned that Filipinos are "the best lovers”. Naturally, American men focused on the negative aspects of Filipino masculinities to assure themselves that the women are truly interested in more stable, serious men, like themselves.

American men in the Philippines did not mention 'problems' with local men as often as American men on tour in Ukraine or Colombia. Jerry, a man in his fifties and from Ohio, complained that Filipino men have mistresses while he cannot find one woman in his hometown, "Apparently the local guys drink more than they tell you, and they smoke, and usually, in Thailand too, they always have a mistress. How is it I can't find one woman and $3 / 4$ of the men here [Philippines] are dating three [women]?” While Jerry focused on Filipino men’s infidelities, drinking and smoking, Jamey only discussed their infidelities. Jamey argued, "Yeah. I don't know if you've noticed this or not, whether they're married or dating, a huge percentage of the Filipino men are not particularly faithful.” Regardless of the tour location, American men tended to 
characterize local masculinities in terms of infidelity, instability and immaturity. While many American men felt that they were simply repeating what women in each country shared with them about local men, these reconstructions of 'othered' masculinities demonstrates that individual articulations of difference recreate transnational hierarchies of desirability. In addition to denigrating local masculinities, women in all three tour locations denigrated racialized American masculinities, demonstrating that these women not only have agency, but are in fact 'picky'.

Not all American Men are White

Many women in all three tour locations denigrated local masculinities in terms of infidelity and instability, and constructed American masculinities in terms of fidelity and stability. However, seriousness and fidelity are traits that do not extend to ALL American men. In fact, women's constructions of the idealized American man often racialized him as white. Women in all three tour locations were hesitant about dating African American, Asian American, or Muslim men for a number of reasons. Women in Ukraine are intrigued by nonwhite men from the U.S., but also find them to be extremely exotic and ‘different'. A lot of my interviewees traced black men’s designation as different and exotic to the fact that not many people of African descent have lived in Ukraine or the Russian/Soviet Empire and thus, black people are 'new' to them. Alexis explains many Ukrainian women's hesitations regarding dating a black man,

No, I'm not interested in black men because when I was in Paris, I have meeted with one man, black also, we photo one another and talk maybe one hour and he wrote me, but you know, it's...I understand that in America it's very strange to share black or white, you know, here we don't have black....almost black people and you know, in my mind it's very, very strange in our parents don't expect that we take...we will be with black man, yes. It's very strange and it's...it's difficult more mentally, mentally difficult. 
Alexis references her family's reactions as a major deterrent in showing interest towards black men for marriage, but relates her family's fear of blackness to the fact that black men are rare in the area. Thus, many women in Ukraine exoticize and other blackness. The employees of the local office in Sumy told me that relatively few black men attend tours, and the employees in the local Kiev office also mentioned that black men seldom attend tours in Ukraine. If African American men do attend tours, the assistant manager in Kiev, Layla, told me that only a few have any luck finding dates. Julissa explained that many African American men do not find dates in Kiev and told me a story about Jamal as an example,

That's where my communication with Jamal starts. Girl refused to come on a date. Because he was black, yeah. He said, ok, so, she didn't come, this girl, for dinner or whatever. I said, I dunno, I can't. So I took him sightseeing, and we start to talk. Then I meet him the next day again, cause most of the girls refused. Cause here it's still like oh he's Afro-American, oh he's black, no no no I can't. But I'm happy that this situation is changing. A lot of people, a lot of students for example, you saw the guy, still a lot of people are looking like, oh my god, is he black, oh he didn't take a shower... [laughs] But, the situation is still going up.

Despite the largely mysterious nature ascribed to blackness in Ukraine, some women are intrigued by and attracted to the exoticized difference they associated with black men.

Alina shared with me that she was in fact talking to an African American man, as well as two other 'white' men through AFA. She told me that one of the American clients that she translates for warned her that black men are too culturally different to make a good partner for her,

I was interpreting for a couple, yesterday for example and when the girl, when we had some, some time to chat with that guy, I asked him what he thinks about mixed couples, like black and white, and he asked me whether I was going to meet someone or to date someone and I told. "Yes, I'm thinking about starting a 
relationship with a black guy", and he said, "No! No! Don't start a relationship, don't start a relationship with the black guy because they have totally different culture, you will, you will go out and live with black people and you will not be allowed to meet some white friends" and other things like that.

Not only do Ukrainian women consider African American culture to be 'different', but many white American men on tours also reproduce an idea that a 'cultural' difference exists between white and black people. Some scholars argue the discourse of cultural difference is the new, more subtle form of racism (Bonilla-Silva 2013; Hill Collins 2004; Giroux 1993). Even though African Americans are ‘American’, they are still considered to be too culturally 'different' for marriage by many Ukrainian women. Many white male American tour participants would agree that African American men are too 'different' for the marriage to be succesful. Alina was worried about potentially taking the black man she was dating to meet her family. She is from a small village in Ukraine and she told me, "The only thing that would be a real problem maybe for him to go just for fun to visit my town because it's a smaller town and people will be just staring, that's true. There are no black people in that town and there are no Chinese or some Orientals.” Alina mentions that there are not many Asian people in Ukraine either and all of the local employees I interviewed commented that Asian and Latin men rarely come on tours to Ukraine.

Within the Philippines, the stigma attached to blackness and dark skin is much more pronounced. When I asked Halia, the owner of the HLC Lifemates Office (an affiliate of AFA), what race of American men the women preferred, she responded, "Men are writing the girls who are African American and the girl will just respect the letters back and forth and build the relationship. But if the girl finds out that the guy is really a nice guy, she would consider an opportunity of meeting in person. But normally, if she's 
given the chance, she will prefer a Caucasian more than an African American.” Halia traces women's desire for whiteness to the Philippines' colonial relationship with both Spain and the United States. When discussing the racial demographics of American male tour participants, many of the employees told me that black American men are actually more serious about finding a potential bride than many white participants. Denise, a local employee, claims that black men are 'more sweeter' than the white men. However, Zia mentions the fact that black men do not have the right to be as picky when it comes to the ladies they would like to date. Denny, the local office manager, goes as far to say that the tour experience in the Philippines is many black men’s last chance to find a wife.

Riley, who is a popular profile on the AFA website, was disgusted by the thought of dating a black man, "And this black man, dark as chocolate, wanted me to sleep with him on the first night! I would rather date a fat man than a black man. This is not my type of guy." For Riley, being old and fat is repulsive, but neither is as disgusting as blackness, “They suck [black men]! Ewww! We are already black, we don’t need black men! Maybe a darker man, but not a chocolate man. I don’t like the chocolate ones.” Riley traced her disgust with blackness to the cultural understanding that Filipinos already have towards ‘dark’ skin. As mentioned earlier, most women seek to 'lighten’ their future progeny by marrying lighter men, and marrying an African American man is in opposition to her goal of 'whitening'. Missy is also interested in finding a white husband because she does not want to have darker children. When I asked Debbie, a young woman dating a white American man, if she would ever consider a black man, she responded, “No, no.” Even though many African American men participants of romance tours possess the same nationality, mobility, and affluence as a white American man, they 
are still considered less desirable than their white counterparts and are, at times, even considered as less desirable than local Filipino mates. Naturally, there are women in the Philippines who marry African American men but they tend to be the minority. On the other hand, men in the 'moreno' category are still considered to be desirable husbands, even though not many Latino or Asian American men attend tours in the Philippines.

Most Colombian women in Medellin, while desiring a white American man, are still open to men who they consider 'moreno' (brown). Jessie mentions that most women in Medellin find men with an African background to be more exotic and that lighter women have the most currency in the local Colombian market,

So like Medellin is a city in the mountains so they have a lot of race in their past and there are not many dark people here so they are not used to that exposure. They are really closed to that, they don’t like dark men at all. If you talk to a girl from where I am from, Barranquilla, or Cartagena or Santa Marta because we have a lot more exposure to darker people, you get some that want to date black men, but within Medellin specifically, it's really hard. It always seems that the dark women are attracted to them but white girls, well not white, but lighter girls are the really picky girls.

African American men are considered undesirable in Colombia for the same reasons as in the Philippines: many Colombian women want to pursue lighter mates in order to lighten their progeny. Xiomara explains that most women who sign up with AFA desire a white American man, “

Cause you know, "Uh, an agency. We can marry with the American guy." So, every girl wants an American guy like blue eyes, white, blondie or with the dark hair, but white. White and the blue eyes or green. They don't want American guy and, "Hi mom, this is my boyfriend from United States and he's ..." No. That would be awkward or embarrassing."

Lindsay further explains that most women ask a number of questions regarding potential dates' appearance before they agree to meet with a potential suitor, "When we make a 
day with that kind of guys, the first thing that the girls ask, "How is he? He's black? He's white? He's tall? He's short? He's heavy? He's thin? How is he?" When I say, "He's black", they say, "Oh, I'm not interested" and say 'no'.” Most of the Colombian women I interviewed did not consider African American males to be a good match.

Elisa begins discussing her desires for a lighter man by stating she is not racist, "I am not racist or anything, but I do not want to date a man darker than me.” Maria states, “I don’t like black guys. Brown yes, black no.” Alejandra discusses her discomfort with dating a black man in terms of her past experiences, "Well my ex-husband was half black and half white, so I would prefer to find someone who is white because I don't want to be reminded of my ex-husband. He really traumatized me. He was a womanizer. He was cheating on me, he was irresponsible and he was beating me. I'm really not a racist, I have a lot of black friends but in a love relationship, I can't help being reminded of my ex by black men.” Alejandra's story of her ex-husband reveals the importance of emotions regarding our personal constructions of race, through her association of negative qualities with blackness (because of her prior negative experiences with a black man). Carolina also describes her ideal man in terms of white or brown, not black, "In terms of race, he can be mulatto or white, but not too dark.” Elisa states her preference regarding race very simplistically, "No black guys but otherwise open.” Sofia is one of the few women who would potentially be open to dating a black man, “Well I don’t really like black guys much but you never know. You just cannot discard them right away.” Thus, discourses of blanqueamiento continue to inform Colombian women's articulations of what makes an American man desirable. Valerie, the office manager, told me that she actually preferred 
Hispanic and African American men to white American men, since they were "too stuffy” and “can’t dance”.

In Colombia, unlike the Philippines, many men of Latino origin attend tours and they often have the advantage of speaking Spanish. Latino men have mixed success rates in Colombia, as they have the clear advantage of Spanish linguistic skills, but are also at a disadvantage, since many women assume that these men will resemble local Colombian men in their behavior and attitudes. Colombian women were seeking men outside of their own national context for a reason, and therefore, often did not want to date men they associated with the negative qualities ascribed to local men. Despite being associated with a stereotypically Latino man’s 'flaw', many Latino men do well in Colombia, since a majority of the women do not speak any English and a majority of the white men traveling there for a bride do not speak Spanish. When I asked the office manager at the time in Medellin, Valerie, how many Latin men attend tours, she replied, "Not too many, because the girls are looking more for white features, but there are some Latin guys who are too extraverted and they are like nice and they actually speak the same language, they do fine.” Xiomara mentioned that speaking Spanish is a definite advantage on tour in Colombia as well. Unlike the Philippines, the group of men attending tours in Colombia is much more ethnically and racially diverse. Interestingly enough, not many Latino men attend tours in Ukraine or the Philippines.

\section{Conclusions}

Disgust is a powerful emotion, just as powerful as its complimentary emotion, desire. Even though scholarship has focused more on the emotion of desire as an important point of bodily contact, I aim to highlight the ways in which disgust is just as 
important. Within the romance tour industry, disgust is actually the first emotional response that both female and male participants feel, since it is disgust with their various local options that lead both men and women to explore the international dating market. American men have become disgusted by American women's appearances, their career foci, and their 'feminist' ways, while women in Ukraine, Colombia, and the Philippines have become disgusted with their local men’s infidelities, instabilities, and immaturity. Women and men's disgusts manifest as a desire to search for relationships, marriage, and love outside of their local markets, ultimately creating the basis for the entire romane tour industry.

Besides disgust towards local options, many men and women involved in the industry expressed disgust towards various forms of racialized 'others'. For American men searching for brides, women associated with blackness are often not considered 'marriage material'. Men do not attend commercialized romance tours with AFA in Africa and at the same time, the most popular location for AFA tours is in Ukraine, demonstrating most men’s preferences for finding a white wife. In Colombia, men’s disgust with blackness becomes glaringly clear. Colombia is the only tour location where finding an Afro-descended woman is a likely possibility and a number of men mentioned their choice of Medellin as racially motivated. Salvatore and Kyle exemplify men’s understandings of racialized beauty by reproducing notions of 'lighter' women in Medellin as more attractive and desirable than 'darker' women from the coast in Cartagena or Barranquilla. American men are not the only ones avoiding blackness in their marital choices; many women in Colombia, Ukraine and the Philippines mentioned that they often felt an aversion towards marrying an African American or Muslim man. 
The individualized expressions of disgust towards dating or marrying people associated with blackness and 'otherness' I encountered in my interviews serve to reconstruct global hierarchies of desire and demonstrate the importance of race within the international marriage market. The interplay of disgust with local options and desire for exotic mates lays the foundation of the romance tour industry, but the emotion of anxiety characterizes much of the mainstream discourse surrounding the industry at large.

Chapter VI: Anxiety Surrounding Scammers, Gold-diggers, and Abusers

Romantic and intimate relationships are often presented in popular discourse and cultural productions as anxiety inducing: will the object of one's affections reciprocate 
those feelings, will their affections and intentions be pure, and will the connection last in the long term? When intimate relationships enter the commercial market, these anxieties are heightened. For many American men on romance tours, they are looking to feel reassured of their intrinsic desirability: that they are desirable as themselves, and not for the potential financial and migratory opportunities that they represent. Men discussed issues of potential scams the most frequently in Ukraine, and Ukrainian women are considered to be the professional scammers of the industry. I argue that most American men attribute a level of agency to Ukrainian women that they do not extend to Colombian or Filipina women, because of their whiteness. Men’s intense discussions of scams during my tour observations in Ukraine convinced me that they recognized and feared Ukrainian women's agency. Filipina women are often characterized as too poor and desperate to be agents. American men attribute scams by Filipina women to poverty or desperation, and not agency. Finally, most men characterized Colombian women as sincere, as they are not destitute enough to be desperate to leave their country.

The anxieties that both male tour participants and female profiles in each country expressed regarding dating were often similar to any anxieties found within local dating relationships: will we have chemistry? Can I trust them to be faithful? However, the anxieties that many men and women involved in international dating shared with me demonstrate the ways in which various anxiety producing issues, such as infidelity, are interpreted and represented in terms of class, racial, and national hierarchies. Women in Colombia, Ukraine, and the Philippines also expressed anxieties regarding the international dating process. Women shared their concerns about leaving their homes, 
countries, friends, and families in order to migrate to the U.S. with a man that they did not necessarily know very well. A number of women expressed concerns about 'being played' while involved in a long distance relationship. Despite women's anxieties about leaving their homes, families, and cultures, many women believed that the opportunities available to them in the U.S. outweighed any of the potential negative consequences of migrating. In comparison, however, to the American men, women in all three countries expressed much less anxiety surrounding the entire international dating process and potential migration than American men, who constantly discussed scams. Anxiety itself, as an emotion, has often been gendered as male within Western discourses and philosophies, as it is often the emotion connected to intellectual pursuits.

\section{What is Anxiety?}

Rachman (2004: 3) defines anxiety as, "the tense, unsettling anticipation of a threatening but vague event; a feeling of uneasy suspense.” Anxiety is closely related to fear and the two terms are often used interchangeably. However, Kingsbury et al. (2012), point out that anxiety, unlike fear, does not have a specifically perceivable focus or object and thus, is a more difficult emotion to understand. Therefore, anxiety is a "state of heightened vigilance”, whereas fear is an emotional reaction to "a threat that is identifiable” (Rachman 2004). Many geographers have addressed the overlap between embodiment and the emotion of anxiety through examining: the pressures to enjoy (Proudfoot 2010), the racialization of sexuality through colonial violence (Nast 1999), and the unstable boundaries of both individual and collective bodies (Longhurst 2001). 
Within the romance tour industry, anxiety is a prominent emotion displayed by the American men going on tour.

The act of attending a romance tour in the Global South is anxiety inducing for a number of American men, simply because they are stepping outside of their comfort zones. Travel to new places and encounters with the 'Other' can often produce anxiety for men, and thus, AFA provides invaluable guidance in navigating unfamiliar landscapes. A number of American men commented that AFA provides an important service to men that have never traveled to Ukraine, Colombia, and the Philippines before. Men's travel anxieties are reduced by utilizing an introduction agency, since agencies provide transportation to/from the airport, hotel accommodations, and a 'safe' environment to meet women. Kingsbury, Crooks, Snyder, Johnston, and Adams (2012) argue that a sudden breakdown or blurring of boundaries is an important element in the socio-spatial production of anxiety, as it is a space of transgression. Traveling to the Global South in search of a bride threatens and blurs those boundaries and induces a variety of anxieties beyond simply those associated with travel. Men, regardless of their tour experiences and locations, displayed anxiety regarding the legitimacy of women’s affections. The issue of ‘scams’ and green card seekers plagues many American men’s minds throughout the entire process. The future oriented nature of anxiety as an emotion makes it an example of an expectation emotion, like fear or hope (Block 1995). Expectant emotions "aim less at some specific object as the fetish of their desire than at the configuration of the world in general, or (what amounts to the same thing) at the future disposition of the self.” The expectant nature of anxiety is highly visible in the romance tour industry, since most American men are focused on what a woman's future intentions 
could potentially be: is she going to leave me once she gets a green card or will she try to use me for money?

Ngai (2005) argues that in addition to being aligned with the temporal dynamics of anticipation, anxiety has a spatial dimension as well. Within psychological discourse, anxiety is an affective response to an anticipated event, as well as a projection of feelings that a subject refuses to recognize in themselves and tries to locate in others. Anxiety, as a psychoanalytic concept, has a history in Western theory of being gendered. The gendered differentiation between men and women in Freud's theories is based upon the influence of sexuality and genitals on emotions. In Freud's model, “only male subjects are capable of experiencing genuine anxiety or dread, whereas female subjects are allotted the less traumatic and less profound (certainly more ignoble) affects of nostalgia and envy” (Ngai 2005: 213). Within the continental tradition of existentialist philosophy, anxiety has been privileged as the distinctive, if not exclusive, emotional province of male intellectuals. Through anxiety's association with masculinity, anxiety has become the intellectual's signature sensibility. Ngai (2005) demonstrates that the connection between intellectualism and anxiety plays a prominent role in the culture of Western intellectualism, eventually becoming codified as the male knowledge seeker's basic state of mind.

Interestingly enough, the gendered nature of anxiety in this case does somewhat ring true. American men expressed much more anxiety towards potential scammers, 'gold diggers' who are potentially only after a green card and money, and many men expressed issues with correspondences scams as well. Women in Colombia, Ukraine and the Philippines, on the other hand, often did not express nearly as much anxiety about 
leaving their families and countries behind in order to migrate. A number of women mentioned that they would miss their families and certain foods from home, but this was not enough to discourage women from potentially migrating to the U.S. Most women looked upon the new opportunities available to them if they migrate to the U.S. as enough of an incentive to cancel out the major risks associated with marrying someone you do not know that well. Thus, this chapter has more focus on men's concerns over being 'scammed', as they were much more vocal about their anxieties regarding the international dating process than women in any of the tour locations.

Too Good to be True?

Many American men experience anxiety about traveling for the first time to a foreign country; especially since most romance tours take place in the Global South. For a number of American men, the impetus to find a romance tour agency springs from their anxieties surrounding travel to exoticized 'Third World' countries. A Foreign Affair provides a 'safe' environment for American men to operate in: the agency provides transportation to and from the airport, accommodations, and small local tours of how to get around. For a man with little to no travel experience, the agency provides an invaluable service, as it makes traveling to a new, unknown place much less anxiety inducing. A number of American men reiterated the fact that AFA was an invaluable service on their first tour, helping them to learn the lay of the land in a new country. However, some men broke away from depending upon AFA to book their hotels and transportation. A number of men return to tour locations and rent local apartments or find other hotels they prefer, without utilizing AFA. Some men return to participate in social 
events and others return to spend time with one or a few women they want to get to know better.

In addition to anxieties surrounding travel to exoticized foreign locales, many men focused on issues of 'scams'. Foreign bride guide writers always devote time to addressing various issues of scamming that can occur while searching abroad for a bride. Most guide writers discuss internet correspondence scams that feature fake profile photos of women and requests for money. As Smith and Maslova describe in their Russian bride guide, "The scam will be in the form of a request for money. Usually to buy tickets to come to you, pay for a visa, pay for healthcare for her or poor old sick mother.” A large number of American men have sent money to online scams and the first lesson that any guidebook or AFA tour guide will tell a man is to NEVER send money to any woman he has never met in person (which may sound obvious to some, but has proven not to be within this industry). During the tour bus rides in Ukraine between tour cities, I heard a number of men discuss various issues they felt existed with the correspondence component of the international dating experience. One older man had already spent over three thousand dollars in email correspondence, and one of the women he corresponded with could not remember any details about him when they met in person.

Bud, the tour leader in Ukraine and a regular employee of AFA, admits that correspondence scams are impossible to completely eradicate, “The problem with correspondence is that's where the scams are constantly. I hate the whole correspondence issue. I mean, we have a lot of people [local agencies] who do it right and then some people who don't. I wish that I had the power, but I don't. If I did, we wouldn't have a lot of correspondence scams.” Bud typically quotes the statistic that only three percent of 
men signed up with AFA actually make the trip out to a romance tour. In his opinion, attending a romance tour in person is the best antidote for correspondence scams. It is essential to remember that AFA, like any other transnational corporation, outsources a lot of its recruitment of women to local agencies on the ground in each country. As mentioned previously, Halia and the HLC Lifemates office in Davao is a prime example of this outsourcing. In Ukraine, the Sumy office is outsourced to another company and much of the recruitment of women is also outsourced to small local agencies.

For this reason, it is impossible for AFA to guarantee that all profiles they feature on the website are actual, 'real' women. Bud elaborates on the ways in which AFA utilizes local agencies in each country, and how there is potentially room for scams and corruption, since AFA does not oversee the daily operations of its affiliate offices,

All these [local] agencies that are out there that will say, " Look, we're gonna try and survive from the letters of guys; and it's less, it's much less who will actually get on the plane and come and meet somebody. We can't exist. We need a process by which men and women can communicate and write letters and get to know each other. We need to do a part of that, we need to be conducting them, we need to make money from them." So, our [AFA] agreement is, "You [local agencies] bring us women that men will be able to meet and who will attend our socials and that kind of thing. I will let you be part of that correspondence process and $90 \%$ of our affiliates - we have over a hundred of them in Ukraine - behave exactly as they are supposed to, but there are scams. There are agencies, are interpreters to write letters. One of our competitors, it's famous for that...published all over the place.

Bud's discussion of the agreement AFA has with its local affiliate offices demonstrates the large amount of work that it takes to recruit and organize local women's profiles. The large number of affiliates recruiting women for AFA makes it difficult to ensure that every single person on the website is 'real', even though they can assure that most of the women are real profiles. Even though the women are 'real', they are not screened by the 
agency for their intentions, nor their backgrounds, "So, we don't screen them and we can't screen them. So, we don't screen them. But we do take their application and verify that they are who they say they are. And so, and doing so, we know that we have a legitimate profile. And presumably a person is joining us for the right reason.” However, insincere intentions can never be fully prevented by the agency, regardless if the women exist and are 'real'.

In order to help American men navigate actual interactions with women, AFA attempts to provide men with a large amount of educational information that can be accessed at loveme.com: blogs, videos, testimonials, and various other materials. The various educational information available on the website is meant to provide men with information regarding potential issues that may arise while attempting to date women in other countries. Bud explains AFA's educational efforts in terms of providing men with an idea of what is genuine behavior on the part of women in each tour location,

We also do a tone of educating, you know, blogs and videos, and writing on the website, my book. Tons of stuff to tell the guys this is what genuine behavior looks like. So, when you see it, pay attention to it. A lot of guys go beyond the red flags, because they start to get emotionally attracted to somebody and find it so easy to just ignore it, that's truly pretty obvious, right? They go on a date, she wants $300 \$$ for the taxi ride home, and she probably spends 50 US dollars, if she lives out of town, whatever. The guys resent that sometimes, and it isn't their fault, but we do our best to educate the guys, to help them, recognize the red light behavior when they see it. Only when they are educated and paying attention to us, they typically will be just fine.

Guidebooks and the AFA website focus upon various 'red flags' and examples of potential scams that men should avoid. The educational information men can access may take a variety of forms, but the industry in general provides a wealth of information to potential American suitors regarding issues of scams and sincerity. Throughout the tour, 
AFA employees encouraged all the men to attend each social event and to date as many women as they can. AFA employees warn that focusing on one woman the entire week of the tour may lead to disappointment and negative feelings about the international dating process if that relationship does not develop into something long-term.

AFA does recognize that their clients are the American men paying for the tour and correspondence services AFA provides (women do not pay to join AFA, only men do). Thus, some American men feel entitled to a certain amount of affection or attention from women on tours that can at times be unrealistic. Many men would also consider women to be 'scammers' when they do not receive the attention that they have essentially 'paid for'. Bud discusses this issue in terms of having realistic expectations,

Sometimes there is a scam, sometimes it's just the cultural thing, you know. So, some guys are saying, "I'm 61 years old and this 19-year-old girl, I dated her, and you know what? She didn't like me. That's a scam." I'm sorry, but she wrote to you, I get that, and when you're mad, she looked at you and said, " in the two dimensional world maybe, but in person I don't think we can", and I don't think there's anything wrong with that. A 61-year-old guy should be probably more realistic about that. That's just my thought. There are times when, you know, you meet a girl and she definitely asks you to spend tons of money on her, and it's usually 19-21-year-olds, so whatever, and if they never allow the relationship to get serious, it's fine. They may string the guys along for a series of dates jus to go places and that is a scam. We remove that profile. We tell the girls when they are on our site not to ask guys for money, don't ask them for expensive gifts and that sort of thing. We'll end removing your profile. But there are guys that show up with a lot of money and they don't have the common sense. They know how to make tons of money and spend it on beautiful women. There are a lot of women, you know, who see them [American men] as money, so, their fortune process involves money. They [American men] get here and they are not afraid to spend their money around like crazy and buy all kinds of things. When the girl doesn't right away with the man, they'll say, "That's a scam. I spent 12000 grivna on her". It's very delicate, but if there's something wrong with a girl, then I remove that profile.

For Bud and the employees of AFA, the tension between what American men considered as 'scams' and real scams can often stem from miscommunications and unrealistic 
expectations. As Bud mentions, men who date women significantly younger than themselves cannot be upset if the woman 'uses' him to go out on the town, etc. He stresses the importance of common sense thinking within the international dating process and encourages men to date women closer to their own ages. While acknowledging the obvious draw of younger women in their twenties, Bud continually advised men to think more about issues of compatibility than physical appearances.

The common public image of the scamming mail order bride is typically a Russian or Ukrainian woman. Potential scams are a major focus for men on tour in Ukraine, and scams were mentioned most by American men during the Ukrainian tour. In addition to being considered scammers in the international dating industry, Russian and Ukrainian woman have a long history of being constructed as sex workers. Tim, who I met on tour in Medellin, Colombia, discussed his decision to attend tours based upon the ‘scams' going on in Ukraine. He described a large section of the female event attendees as sex workers, "Like the socials in Kiev, the first social I went to in Kiev there was probably 100 women there, but out of that 100,35 to 40 of them were hookers that was at the party.” His friend and romance tour travel buddy Jerry told me, "Kiev is Europe’s whorehouse.” Besides asserting that a large percentage of the female attendees at the social events are in fact sex workers, Jerry and his friend Tim characterized Ukrainian women as 'jaded'. According to Tim, "Well in the Ukraine, I think you have probably a ten percent chance of meeting a real woman that hasn’t been jaded.” Jerry interjected at this point, “Or doesn’t have her own agenda.” Tim then described Ukrainian women as robots, “Ukrainian women, you know they're like, like a robot, I guess. They turn into robots over there. Oh yea. I think that they are jaded early in life but then as life goes on 
they use to their advantage.” The advantage Ukrainian women have within the global economy is their legendary beauty. Jerry explained that most Ukrainian women are into going to dinners with foreign men, but he doubted their sincerity in wanting to find a serious relationship, let alone a husband, “ It’s like, sure I will go out with you, because I know you are going to buy me dinner and take me out and dancing and spend money. But I question how many dinners they go on and how many dates they go on where they are really interested in a guy.” Tim and Jerry had been on at least five tours of Ukraine. In fact, they met on a tour in Ukraine and became travel buddies, going on other AFA tours together.

The main type of 'scam' that men discussed in Ukraine focused on local women dating foreign men in order to eat and drink lavishly, even if they are not genuinely interested in American men. Tim mentions that most local women have some sort of 'discount' card that they use at restaurants,

We go out to a nice restaurant and it must have cost 90 bucks American, which if you really know the restaurants in town, you can go have a nice meal for 20 bucks. Well somehow or another, they got these cards over there, every girl has cards. Its like a credit, its not a credit, it's a discount card. You know, you go to a restaurant, and when you ask for the check the waiter always looks at the girl, do you got a card? I think they get credits for those cards. So if they bring this guy to a restaurant, they are benefitting from it. Like if you bring a guy from America or Germany or some place like that, you don't really care if you spend 100 dollars. You're with a good looking woman and you think you got a chance at it, what's 100 bucks? I mean, you spend that all the time.

Jerry interjected, “Believe that the discount isn’t for you! They get credits.” Jerry also

had issues with women at restaurants,

Like I would pick a girl up there and it was the second date. I met her at the social, went out with her the next night, the first night of the social, actually I took her to dinner and spent a bunch of money. It was like midnight and we were having dinner and spending money. So you know it's the first time, so the next 
day I was like ok, you know let's go out and I am thinking something a little more casual, I mean I was even trying to pick the restaurant based on places I had seen. So we go into this place, and she looks at the menu and she starts ordering, this, this, this, boom, boom, boom, and she closed her menu so I closed my menu and she looks at me and says what are you gonna have? I am sharing with you! I'm thinking she's ordering for the both of us, the waiter and the busboy too! A ton of food! I mean this is like going to TGI Fridays and this girl still figured out how to spend 100 dollars.

At this point, Tim chimed in to say, “And they will eat every fucking bite of it!” Both Jerry and Tim's anecdotes about going to restaurants with Ukrainian women demonstrate the ways in which American men feel 'taken advantage of' while on tour in Ukraine, especially in Kiev. Taking women to expensive dinners and nightclubs is not the only 'scam' these experienced romance tourists discussed. Another major 'scam' in Ukraine that they discussed was paying for cabs. Jerry explained that all women ask for cab fares way over the real rate in order to hustle some extra money, "If you take a taxi anywhere in the Ukraine, and you are hard pressed to find anywhere in the city of Kiev, you are hard pressed to spend more than 12 dollars. You have to drive around the city to spend 12 bucks but every time the girl asks you for taxi money and you say how much it will be 50 bucks. And it’s like the little things like that.” The ‘scams' Tim and Jerry described are what convinced them that they had very little chance of finding a serious relationship in Ukraine. Thus, they branched out to Colombia and other more 'exotic' tour locales.

Men I met on tour in Ukraine also discussed a variety of 'scams' that they were concerned about. Many men on the tour discussed the fact that email correspondence increases the likelihood of scams, and many men traced their decision to actually travel to Ukraine on a tour to meet the women in person to fear of being scammed online. Jared traced his desire to attend the tour to the increased likelihood of scams via email 
correspondence, “That's really what I'm looking at this like that we really got to know each other through our correspondence. And it was real, wasn’t fake. Cause I was worried about fraud email. Holy shit, I've got two years invested into somebody that may not be her.” Once Jared met the girl he corresponded with, he was relieved to see that she was 'real'. Duncan, a middle aged man from Texas, explained that besides email scams, many women utilize their friends as 'translators' and then the women will just end up talking to each other, receive payment, and eat a free meal,

[There are] email and also interpreters scam. We don't need an interpreter but that interpreter is a friend and just acting as an interpreter. It's basically like she's an escort, she's not a real translator. Or another kind of scam. This happened to me today. I'm on a date, this girl has her own interpreter and we are going in a taxi. She came here, picked me up in a taxi and so...wanna go to eat something or whatever, do you wanna see the museum of the great battle of Poltava. Ok, yes, yes, let's go. And I start watching the taxi driver going for places that I didn't know, I didn't see going out from the city. This is a scam. Ok. Now, we went to the museum, then we went to a restaurant, a beautiful restaurant outside of the city and they charged me 50 grivna [approximately seven U.S. dollars] for the taxi, you know, but you it is in your mind that they are gonna scam you, that's the bad thing.

Duncan also mentioned the cab scam that Jerry and Tim highlighted. Alec, who was on his second tour to Ukraine, told me that the first tour is a learning curve about 'scams', "When I went to the first tour, I mean it takes time to get it, women they can scam you, you know and you have to learn about those and avoid them. It's usually girls in their 20's that just want to drink and have you buy drinks, dinner and then never see you again. So you gotta learn about that.” The need for a 'learning curve’ in Ukraine encouraged a large number of men to attend many tours and become 'repeat clients'. 
Some of the 'newbies' on the tour did not necessarily want to hear about the scams or even read about them ahead of time on various blogs. Mickey, explained to me that he did not want to hear the repeat tour clients' stories,

I think for me it's worse reading about the scams. Ok, you have two sites. You can read it on the website, on the blogs, iPad. This is a scam, this is not a scam. Ok, you read it and say, " Maybe yes, maybe not." But when you come here and you start talking to other people, one time they did this to me and they just started explaining various scams they have experienced. What the fuck?"

Mickey personally did not want to hear about other peoples’ negative experiences of scams. He wanted to be assured that he would have his own experiences and not be paranoid about potential scams the entire time he was on tour. Another repeat clients, Josh, argued that the entire situation cannot be a scam, because the industry would simply fold under the pressure,

But here's what. They [AFA] have been here for a long time, if they [local women] were all scams, they [AFA] would not be in business. If they were all scams, they would not be successful. The thing is I met other people on the trip; this is not the first time they are on the tour. I came because the first time, I came to meet a woman I was interested in, I didn't think it was scam, but I couldn't keep eye contact with her. The second time I came, I met a lady I was interested in. I've yet to meet anyone this time. I don't think there is major scamming. It's not all a scam.

To Brad, who has forayed his tour experiences into a blog and contractual work for AFA, scams on tours do not happen if the man does not allow it to, “Scammers? It can’t happen, unless you're a fool. Are they going to pick your pocket? No. If it happens (and I have seen it VERY rarely), it is because the client permitted it - a fancy meal, expensive gifts, etc.”. Both Brad and the tour leader Bud highlighted the fact that a real tension does exist between what American men consider to be a 'scam' and what is a realistic choice for them in women to date. 
Bud explained to me that once he realized that most of these types of 'scams'

occur with the younger women on tour, he began to utilize another strategy,

Well, what I did is I started writing one of them that I thought I wanted to meet, and then they wrote back and got some communication going so when I came here I would invite these women to the socials. Usually they're women in their 30 's and 40's and you ask them if they want to go to the socials and they say no, they don't want to have to go there and compete with these young 20 year olds. So if you maybe want to find a really nice girl, write her and get to know her. That's much better to do than go to the socials.

Bud's strategy reflects the advice that Brad and other AFA employees give to American men on the website, in blogs and guides, and on tour. One translator, Nadja, explained that she often attempts to help her clients to identify women who are scammers. She told me the story of Gary, a middle-aged man divorced from a Russian woman who was on his second tour. Gary's date was clearly only interested in dating him for financial stability. Nadja worked as his translator and began the story with the fact that the woman ordered a ton of food, reaffirming Tim and Jerry's stories about 'scammers' and their voracious appetites,

She ordered a lot of food; really, she was like, "All this mine". Eating all the time, she almost didn't talk, cause she was eating. Then when she finished all these dishes, she started to talk, you know, not to talk, just to ask, ask questions about his money. "You know, I have a small child, small son, and if I will come to your country, you need to support me", - MUST, even not have, MUST! "I told, I said, you must support me, because I don't know language and I'm not going to work" and he was like, "Ok, that's not a problem, yes, I will, I'll do everything for you".

Nadja, being an empathetic translator, attempted to help Gary out by telling him that his date was potentially not sincere in her intentions towards him.

Nadja was especially frustrated with Gary, as he would not listen to her advice.

She told me, 
I explained him that she's not interested, and I explained him that she's a terrible person. And this stupid lady was asking stupid questions, so this slow guy - cause he didn't understand what is going on. Then she went outside, like she went to the restroom or something like that - to call, someone to call, to talk on phone. And I tried to explain him what is going on, then he was looking at me like, "What? No. No way! I don't believe you!" Ok, don't believe me. I try to save you, and now I give up. I will just sit and interpret, like word by word, and you will understand. I did, and he was like, "Wow". He was like, "Ok, let it be. Tomorrow in the morning she will leave Kiev, that's all. And now we are coming upstairs just to sleep, to rest, that's all."

Besides being frustrated by Gary’s ‘stupidity’ in not recognizing an obvious scam, she then told me that he did not even pay her for her translation services. Nadja complained that, "Someone had to send him [Gary] money, but nothing happened. He promised me that he will bring this money to office, but we don't have his phone number, like they don't have his phone number, they don't know where he stayed. So, ninety dollars are somewhere. Probably he already left this country.” In Nadja's story, both American men and Ukrainian women utilize scams, demonstrating the uncertainties of the industry for all participants, regardless of their gender, and even at times the uncertainties that face local employees. Besides discussing Gary's story, Nadja also explained other 'scams' she encountered.

Nadja admitted that women realize that they can earn money by overcharging foreign men for cabs. She confirmed Tim and Jerry’s stories regarding women who overcharge for taxis,

You know, usually like ladies also can earn money just dating with someone, like, "I need a taxi, and it will cost 400 grivnas [Ukrainian currency, approximately 50 U.S. dollars]", but I live over here the next street, but it will cost 400 grivnas. So, they come here just walking, even not train, I mean metro or bus, just walking here. She takes 400 grivna, go to really expensive restaurants, have really nice dinner. Then she say, "Thank you so much, write me, don't forget me. See you! Bye-bye!" That's all. Then in half an hour she has another meeting. 
The women who hustle to make money off of dating foreign men are often called 'professional daters' and blogs often focus on identifying 'red flags' of women that engage in these types of hustles. On a blog dedicated to identifying professional daters, one American man suggests, "It seems to me that one of the best ways is to avoid this kind of scam is to arrange the first meeting at a café or coffee shop. I'm not so sure a professional dater will display the patience needed to sit and chat with you for a couple hours before she tries to direct you to an expensive restaurant or expensive shopping mall.” Men's anxieties surrounding the potential scams they can encounter while on tour served as a focus of many conversations, and many men that get discouraged on tours in Ukraine begin to branch out towards attending tours in more exotic locales, like the Philippines and Colombia.

Professionalism

Tales of scams in Ukraine and Russia scared enough American men away from even attending tours in Ukraine or sending letters to women in the region. Some newbie men interested in finding a foreign bride hear stories from men like Tim and Jerry, and then decide to begin their search in a more exotic setting. Mel began attending tours in Latin America based upon stories of scams from people he knew, "I have many friends who lived in Russia for some period of times. I know their a lot of guys really into Russian women and they are stunningly beautiful and typically they are more appropriate in height too however, they also have a whole bunch of ulterior motives. Girls here [Colombia] don't." His friend Howie mentioned that the scams seem more likely in the FSU, since divorce statistics for Russian women are high, “That's another thing. The Russian woman, the statistics of Russian women that get married and divorced when they 
get to the US is very high.” For this reason, Mel and Howie decided to attend romance tours in Colombia. They felt the women they met on tour would be more serious there than in Ukraine. Kyle also began his tour experiences in Latin America, based upon other people’s failures with Russian and Ukrainian women,

But the one's I've met, at least in the United States that were Russian, were very bright but it seemed like every interaction you had with them it was like a chess match. They were trying to get one step, they were one step ahead of you. I had a lot of friends who dated Russian women and it just didn't work out. Like Joe Namath married a Russian woman and it didn't last very long. Even big name people have gone for that beautiful Russian woman and it just did not pan out so I figured if Joe Namath couldn’t make it, I probably can’t either.

A few of the men I spoke to immediately began their tour experiences in Colombia because they had heard too many stories of scams in Ukraine and did not want to even subject themselves to the anxiety of navigating potential scams.

The assistant manager of the Medellin office, Xiomara, explained that Colombia is often the second or third stop for repeat tour offenders who have become disillusioned with the tour process in Ukraine, "Well, I've heard like some...yeah, most of the guys go first to Russia, to Ukraine, then they just come here disappointed, because they say like this kind of comments like, "Girls in Ukraine and Russia, they are just gold diggers, they are just looking for money, for green cards." So, they come here.” Kari, a translator, confirmed this movement of American men from tours in Ukraine to tours in Colombia, "I know that they try always with the girls from Ukraine. With Ukraine, because they are really beautiful. But then they know that, they find that these girls just want only money, and Latin girls maybe want a serious relationship, that's what they are looking for, so they decide to come here.” Many of the men on tour in Colombia did not consider the women in Medellin to be as likely to scam them as Ukrainian or Russian women. Howie told me 
that a lot his female friends warned him, "You know they [Colombian women] are all looking for a green card.” However, both Howie and Mel disagreed with this assessment. In fact, Mel argued that the opposite is true in Colombia,

Most of the girls here [Colombia], they are not looking for a green card, they are just looking for that loyal guy who will stay with them and spend time with them. And the ones who do just want money or a green card, they are usually very easy to spot because the idea is you simply have to see what their logic and thought process is, what would they want. If a girl only wants your green card, she has no plans, she has idea what she wants to do, well I want to go to the States, well I want to get there.

Men felt more confident in women's intentions in Colombia and the discourse of scams is much less prevalent on tours in Medellin. Tim and Jerry, both jaded by multiple tours in Ukraine, consistently stressed that if you want to find a woman serious about marriage, Colombia is the place to do it. Even though men felt more secure in the sincerity of Colombian women, employees at the local agency mentioned that money and a green card are definitely an attractive bonus to dating foreign men, and often inspire initial interest in the industry.

Greg began dating a Liana, a woman who runs her own business and owns her own property. Liana’s high status in the local economy assured Greg that she was interested in him for the 'right' reasons,

Like I asked her would you like to stay in Medellin or would you like to go to the USA, where would you like to live? She said it's up to you. She said I would be glad to be wherever you go. I mean she's not just in it to get to the US of A, which you know a lot of them could be. Like she owns a condo in Bogota and a condo in Medellin and she's the manager of a manufacturing company that sells saw machines all over the world.

Greg was pleased to hear that the woman he was interested in dating seriously had her own property, a solid income, and was not desperate to leave Colombia. Greg felt that 
more 'professional' women, who are already financially secure and successful within Colombia, are more genuine in their desire to find a good man and are not simply looking for an opportunity to migrate out of Colombia. Greg characterized the women in Colombia as happy with their lives, "The women in Colombia are happy with Medellin; it's nice. Most of them work, and don't live in poverty, they're not out on the streets. They got problems but they're not in disarray. I mean they're not rich, but they're not in poverty. I mean everyone woman that I met, they weren't unemployed that kind of thing. But they're not desperate to find man to take care of them.” Once again, Greg focuses on the fact that most women in Colombia are employed, can afford decent housing, and are not living in abject poverty. On the other hand, when Greg compared Colombian women’s living conditions with Filipina's conditions, he felt that Filipinas' poor living conditions made them more 'desperate' to leave their country with a foreign man.

\section{Poor or Desperate?}

While Greg characterized Colombian women as working women, happy to live in Medellin, he discussed Filipina women as often living in abject poverty, desperate to leave their impoverished lives, "I think the women in the Philippines are more desperate. They're willing to like...whatever I need to do to get out of here and find someone to support me.” He characterized the Philippines' economic situation as much more dire and abject than Colombia's situation, and therefore, felt that women in the Philippines were more likely to be interested in marrying American men for money or an opportunity to leave,

The difference is that in the Philippines, it's so poor that parents have tons of kids to help support them, and unlike the United States and countries like the United States where it's civilized or whatever, they basically throw the kids out at an 
early age to work, to make money, to bring back for them because they are getting elderly and they need money to do this stuff. So a lot of them don't really want to be there doing whatever they're doing.

He even want as far to claim that some Filipina women did not even necessarily want to be looking for a foreign husband, but instead were encouraged by their families to look into marrying an American with money that could support the family. Greg explained to me that had experiences dating both a successful Filipina woman and an abjectly poor Filipina woman,

In the Philippines, there were some that were desperate. That wasn't the case for all women, because I met a gal in real estate and she had her own car and took me around. We did a lot of fun things. She wasn't desperate; she had her own house so I went out with her, and I went out with another one that was actually gorgeous and dressed up to the hilt. Found out she sold coconuts on the street; worked on the street with her parents. She borrowed the shoes from one girlfriend and the dress from another girlfriend. She had no running hot water, her hair was...I mean I feel bad for them. Actually, I feel bad for them. I mean, I told her that I wasn't really interested but here's some money and I hope that it helps you. I wasn't interested in getting into that kind of a situation; she had a kid. I mean, it's like oh God, no. I was looking for a woman who has a good career, that is smart.

While Greg characterized his time with the successful Filipina woman as ‘fun', he characterized the woman selling coconuts on the street with her family as too poor and too 'desperate' to be interested in dating him outside of economic interests.

Men I met on tour in Davao mostly considered Filipina women to be friendly and genuinely interested in serious relationships with foreign men. The main scams that men discussed derived from issues with email and web-based correspondence. Dan, a small business owner from Colorado, told me about a scam he encountered that uses webcams and transgender women,

Like the company [not going to name], I would see all kinds of crap, like could you send me 50 dollars for a webcam so you can see me and I can see you. They always say don't send money, I understand with difficult times, can you send me 
30 dollars to pay for expenses, which for us is nothing, but down here it's a lot of money. I mean they are on the camera, saying hi Dan, and I can't send you a picture because my camera's broken and they are really a guy. I have seen many guys that look like girls and thought is that a girl? And then they're really guys.

Dan's story regarding shady webcam based websites pertains to a competing website that Dan considers to be a major scam. Duncan told me that he felt Filipina are more open than in other locations to finding a husband. While Duncan did not think that Filipina women were trying to scam men on tour, he did suggest that scams are more likely to occur through email correspondence,

Here I mean the girls are not guarded and they're like let's exchange phone numbers. There's Jamey that feel in love with this girl and he paid 5000 already to AFA. After \$1000, I was like I want a personal email address, a telephone number or I'm finding someone else. Yeah, I mean I would have spent 1000 dollars and said I'm really coming to see you, or I would talk to her on the phone or get her email. Jamey already spent 5000 dollars [for nothing]!

Many of the local employees in Davao reaffirmed that most men are concerned with the 'realness' of the profiles.

Zia, one of the night shift employees, told me, “The main thing that they're [American men] after is if the girl is really real.” Dree, the night shift manager, told me this desire to see that the women are 'real' derives from the fact that many other websites are indeed scams. In order to ensure that profiles are the most up to date, Zia explains, "AFA contacts us. To see if the girl is still existing, interested, ah, doing their part.” The constant contact between employees and women signed up with AFA as profiles is a measure to ensure that the women are 'real'. Dree stressed to me that the profiles from the Davao office are as current as possible, "We always contact our profiles. If the profile is not attended to, and we cannot contact them, we inform the AFA office the girl is no longer existing. Then we remove her from the site.” Much like in Ukraine, many of the 
profiles work for the AFA local office as translators in order to demonstrate that the women from the website do exist in real life. Riley told me that she was hired to work at the local office since she was one of the most popular profiles in Davao. Riley explained that since she worked at the office, any men who were in correspondence with her could easily meet with her, and see that she is in fact a real person. Many of the most popular profiles work at the local Davao office for this reason.

Most men did feel concern that the women they met on tour may only be interested in them for money or an opportunity to leave the Philippines. As Jamey put it, "Having talked to the other men, basically they're all tired of being used and taken for granted, and the last thing in the world they want is to hook up with some girl who's just looking for a green card to the United States, who takes their housing in the United States.” Many of the men on tour in all three countries, and especially in the Philippines, had already experienced divorce and did not want to have worry about another failed marriage. Jamey, who Duncan claimed had been 'scammed' into spending too much money on correspondence, felt that going slow is the way to avoid scams,

You can't worry about that [scams]. That's why you don't rush stuff. You just got to be patient. If they do, you know, how could they do that? There's gold diggers in the U.S. too of course. Basically what you do, you keep your marriage like a company, you keep whatever assets for two years, then split it in half. That's if you don't have a child, which is a different issue.

Jamey points out that any marriage is a risky investment, even with women in the U.S. In fact, a number of men participating in any AFA tour would argue that American women are more likely to be 'gold diggers' then women in other countries. Jamey pointed out that because women change and evolve over time, does not necessarily mean they 'scammed’ you, “Just because she's from the Philippines doesn't mean that she'll never 
gain an ounce or that she'll always be sweet, submissive and non-confrontational.”

Ultimately, Tim makes an important point, "The money issue is always gonna be there. It's like I told you earlier today, all beautiful women, I don't care where they are from, all beautiful women have options. You are not their only option. I promise you that.” Thus, while many men hope to escape the materialism prevalent in American culture, they remain anxious about foreign women's true intentions for seeking relationships with foreign men. Riley agreed with Tim that money is a major motivating factor for women to join AFA, "That is the number one reason. Filipina women are looking for foreign men because of money and that we can get the hell out of this country. It's like, it's easier than applying, you need to spend money on that and working a lot." Many women prefer marriage to a foreign man over migrating as a worker, since work visas are more difficult to obtain and are much more temporary.

Men's anxieties varied depending on the location they were touring in. In Ukraine, conversations about scams and how to avoid them are extremely common. Most men returned to Ukraine for multiple tours, since as Alec pointed out, there is a 'learning curve' to navigating the tour experience there. Numerous blogs, advice columns, and guidebooks have been dedicated to the subject of navigating potential scams within the Ukrainian romance tour scene. Even the owners of AFA advise men to attend a tour, as most scams are likely to happen through online correspondence. Despite all the advice that is available to American men about how to avoid scams in Ukraine, many men give up on finding a wife in Ukraine and move on to more exoticized locations, like Colombia and the Philippines. Within Latin America, Colombia is a popular choice and most of the men I spoke with on tour in Medellin characterized the local women as sincere and 
professional. Colombian women are often placed ahead of Costa Rican women within the desire hierarchy, as many men characterize Costa Rican women as desperate or on welfare. Even within Colombia, women in Medellin are considered professional, while women in Barranquilla or Cartagena are thought of as younger and less serious. The dire poverty that many men witnessed in the Philippines heightened their anxieties regarding potential 'scams', since women's intentions could be based upon escaping poverty and providing remittances to their families. A number of men recognized that marrying a Filipina also meant supporting her entire family that remained in the Philippines. Men like Greg, however, felt that a large number of women in the Philippines were simply too desperate to escape poverty to actually be sincere.

\section{Challenging Scam Narratives}

Most of the local AFA employees I spoke to explained that a significant percentage of both men and women participating in the industry are not necessarily looking for serious relationships. In fact, most employees argued that approximately fifty percent of the men and fifty percent of the women are not serious in their search for a relationship. Kari, a Colombian translator, explains that the split between serious and non serious tour participants is 'fifty-fifty'. In the case of Colombian women, Kari told me the fifty percent that are not serious simply are unsure of their desires, “They don't know what they want and why. And they meet...probably some of them meet for money. But actually it can be seen from the very first meetings, it can be seen, when you meet someone, you can see if she is ok, serious or not.” Once again, Kari reiterates the fact that American men need to be aware in order to discern potential women's serious intentions (or lack thereof). Nadja is one of the few employees who made the split sixty-forty, "Ok, 
let us imagine that there are hundreds of ladies, Ukrainian ladies. Probably sixty of them will be interested in people, I mean, in some relationships, and forty will be interested in just to have nice time here in Kiev, to go to expensive restaurants, to have fun, to go to bowling." Riley told me as well that, "Yeah. Maybe twenty to thirty percent think you should be a member of the site because they [American men] are sending gifts, like cell phones, laptops and everything so, and that happens if they are really interested, they send you gifts for free, so women grab the opportunity to [join the site].” According to the local employees, there will always be a percentage of women who are just seeking financial opportunities, but a large number of the women signed up as profiles do sincerely want to marry a foreign man.

I spoke at length with Alexis, who is both a translator and profile on the site in Ukraine, about the discourse that American men utilize when discussing 'scams'. She told me that she always meets with any man who is interested in her, to prove to him that she is indeed a 'real' person,

I can meet people, because if I refuse to meet him, I know clearly that if I refuse to meet some guy, he for sure will be, it’s like $90 \%$ or $80 \%$ [chance] he will write to the site or write on the service that I'm a scam girl. A lot of them complain that you are a fake or you're a scammer. That's why I meet them, that's one more reason why I meet, I have nothing to hide, I can meet.

She argues that many of the American men who are unlucky in their search for love in Ukraine just blame it on 'scamming' Ukrainian women, when the only money he is realistically spending is the money needed for her to get home,

Many of them, if they don't have some luck, it seems like if they have bad luck, they start to, they start to complain that all the girls are scammers, that this is shit fucking Ukraine, that this is fake and all the bad things, only the bad factors, bad points of the complete situation, but the situation which he chose himself. He is complaining because he thought that he gave, for example, he gave some money 
to the girl for the taxi, which is necessary here because here almost there are poor guys from Ukraine, and if you date a girl you should either bring, if it's late, you should bring her home. Or you pay for her taxi at least. If you don't have money to pay for her taxi, you should walk her home at night. But she should be delivered by you. You are responsible for her safety.

At this point, Alexis delved into the 'taxi' scam that a number of American men commented on and explained how men over-exaggerate the situation,

And some guys give, for example, two hundred for the taxi for both ways, because, for example, some girls maybe come for a date by public transport but many of them should go to the beauty salon, make hair or probably she is in a hurry and she comes, and then she takes a taxi to come to the date. And in the end he gives her 200 grivnas. Yes, the taxi can cost 80, the taxi can cost 55 or 60 . Each time it depends, it depends on the service and it depends on the time of the day. And sometimes when she takes a taxi at night a lot of taxis only in the center can say 100, and he gives those money and he... he is going by the some other taxi service and he pays 60 and he starts complaining that is a scammer, that she took 40 grivnas more for the taxi and that's a scam.

Alexis' stories highlight the tensions surrounding discourses of 'scams' that many American men utilize, since many of the 'scams' the men discuss are nothing exorbitant, such as paying a few extra dollars for a woman’s cab ride.

Numerous translators and office employees told me that half of AFA's male clients end up coming on tour 'to have fun', date a bevy of beautiful women, and take tons of photos with beautiful women to show off to their friends at home. Kari explained to me that most men cannot help but get sidetracked by the 'fun' atmosphere of the tour, "They want to have a serious relationship, all the Foreign Affair clients, but when they start doing dates, they want to be fun, have sex with another girls and then choose the good one. It's like shopping.” Kari told me that fifty percent of those men are not truly serious about finding a serious relationship, and many other local AFA employees in Medellin, numerous cities in Ukraine and Davao City corroborated this statistic. Riley 
told me that fifty percent of the men on tour in the Philippines are not serious about finding a wife, and are just looking to date younger women. A number of women in Ukraine explained that foreign men are constantly on tour and that many of them have absolutely no interest in anything but meeting beautiful women. Nadja places the men's sincerity lower than Ukrainian women's, "Some of the men are not serious at all. It is about fifty-fifty.” AFA employees at the local Davao office also said that fifty or sixty percent of the men on tour are not serious in their intentions of finding a wife.

Riley explained to me that most of the men are corresponding with a number of women at one time; they are not 'monogamous' in their attentions to women from the site and they often date multiple women while they attend tours,

Well maybe tomorrow's there one writing, and the next day one, but all of these guys are writing other girls too. If you are really serious about knowing me, only me, then all of the girls you will want to write, it's like you are cheating on me. Same thing, same thing. Even Dennis, my friend from Texas, he writes five girls. I didn't know, I asked him and found out there is four girls, 3 Ukrainians, one in Cebu and me. Three or four, yeah, it's like fine with me.

Riley did not mind the fact that Dennis emailed other women, since she was not romantically interested in him. Dennis had mailed her a number of gifts, and Riley found this to be very strange. She felt that he must have a lot of money to waste if he is sending gifts to women he has never met in foreign countries, "Yeah. He sends money and the stuff. The first time he write me, he send me flowers and chocolates and the second one chocolate and flowers again, and the third one a fruit basket that had everything, the third one flowers and fruits. The last one, cake, it was my birthday, cake and flowers and balloons. Maybe he has a lot of money, wasting for this girl he didn’t even know.” Dennis sent gifts with his letters to other women as well, and Riley was just amazed that 
American men had the funds to 'waste' on women they wrote to via email. She was not interested at all in Dennis romantically, and expressed her interest in friendship with Dennis, “I said yeah that's what friends are for, but romantically I do not have feelings for you for now. I don’t know, but I told you I don’t like old, fat guy.” In Riley’s mind, Dennis was 'old' and 'fat', and therefore, extremely unattractive. She did not, however, consider her relationship with Dennis to be a 'scam', even though she was not romantically interested in him. She told him that she just wanted to be his friend, and he continued to want to visit and send her gifts.

Migration and Uncertainty

As mentioned before, anxiety has often been gendered as male in western thought, and this largely applies to the women who participated in my study from all three countries. While American men are hyper-focused on identifying and avoiding scams, women in Colombia, Ukraine, and the Philippines are much less anxious about migrating, leaving their families and friends behind, and adapting to entirely new culture and way of life. When I asked Betty if she was anxious about moving to the U.S. with her fiancé, she told me her experiences traveling abroad prepared for her migrating to the U.S.,

No. I'm not scared because I've been to some other countries before. Not in the US though. Some Asian countries who have those people or folks who don't know how to speak English. It was pretty tough for me but I did...I mean I survived. I've been to Australia and some other Asian countries so I'm not scared anymore. In fact, when I went to Australia. I don't care, nobody knew I was there. My parents knew I was there a month after I arrived in Australia. I was actually gonna do that the same thing at this time but I realized that "oh they're my parents and I'm gonna be away from them forever. So I have to go home and ask...okay Dad, Mom, I’m leaving. Yeah. Do you have some doubts? I said nope.

Betty was one of the few well-traveled women I met in the Philippines (or in any other tour location for that matter), but a lack of travel experience did not necessarily preclude 
other women from a lack of anxiety towards potential migration. Lana, a Colombian woman engaged to an American, told me she was not worried about leaving, "No, no worries. I am so excited to live there! I don't need to worry about that.” Isabella told me, "If I have the chance, I would be willing to move. No, I don't really have a preference. I am open to it all.” Of course, some women did express anxieties surrounding how migrating would separate them from the life they were used to living.

Nadja, while a working as a translator, met her fiancé on a tour. She was engaged to him, but still felt apprehensive about making the big move to the U.S. Besides missing her family and friends, she considered moving to a new country with a different culture, language and way of life to be a much more difficult path,

I mean, it would be much easier to stay here in Ukraine, cause I know everything here, I know the language first of all, I know language. That's my native language. I don't need to think before say. I know all the traditions, customs, how to behave in... Yeah, in public place. I know all these things about our country, I mean, that's all my, my own. I know what to do here. I'm afraid, I really want to go to America and I will do that, but I'm ... I'm really afraid. Cause the only person, no, not only person - I know a lot of guys from Foreign Affair, from tour, - but the only person who I will talk all the time is my boyfriend, and I'm really afraid that something will go wrong, and then I will have to come back here and, "Oh, no!" I would like to say some word at least in Poland or the countries near Ukraine in Europe. Not so far, it's really so far from Ukraine.

Nadja had serious misgivings about leaving her entire way of life behind, but also was interested in trying something new and different. Most women, like Isabella, discussed potentially missing their families, but ultimately looked at the opportunities present in the U.S. as offsetting many of their anxieties, "Leaving my family would be the hardest thing. I am not really sure, but I'm sure it will be better opportunities than in Colombia.” Alejandra expressed concern over leaving her sons and was still on the fence about migrating to the U.S., "I would have to think about because my sons are still young and I 
am very close to them. They are eighteen and twenty one. It would be really hard to leave them.” Many women expressed concern over leaving their families, but only a few women shared deep anxieties about migrating away from their families with men who are, in a sense, 'strangers'.

Missy expressed deep anxieties regarding migrating far away from her home and her friends. For Missy, meeting a man at the social event, getting engaged during the tour, and then migrating to the U.S. provoked a number of anxieties,

But to me personally, it's so strange that you meet someone, then after that you get engaged, then you get married. It's so, so fast! For me, it's not that easy, for me it's years before I marry someone. Marriage for a Filipina, it's a different country, a different culture. So, for me, it's so hard to go in America, I didn't know that, I didn't meet people, I didn't any know people really there. Also, what if?, it's a lot of what ifs. For me, if I go in America what will happen? What will really happen for me? Is it good or bad? It's that chance of finding some American people that is good for me. I'm afraid. I'm afraid.

Besides questioning if moving to the U.S. would be better for her, she feared not having a social network outside of her husband, “There's no my mother, no my father, there is no one I can go [to]. What if he leaves. Maybe he kill me. I don’t want that! I don't know him already. It's just one night at a social party. It’s ridiculous. For me, it takes a lot of time to learn that. I have to get understanding for me to go in America with some American people.” Missy is actually the only woman I interviewed in any country that mentioned being afraid of potentially being not only physically harmed, but killed. I assumed that many women would afraid of being vulnerable to potential abuse and isolation by their husbands, but only Missy mentioned this possibility. More women expressed anxiety about finding a potential mate versus being abused by a foreign man. 
In the Philippines, Colombia, and Ukraine, women felt pressure to find a good husband. Women in all three countries expressed that most women get married in their early twenties, and that women over thirty have a hard time finding a husband. Julissa explained the 'marriage expectation' in Ukrainian society as, “The typical age to get married is twenty five. They are so afraid not to get married by thirty. They always count the calendar, and by thirty or thirty one, by thirty I have to be married, thirty one is the last trip.” The age bracket Julissa discussed also applies for women in the Philippines and Colombia, who are already often considered 'old maids' once they are over thirty. Many younger women that join the agency, and that are genuinely looking for marriage, are anxious about finding a husband within the 'proper' timeframe allotted to women within their respective cultural settings. While cultural timelines of marriage often induced anxiety for women in all three countries, the most anxiety inducing situation for most women signed up with AFA is the struggle of being a single mom and finding another man to accept and care for their child.

As discussed in the previous chapter, many women in Ukraine, Colombia, and the Philippines characterized local men as adulterous and unfaithful, while they imagined American men as faithful and loyal. Isabella, who had a string of bad relationships with local men, told me, "I’m scared to get hurt and to be played.” The anxiety surrounding 'being played' is present for many of the women signed up with the introduction agencies. Many women are single mothers, and have had negative experiences with men in the past. Jessie explains that the high number of gay men in Medellin, as well as the high number of attractive women, gives Colombian men high currency in the local dating market, increasing the chances that they will be unfaithful, 
I don't know if you have noticed, but we have a lot of gay men. We have a lot of openly gay men, so there's few straight men to choose from. And the attitude that the straight men have adopted is oh, I can have my pick of women. Why just have one? Most of the girls have been burned really badly here so they are really disappointed and don't want to deal with any kind of drama and like I told you, a lot of single moms. So they don't want another guy that gets you pregnant and leaves. They want really responsible as well. The guys here are really charming but not really responsible, not really into the relationship. This goes for all the guys I have dated. The norm.

In fact, men's value within the marriage market is determined by the amount of 'choice' that they wield: men with increased choice have increased marriage market value. Most of the American men on tours mentioned to me that they felt they had much more 'choice' in Colombia, Ukraine, or the Philippines when it came to finding dates. American men often complained that women in the U.S. have the 'choice' in the marriage market. Therefore, AFA selects countries to be tour destinations based upon where men are more likely to have 'choice'.

Some women expressed anxiety over the long distance aspect of maintaining an international relationship. Before Isis met her husband in person, she conducted a longdistance email correspondence relationship with him. She told me that opening up to a person via the online realm is often fraught with much more anxiety, since finally meeting the person can either solidify or break the bonds forged online, “[I'm] not used to trust first like that. But at the same time I used to study how was his good intention to me, if he is really interested like that. So long way...a long way we have been with each other before I really felt so much in love with him, till we met here.” The romance tour industry also fosters an air of competition between women profiles, as there are far fewer men on tours than women who are interested in dating foreign man. Isabella told me that she often felt jealous when she saw the men dating a lot of women while on tour, "I mean 
part of our relationship there's jealousy, right? We got jealous because we're afraid that we would lose him.” The anxiety around potentially 'losing' a relationship partner is a common feeling beyond the romance tour industry, and anxiety surrounding love relationships is truly universal. However, how people interpret those anxieties is often contextualized within their understandings of racial, national, and class based hierarchies. 


\section{Chapter VII: Conclusion}

The romance tour industry provides an important look into the global intimate, and the ways in which globalized processes are created through everyday intimate emotions and interactions. In the intimate spaces of the body, international relationships created through romance tours are negotiated and articulated, constantly challenging the imagined binary between the intimate and the global scale. The emotions and affects articulated to me by both male and female participants within the commercialized romance tour industry often reproduced neocolonial hierarchies of race, gender, sexuality, class, and ethnicity. Hierarchies of identity were created in the realm of the intimate during colonialism (Stoler 2006) and they are negotiated, challenged, and reproduced together within the intimate realm during the contemporary era. Colombia, Ukraine, and the Philippines are post colonial sites with deeply embedded intimate tour industries, ranging from sex work to 'the girlfriend experience' to romance tours. Intimate sexual industries have been developing in all three sites for numerous years and it is no surprise that they are the some of the most popular sites for sexual and romantic tourism in the world.

When I asked one of the owners of AFA about how they choose the countries for their tours, he responded that a number of factors are involved. As mentioned earlier, the main discourse that agencies utilize is one of gender imbalances in the population of their tour locations. In all three locations, numerous employees and American men mentioned that there was a shortage of available men in the local populations and the shortage made American men's 'currency' as transnationally mobile men incredibly high within the local dating markets. Most of the men participating in the tours no longer have a lot of 
currency within their own local dating markets and seek to increase their value by going to countries where 'good' men are a precious commodity. As the reporter on Nightline pointed out, "Many of these men have never had female attention like this ever before." Indeed, it is a surreal experience to observe the number of women that attend social events, and the amount of female attention that many men receive while on the tour. Even men that are not typically considered physically attractive will still go on dates with much younger and better looking women.

Marley told me that all relationships are a form of exchange as we sat in the hotel bar in Poltava, Ukraine. Marley explained his idea of the love exchange, "You see, all relationships are an exchange. We American men come here, and we are financially stable, and can provide a good life. Women here in Ukraine are young and beautiful. We are essentially exchanging financial stability for youth and beauty, and I am okay with that." Marley was one of the few men who characterized his romantic relationships and interests as an exchange. Most of the other men did not and were often offended by the hint of economic undertones in a women's romantic interest. Thus, anxiety surrounding being 'scammed' by women abroad for money, meals, and migration opportunities were a common emotion shared by many American men in my study. The common discourse that men utilized to describe the types of relationships they were seeking focused on being loved for who they are, not what they can provide. Of course the great irony of the industry is that men expect women to like them for 'who they are', but often employ very shallow standards in selecting which women to date while on tour. Tim told me that his friends' wives at home in the U.S. hated to see him with a foreign women, "Women don't want their husbands to know that they can dump their fat ass and come over here and 
have a twenty eight year old. They don't like that.” Tim's comment highlights the importance of a potential mates' appearance to American men who attend romance tours, but at the same time, Tim wants to be desired for who he is. In many cultural narratives, men are considered to be shallow and appearance based, while women are thought to be more forgiving of appearance.

In Colombia, all of the employees that I interviewed mentioned the hypocrisy American men on tour exhibit, and found it to be funny. Kari told me that not all the men are shallow in terms of deciding which women to date, and the men that 'go with the flow' tend to be more successful, "Not all of them [are shallow], but it's pretty funny, cause the guys that want to have a perfect girl is pretty ugly or is pretty picky, or is a shit. Yeah, but a guy like, “Ok. I want to find everybody and everyone. I will try with this or something like that.” It's those guys that'll find someone.” Jessie, who had worked the longest at AFA translating, was the first employee to highlight what she felt was the deep hypocrisy and shallowness that a lot of the American men showcase while on tours in Colombia,

Sometimes the guys that come here are really shallow, or they don't see that the American girl they are describing is the female version of themselves. I have seen guys wear the same shirt three days in a row. I am not kidding you. They come with a carry-on bag, with all these clothes you see, but they have some serious hygiene issues. You are wearing the same shirt to meet a girl three days in a row, and a lot of the guys get sweaty down here, so you're like in a sweaty shirt three days in a row. They all wear sandals and they are always in shorts and they are always not looking their best. And then you have the other guys who look their best all the time, or they dress casually but its like good. But yeah, they are really hyper-critical. They are really critical. It is really funny. Some of the times they really smell. You have to [holds breath], sometimes because they sweat a lot, so you have to get not that close. All of them sweat, but the smelly ones are not that much. But there's always one. Sometimes he will take a lot of showers and take cologne, but not all of them. 
Both the manager, Lindsay, and Xiomara concurred with Jessie, and they agreed that many of the guys who are on tour have issues maintaining their hygiene, yet expect the Colombian women to remain thin, made up, and fresh. The assistant manager Xiomara told me, "Yeah, they smell. Most of the guys smell, you know, like they don't really wash, they don't really know about the deodorant or something. Yeah. They don't really like to wash their clothes. As you see, ladies here take care about themselves. And here men are like that too. They are respecting the date, they respect and take care about themselves.” The manager Lindsay continued, "Yeah! If you are sweaty, you change your clothes. If you smell like something, you change your clothes. If you feel smelly, you just take a shower." For many reasons related to appearance and hygiene, none of the women I met working at the local Colombian office were interested in dating the men on tour, even though they had the advantage of speaking English.

On the other hand, many employees of AFA in local offices in Kiev, Ukraine and in the Philippines are actually profiles on the website. Riley is one of the most popular profiles on the site, but did not consider many of the men who corresponded with her, or who came to meet her on tour, to be very physically attractive. Riley is only twenty five and beautiful enough to do modeling in her local community, and, therefore, she has enough currency within the international dating market to be shallow or picky,

I haven't seen anyone yet who I thought would be a nice father for a kid. They're good but their physical appearance is not. Fat, old, ewwww...it's yucky! I can't imagine myself having this guy, having to sleep with this guy..ewww. I am not into. I just do my work at my job, not any more, not any less. And I'm like ewww, whatever, because I don't like it. If I like you, I will be like, yeah I do like you, but if you are not my type. I don't care about the appearance but I hate the fat one. That's it. I don't care if you are not handsome, if you are not that really hot one but I want the real one and not the fat one. Or the old one. 
Unlike most of the women I spoke with in the Philippines, foreign men's appearance and age mattered to Riley; while she is not seeking the most handsome suitor, she is looking for someone that is not fat or old. Other women in the Philippines are much more forgiving than Riley about American men’s physical appearances. Lila, who began dating Mark, openly talked about moving beyond his 'fatness' to see that he was potentially a good boyfriend for herself, "I am open to possibilities because why should I have to let go of this guy that he has the qualities, the looks because he's good looking. Even though he's fat (laugh) he said to me that I will reduce, I will eat chicken and veggies only. When I come back here I will be slimmer.” American men in the Philippines expect women to move past very large age gaps and often times very large size gaps, but they are not willing to afford Filipina women that same luxury. Zia told me, "If you're fat, you're not qualified, of course yes! You know the taste of foreign guys.” She further explained that the HLC Lifemates office is just following the standards of AFA when it comes to imposing weight restrictions on potential profiles. American men are expecting a petite Asian women and the weight limit is the strictest there.

The weight limit imposed on Filipina women often did not apply to Ukrainian women, who are typically taller in height. Ilona, who is both a translator and profile with AFA in Ukraine, told me that there is 'propaganda' in the West about what Ukrainian women are like, "A lot of European guys, a lot, a lot of people come here. But maybe a lot of men think that it depends on some propaganda, American propaganda that Ukrainian girls like to cook, and they like to clean up and they all are pretty, thin. I'm thin but, a friend of mine is not thin and she's pretty, but she doesn't like to cook.” Here, Ilona challenges the typical discourse that describes every Ukrainian woman as a thin potential 
June Cleaver. She also discusses the deep hypocrisy that many American men display

when choosing a woman to date,

And a lot of very ugly just, I'm sorry, but a lot of very ugly men come and they want to meet just a princess. The prettiest and, of course, it doesn't work out. It doesn't work out, almost never. If he is very ugly he should compensate it in some way. He should be very charismatic. He should be very charismatic. And he has to spend something on dating. And in our culture, in our culture we are brought up on books, some fairy tales about princesses from the early childhood and when some ugly, fat American man probably 52, 53, 56 comes and says that he is eager for somebody to love him, just for what he is. That's not realistic, especially I'm poor, I won't spend money on you because I'm poor, but I want you to love me because for who I am, just fat. I know maybe he has some soul, maybe he has some soul in that big body and as an interpreter I can support him, but as a girl why should I spend my time?

Once again, a local employee highlights the main irony of the international dating industry: most American men have high standards for women they want to date in foreign countries, but often do not hold themselves to the same standard. White and affluent American men have the ability to be 'picky' in the marriage market, based upon their privileged status within the global imaginary.

The romance tour industry capitalizes off of American men's currency within the transnational imaginary and their lack of currency at home. A Polish American expat I met living in Medellin explained to me that white American women no longer want to be with white American men, and instead are interested in black men. He found the inversion of desirability within American to be offensive enough to move permanently to Colombia, where he found a much younger Colombian girlfriend to live with. Most American men never experience the level of female attention they receive on tour within their local dating markets. In America, these men are largely considered 'normal': most are middle to upper middle class, most are older than forty, and most are white. However, 
these same 'normal' men, who do not get a second glance in the U.S., are a hot commodity within the Philippines, Colombia, and Ukraine. American men’s financial privileges allow them to employ shallow, appearance-based requirements for women they are interested in dating abroad.

The fact that white American men enjoy such high currency in foreign dating markets speaks to the staying power of transnational hierarchies of gender, class, nationality, race, and sexuality. American men’s whiteness is often associated with financial stability, affluence, modernity, and transnational mobility, providing them a high currency in foreign dating markets. Even though African American and Hispanic American men also possess many of the qualities associated with whiteness in the romance tour industry, such as affluence, they are not necessarily considered desirable to many women in Colombia, Ukraine, or the Philippines. The fact that women in other countries employ clear hierarchies of race when it comes to dating American men demonstrates the important ways in which whiteness remains a signifier of attractiveness when linked to masculinity. On the other hand, many American men decouple whiteness from attractiveness in the case of white American women. To them, white American women have become too spoiled by their economic power and are no longer interested in prioritizing their husbands as number one.

Since American men have the privileges of relative affluence and transnational mobility, they can search for a potential mate worldwide. The countries that American men have made popular through romance tourism, such as Ukraine, Colombia, and the Philippines, have colonial histories of occupation and new forms of neocolonial economic occupations are becoming entrenched in all three societies. Neoliberal 
economic reforms have impacted the Philippines, Ukraine and Colombia in major ways; the Philippines has become the number one exporter of migrant labor globally, women from the Former Soviet Union are globally employed as sex workers, and women from Colombia are also globally employed as sex workers. The dramatic economic restructuring of the neoliberal era has made it more difficult for working class people to survive in many countries. As Marley pointed out, the romance tour industry is engendering new forms of economic exchange: American men desire youth and beauty and are willing to exchange financial stability for the privilege of marrying a younger woman. Even though American men have high currency in foreign dating markets, not all foreign women have high transnational dating currency.

Women in Ukraine, Colombia, and the Philippines have high currency within the transnational dating industry. Women in these countries are considered the most desirable wives in each of their respective geographic regions, since these women belong in the category of 'exotic light'. Since Ukrainian women are considered 'white', it is not surprising that they are the most popular women in the romance tour industry. Ukrainian women's whiteness allowed them to surpass Filipinas in popularity as potential brides, even though most Filipinas speak English and a long history of intermarriage between American service men and local Filipina women exists. Filipina women, because they fall within the Asian racial category, are considered close to whiteness. Therefore, it is not surprising that the Philippines is the second most popular tour location for AFA. Finally, Colombian women are imagined in terms of a stereotypically Latina look: long dark hair, tan skin, and brown eyes. Most of the American men on tour are seeking women who fit the Latina stereotype, and do not want women who look too African or indigenous. 
Therefore, most men prefer Colombia to countries like Costa Rica or Peru, where the women are deemed too indigenous looking, and within Colombia, prefer Medellin to cities associated with blackness, like Cartagena or Cali. Ultimately, it is American men’s desires for a beautiful, younger wife that inspired the creation of the entire romance tour industry, demonstrating once again the maintenance of raced, gendered, classed, and sexualized global hierarchies.

The globalized dating circuits that are engendered through romance tourism are an example of instantiated in neoliberal globalization that has spread to the former Soviet bloc and the Global South. The commercialized romance tour industry is popular in Latin America, Eastern Europe, and Southeast Asia and represents a reinscription of colonially based racial hierarchies. The neocolonial hierarchies that are being reinscribed in these locations are produced and reproduced through individual people’s emotions, such as desire, disgust, and anxiety. The globalized dating circuits that American men and women in Ukraine, Colombia and the Philippines participate in can often be tracially ransgressive and, therefore, international relationships trouble heteronormative ideals. American men on tour attempt to normalize their search abroad for wives by first searching for exoticized white women in Ukraine. For those men who move on to more exoticized locales, or who begin their searches in non white countries, the trope of stereotypical 1950’s white middle class femininity becomes a way in which to 'whiten' Filipina and Colombian women into acceptable, and even preferable, marriage partners.

While black sexuality is considered disgusting, it is at the same time pleasurable to engage in. However, the pleasure of black sexuality is often kept in the liminal spaces of travel and tourism, as black sexuality is already too non normative to assign the trope 
of traditional femininity. In order to avoid blackness and indigeneity, men followed certain geographical circuits and tended to travel to Asia before Latin America, and to certain regions of Colombia that are associated with lighter skin. It is important to note that my findings are deeply contextualized, as men who travel to Dominican Republic are not necessarily looking for light skinned women. However, the hierarchy of popularity between tour locations suggests that an important majority of the men do employ racialized geographies in choosing their tour destinations. In addition, certain racialized notions of women in all three countries as the 'Other' intensify already existing anxieties that surround developing intimate relationships.

\section{Desire}

Desire is an important emotion that scholars have analyzed from a variety of theoretical lenses. The entire commercialized romance tour industry sells American men on the idea of finding an exotic June Cleaver, a woman untouched by the ills of feminism. American men are seeking a wife that will prioritize her husband, as Mark Davis points out,

I wanted a gorgeous woman with traditional values where I come first and who loves me unconditionally. If you are a North American guy and have only dated women in your home country, then you know what I'm talking about: the majority of American women are too modern, too career-oriented, and too insecure to be focused on us. Tell a $21^{\text {st }}$ Century that you wish she was a cross between Marilyn Monroe and June Cleaver and watch how quickly your phone calls end up in voice mail.

Mark Davis argues that women in other parts of the world are intent upon keeping their partner satisfied, thus they maintain a beautiful appearance and work to please the man

they are with. Men's desire to be the number one priority in their partner's life often lead 
them to search for a traditional woman on the internet, where they find a variety of websites and companies that provide an opportunity to meet women who still possess the qualities of a contemporary June Cleaver.

Women from Ukraine, Colombia, and the Philippines are considered modern day, exotic June Cleavers and are thought to prioritize men, family and at same time have no problem maintaining an attractive physical appearance. Yet, within the international romance tour market, Ukrainian women are the most coveted and desirable potential wives. Ukrainian women are thought to resemble June Cleaver the most, based upon their whiteness. Many American men begin their tour and correspondence experiences with Ukrainian women, and when they do not find success there, move on to more exoticized locales, like the Philippines and Colombia. Within these more exoticized contexts, American men often focused more on women's traditional values and family orientation in order to 'whiten' her into a superior wife over white, middle class American women. Even in terms of skin tone, American men often were seeking out the 'exotic light' in Colombia, since the possibility of encountering blackness is very real in Colombia, especially on the coasts. In places like the Philippines, many men seek 'darker' women, but these women are disassociated from blackness. American men are not the only tour participants that utilize racialized discourses of desirability.

Many women in Colombia, Ukraine and the Philippines desired a transnationally mobile Brad Pitt: someone affluent, blonde, attractive, and stereotypically white. Women in Ukraine often characterize nonwhite American men as 'exotic', and are not accustomed to nonwhite populations in general. The population of Ukraine has remained relatively homogeneous, but there are a handful of women who find Hispanic and African 
American men attractive because they are 'exotic'. In the Philippines and Colombia, the legacy of colonial constructions of race continues to inform women's assessments of American men’s desirability within a hierarchical framework. Women in both Colombia and the Philippines typically desire a 'white' American man, but often consider settling for someone 'moreno'. Most women stressed the fact that they wanted to 'lighten' their future progeny by marrying someone with stereotypically 'white' features. In all three countries, most women simply imagined American men as white, since most men attending the tour are white. Both American men and local women in each country have somewhat given up trying to find a local partner within their own home countries.

\section{Disgust}

Most American men attending tours expressed disgust toward American women and their options within their own local dating markets. American women are characterized as overweight, lazy, materialistic, spoiled, and career driven: all of these characterizations elicit some form of disgust from the men I spoke with. Many American men on tour blame feminism for American women's prioritization of their careers, their lack of feminine appearance, and their overall lack of 'good wife' qualities. Instead of resembling June Cleaver, the pinnacle of white middle class femininity, American women have now become 'masculinized'. Men's frustrations with the shifting definitions of gender roles in the U.S. are exploited to create the romance tour industry. Even though most American men expressed a variety of disgusts with American women's appearance and behaviors, a few younger men traced their desire to find a foreign woman to the fact that many American women are waiting longer to commit, get married, and have a family. In addition to articulating disgust towards American women, many men on tour 
articulated disgust toward women associated with 'blackness', particularly in Colombia. Blackness also often elicited disgust from female tour participants in all three tour locations.

Women in Ukraine often express disgust towards local men, who are typically characterized as unfaithful, lazy, and alcoholics. Ukrainian women also discussed the gender imbalance in the population as creating a very competitive dating market, since men had high currency in the local dating market, with many options. Ukrainian women are not alone in lamenting the fact that the marriage market is very competitive in their local context, and Colombian and Filipina women also commented at great length about the high currency local men enjoyed in the dating market. Men that possess a high currency in the local dating market are often considered unfaithful, since they have many women to choose from. Colombian women tend to characterize local men as unfaithful, as well as financially unstable and immature in relationships. Filipina women tend to find local Filipino men to be more romantic and attractive, they considered American men to be more financially stable and sexually loyal. For many women in other countries, American men's imagined whiteness is fused to ideas of financial stability, affluence, transnational mobility, fidelity, and maturity. The same qualities that are fused with white American men's reputation within the international marriage market are not applied to American men of color. Most women in Ukraine, Colombia and the Philippines are not open to dating African American and mainly Colombian women expressed an interest in dating Hispanic American men. American men of color are often placed below local men within the desirability hierarchy by women in all three tour locations. The clear racialized demarcations of desirability that the women employed across all three field sites 
demonstrates that most of the women are not willing to marry just any foreigner in order to migrate.

\section{Anxiety}

Despite the fact that most women are in fact 'picky' about the men they are interested in marrying, American men continually discussed the potential of being scammed for their money or for a chance to gain American citizenship. Since men are the paying clientele of AFA, many of them feel as if they are entitled to a certain amount of affection or attention from women on the tours that can at times be unrealistic, and consider the women to be 'scammers' when they do not receive the attention that they have essentially 'paid for', a point that many local employees observed. Men discussed tour experiences in Ukraine in terms of a scamming learning curve, which involves attending multiple tours in order to gain a sense of what is a scam versus what is legitimate interest on the woman's part. Numbers of articles, blogs, and guidebooks are written about how to navigate potential scams in Ukraine, and Russian and Ukrainian women are posited as the masterminds of scams. A large majority of American men begin their romance tour experiences in Ukraine, and when they feel as if they have been 'scammed' too many times, they start moving to more exotic tour locales. Men on tour in the Philippines expressed anxiety surrounding the impoverished situation of many women they dated, worrying that women would be interested in a better life for their families rather than the man himself. Men in Colombia felt the most secure in the sincerity of women's attentions, as they often described Colombian women as 'professional' and not desperate to leave Medellin. Many women in all three countries have anxieties regarding migrating to the U.S., to a new culture, language, and home. 
While men discussed potential scams a great deal, women focused much less on their anxieties. However, women in all three countries did express anxieties over moving to a new culture, learning to speak English, learning how to drive a car, and leaving their loved ones and familiar way of life behind. A very small handful of women expressed anxiety over leaving their home country with a relative stranger, with no real social network to provide them with backup if things go wrong in the marriage. Only one woman articulated anxiety and worry over potentially physically abusive situations, but most women viewed the potential opportunities that migration abroad represented as outweighing the potential risks. Many women also mentioned anxiety surrounding infidelity and being played by foreign men, rather common anxieties many women and men experience within their local dating markets. Colombian, Ukrainian, and Filipina women all characterize their local dating markets as competitive, and the international dating market often proves to be no different in terms of female competition. A number of women considered social events to be anxiety inducing, since the gender imbalance creates an air of competition. Thus, many women strive to achieve physical perfection in their attire and appearance in order to compete. The emotion of anxiety, as well as the emotions of desire and disgust, creates the building blocks of both men and women's constructions of race, gender and class within the romance tour industry.

By examining the ways in which the emotions of desire, disgust, and anxiety influence individual romance tour participant's constructions of racialized hierarchies, the links between individual emotions and global systems are revealed. The concept of the global intimate challenges the hierarchy of scale that places the body, the home, and the intimate on a much lower level than the scale of the global or the national, and at the 
same time challenges the binary that divides the individual from the global. Through highlighting the different emotional negotiations that are constantly occurring in the romance tour industry, we can begin to see the important ways in which individual emotions and affects influence global processes on a large scale. The racialized and gendered discourses that both American men and women in all three tour locations articulate are an important example of the ways in which hierarchies of race, class and gender are reproduced on a transnational scale through intimate relationships. 


\section{REFERENCES}

Abrahams, Yvette. 1998. "Images of Sara Bartman: Sexuality, Race and Gender in Early Nineteenth Century Britain." In Nation, Empire and Colony: Historicizing Gender and Race, edited by R. Pierson, N. Chaudhuri and B. McAuley, 220-234. Bloomington: Indiana University Press.

Ahmed, Sarah. 2004. The Cultural Politics of Emotion. Edinburgh: Edinburgh University Press.

—. 2010. The Promise of Happiness. London: Duke University Press.

Alexander, M. Jacqui. 2005. Pedagogies of Crossing: Meditations on Feminism, Second Politics, Memory and the Sacred. Dunham: Duke University Press.

Alexander, M. Jacqui and Chaundra Talpade Mohanty. 2010. "Cartographies of Knowledge and Power: Transnational Feminism as Radical Praxis." In Crtiical Transnational Feminist Praxis, edited by Amanda Lock Swarr and Richa Nagar, 2345. New York: State University of New York.

Angeles, Leonara and Sunanta, Sirijit. 2007. "'Exotic Love at Your Fingertips": Intermarriage Websites, Gendered Representation and the Transnational Migration of Filipino and Thai Women." Kasarinlan: Philippine Journal of Third World Studies 22 (1): 3-31.

Beal, Frances. 1970. Double Jeopardy: To be Black and Female. Detroit, MI: Radical Education Project.

Bernstein, Elizabeth. 2007. "Buying and Selling the 'girlfriend Experience': The Social and Subjective Contours of Market Intimacy." In Love and Globalization: Transformations of Intimacy in the Contemporary World, edited by Mark Padilla, Jennifer Hirsch, Miguel Munoz-Laboy, Robert Sember and Richard Parker, 186-202. Nashville, Tennessee: Vanderbilt University Press.

Block, Ernst. 1995. The Principle of Hope, Volume 1. Cambridge, MA: MIT Press.

Bonilla-Silva, Eduardo. 2013. Racism without Racists: Color-Blind Racism and the Persistence of Racial Inequality in America. Lanham, MA: Rowman and Littlefield Publishers.

Bonilla-Silva, Eduardo and David R. Dietrich. 2009. "The Latin Americanization of US Race Relations: A New Pigmentocracy." In Shades of Difference: Why Skin Color Matters, edited by Evelyn Nakano Glenn, 40-60. Palo Alto, CA: Stanford University Press. 
Bourdieu, Pierre. 1984. Distinction: A Social Critique of the Judgement of Taste. New York: Routledge and Kegan \& Paul Ltd.

Brennan, Denise. 2007. "Love and Work in a Tourist Town: Dominican Sex Workers and Resort Workers Perform at Love." In Love and Globalization: Transformations of Intimacy in the Contemporary World, edited by M. Padilla, J. Hirsch, R. MunozLaboy, R. Sember and R. Parker, 203-225. Nashville.

. 2004. What's Love Got to do with it? Transnational Desires and Sex Tourism in the Dominican Republic. Durham, NC: Duke University Press.

Brown, Gavin, Kath Browne, and Jason LIm. 2007. "Introduction, Or Why have a Book on Geographies of Sexualities?" In Geographies of Sexualities: Theory, Practices and Politics, edited by Gavin Brown, Kath Browne and Jason LIm, 1-20. Burlington, VT: Ashgate Publishing.

Burawoy, Michael. 2000. "Introduction: Reaching for the Global." In Global Ethnography: Forces, Connections and Imaginations in a Post Modern World, edited by Michael Burawoy, Joseph Blum, Sheba George, Zsuzsa Gille, Teresa Gowan, Lynne Haney, Maren Klawiter, Steven Lopez, Sean O Riain and Millie Thayer, 1-39. Berkeley: University of California Press.

Butler, Judith. 1993. Bodies that Matter: On the Discursive Limits of "Sex". New York: Routledge.

1990. Gender Trouble: Feminism and the Subversion of Identity. New York: Routledge.

Cabezas, Amalia. 1998. "Discourses of Prostitution: The Case of Cuba." In Global Sex Workers: Rights, Resistance, and Redefinition, edited by Kamala Kempadoo and Jo Doezema, 79-86. New York: Routledge.

- 2009. Economies of Desire: Sex and Tourism in Cuba and the Dominican Republic. Philadelphia: Temple University Press.

Caluya, Gilbert. 2008. "'the Rice Steamer": Race, Desire and Affect in Sydney's Gay Scene." Australian Geographer 39 (3): 283-292.

Carrera, Magali M. 2003. Imagining Identity in New Spain: Race, Lineage, and the Colonial Body in Portraiture and Castas Paintings. Austin, TX: University of Texas Press.

Chatterjee, Partha. 1990. "The Nationalist Resolution of the Women’s Question." In Recasting Women: Essays in Indian Colonial History, edited by Kumkum Sangari and Sudesh Vaid, 233-255. New Brunswick, NJ: Rutgers University Press. 
Chen, Mel Y. 2012. Animacies: Biopolitics, Race Mattering, and Queer Affect. Durham, NC: Duke University Press.

Cheng, Shu-Ju Ada. 2003. "Rethinking the Globalization of Domestic Service: Foreign Domestics, State Control, and the Politics of Identity in Taiwan." Gender and Society 17 (2): 166-186.

Clough, Patricia Ticeneto. 1997. "Introduction." In The Affective Turn: Theorizing the Social, edited by Patricia Clough and J. Halley, 1-33. Durham, NC: Duke University Press.

Cogua-Lopez, Jasney. 2010. "Through the Prisms of Gender and Power: Agency in International Courtship between Colombian Women and American Men." PhD, Florida International University.

Constable, Nicole. 2003. Romance on a Global Stage: Pen Pals, Virtual Ethnography, and Mail Order Marriages. Berkeley, CA: University of California Press.

_ 2005. "A Tale of Two Marriages: International Matchmaking and Gendered Mobility " In Cross-Border Marriages: Gender and Mobility in Transnational Asia, edited by Nicole Constable, 167-186. Philadelphia: University of Pennsylvania Press.

_ 2012. "International Marriage Brokers, Cross-Border Marriages and the US Anti-Trafficking Campaign." Journal of Ethnic and Migration Studies: 1-18.

Crenshaw, Kimberle. 1991. "Mapping the Margins: Intersectionality, Identity Politics, and Violence Against Women of Color." Stanford Law Review 43 (6): 1241-1299.

del Rosario, Teresita. 2005. "Bridal Diaspora: Marriage and Migration in the Philippines." Indian Journal of Gender 12: 2-3.

Doezema, Jo. 1999. "Loose Woman Or Lost Women? the Re-Emergence of the Myth of White Slavery in Contemporary Discourses of Trafficking in Women." Gender Issues 18 (1): 23-50.

- 2010. Sex Slaves and Discourse Matters: The Construction of Trafficking. London: Zed Books.

Dollimore, Jonathan. 2001. "Sexual Disgust." In Homosexuality and Psychoanalysis, edited by Tim Dean and Christopher Lane, 367. Chicago: The University of Chicago Press.

Enloe, Cynthia. 1990. Bananas, Beaches and Bases: Making Feminist Sense of International Politics. Berkeley: University of California Press. 
Epstein, Debbie and Richard Johnson. 1994. "On the Straight and Narrow: The Heterosexual Presumption, Homophobias and Schools." In Challenging Lesbian and Gay Inequalities in Education, edited by Debbie Epstein, 197-230. Buckingham, UK: Open University Press.

Fairclough, Norman and Clive Holes. 1995. Critical Discourse Analysis: The Critical Study of Languages. New York: Longman.

Ferguson, Roderick. 2004. Aberrations in Black: Towards a Queer of Color Critique. Minneapolis, MN: University of Minnesota Press.

Ferguson, Roderick and Grace Kyungwon Hong. 2012. "The Sexual and Racial Contradictions of Neoliberalism." Journal of Homosexuality 59 (7): 1057-1064.

Fisher-Tine, Harald. 2003. "'White Women Degrading Themselves to the Lowest Depths": European Networks of Prostitution and Colonial Anxieties in British India and Ceylon Ca. 1880-1914 " Indian Economic Social History Review 40 (163): 163190.

Flood, Michael. 2008. "Men, Sex, and Homosociality: How Bonds between Men Shape their Sexual Relations with Men." Men and Masculinities 10 (3): 339-359.

Frankenberg, Ruth and Lata Mani. 1993. "Crosscurrents, Crosstalk: Race, 'Postcoloniality', and the Politics of Location." Cultural Studies 7 (2): 292-310.

Garrick, Damien. 2005. "Excuses, Excuses: Rationalizations of Western Sex Tourists in Thailand." Current Issues in Tourism 8 (6): 497-509.

Giroux, Henry. 1994. "Living Dangerously: Identity Politics and the New Cultural Racism." In Between Borders: Pedagogy and the Politics of Cultural Studies, edited by Henry Giroux and Peter McLaren, 29-55. New York: Routledge.

Grewal, Inderpal and Caren Kaplan. 2001. "Global Identities: Theorizing Transnational Studies of Sexuality." GLQ: A Journal of Lesbian and Gay Studies 7 (4): 663-679.

Guevarra, Anna Romina. 2006. "Managing 'Vulnerabililties' and 'Empowering' Migrant Filipina Workers: The Philippines' Overseas Employment Program." Social Identities: Journal for the Study of Race, Nation, and Culture 12 (5): 523-541.

Hage, Ghassan. 2000. White Nation: Fantasies of White Supremacy in a Multiracial Society. New York: Routledge.

Hall, Catherine. 2004. "Of Gender and Empire: Reflections on the Nineteenth Century." In Gender and Empire, edited by Philippa Levine, 46-76. Oxford UK: Oxford University Press. 
Hall, Michael C. 1996. "Gender and Economic Interests in Tourism Prostitution." The Sociology of Tourism: Theoretical and Empirical Investigations 1: 265.

Hamilton, Anne. 1997. "Primal Dream: Masculinism, Sin and Salvation in Thailand's Sex Trade." In Sites of Desire, Economies of Pleasure: Sexualities in Asia and the Pacific, edited by Margaret Jolly and Lenore Manderson, 145-165. Chicago: The University of Chicago Press.

Han, Alan. 2006. "'I Think You are the Smartest Race I’ve Ever Met": Racialised Economies of Queer Desire." Critical Race and Whiteness Studies 2 (2): 1-14.

Haraway, Donna. 1988. "Situated Knowledges: The Science Question in Feminism and the Privilege of Partial Perspective." Feminist Studies 14 (3): 575-599.

Hill Collins, Patricia. 2000. Black Feminist Thought: Knowledge, Consciousness, and the Politics of Empowerment. New York: Routledge.

. 2004. Black Sexual Politics: African Americans, Gender, and the New Racism. New York: Routledge.

Howell, Philip. 2009. Geographies of Regulation: Policing Prostitution in NineteenthCentury Britain and the Empire. Cambridge: Cambridge University Press.

Hughes, Donna M. 2004. "The Role of "Marriage Agencies” in the Sexual Exploitation and Trafficking of Women from the Former Soviet Union." International Review of Victimology 11: 49-71.

Hunter, Margaret. 2005. Race, Gender and the Politics of Skin Tone. New York: Routledge.

Jackson, Suzanne H. 2007. "Marriages of Convenience: International Marriage Brokers, "Mail Order Brides" and Domestic Servitude." The University of Toledo Law Review 38 (895).

Johnson, Ericka. 2007. Dreaming of a Mail Order Husband. Durham: Duke University Press.

Kempadoo, Kamala. 1999. "Continuities and Change: Five Centuries of Prostitution in the Caribbean." In Sun, Sex and Gold: Tourism and Sex Work in the Caribbean, edited by Kamala Kempadoo, 3-35. Oxford, UK: Rowman and Littlefield Publishers, Inc.

2004. Sexing the Caribbean: Gender, Race and Sexual Labor. New York City: Routledge. 
— 2001. "Women of Color and the Global Sex Trade: Transnational Feminist Perspectives " Meridians: Feminism, Race, Transnationalism 1 (2): 28-51.

King, C. Richard. 2000. Post-Colonial America. Urbana-Champaign, IL: University of Illinois.

Kingsbury, Paul, Valorie Crooks, Jeremy Synder, Rory Johnston, and Krystyna Adams. 2012. "Narratives of Emotion and Anxiety in Medical Tourism: On State of the Heart and Larry's Kidney." Social and Cultural Geography 13 (4): 361-378.

Lan, Pei-Chia. 2003. "Maid Or Madam?: Filipina Migrant Workers and the Continuity of Domestic Labor. " Gender and Society 17 (2): 187-208.

Law, Lisa. 1997. "A Matter of 'Choice': Discourses on Prostitution in Hte Philippines." In Sites of Desire, Economies of Pleasure: Sexualities in Asia and the Pacific, edited by Margaret Jolly and Lenore Manderson, 233-261. Chicago: The University of Chicago Press.

Leupp, Gary. 2003. Interracial Intimacy in Japan: Western Men and Japanese Women, 1543-1900. London: Continuum.

Levine, Philippa. 2004. "A Multitude of Unchaste Women”: Prostitution in the British Empire." Journal of Women's History 15 (4): 159-162.

_ 2000. "Orientalist Sociology and the Creation of Colonial Sexualities." Feminist Review 65 (Summer): 5-17.

Lloyd, Kathryn A. 2000. "Wives for Sale: The Modern International Bride Industry." Northwestern Journal of International Mail Order Bride Industry 20 (341).

Longhurst, Robyn. 2001. Bodies: Exploring Fluid Boundaries. New York: Routledge.

Lowe, Lisa. 2006. "The Intimacies of Four Continents." In Haunted by Empire:

Geographies of Intimacy in North America, edited by Ann Laura Stoler, 191-212. Durham, NC: Duke University Press.

Luehrmann, Sonja. 2004. "Mediated Marriage: Internet Matchmaking in Provincial Russia." Europe-Asia Studies 56 (6): 857-875.

Manderson, Lenore. 1997. "Parables of Imperialism and Fantasies of the Exotic: Western Representations of Thailand-Place and Sex." In Sites of Desire, Economies of Pleasure , edited by Manderson, Lenore and Margaret Jolly, 123-144. Chicago: University of Chicago Press. 
Martin, Philip, Manolo Abella, and Elizabeth Midgley. 2004. "Best Practices to Manage Migration: The Philippines." International Migration Review 38 (4): 1544-1559.

Mayorga, Laura and Pilar Velasquez. 1999. "Bleak Pasts, Bleak Futures: Life Paths of Thirteen Young Prostitutes in Cartagena, Colombia." In Sun, Sex, and Gold: Sex Tourism in the Caribbean, 157-182. New York: Rowman Littlefield.

McKay, Deirdre. 2006. "Ara Wilson's the Intimate Economies of Bangkok: Tomboys, Tycoons, and Avon Ladies in the Global City and Anna Lowenhaupt Tsing's Friction: An Ethnography of Global Connection." Women's Studies Quarterly 34 (1/2): 476 .

_ 2003. "Filipinas in Canada-De-Skilling as a Push Toward Marriage " In Wife Or Worker?: Asian Women and Migration, edited by Nicola Piper and Mina Roces, 2352. Oxford: Rowman Littlefield Publishers.

McKercher, Bob and Thomas G. Bauer. 2003. "Conceptual Framework of the Nexus between Tourism, Romance, and Sex." In Sex and Tourism: Journeys of Romance, Love, and Lust, edited by Bob McKercher and Thomas G. Bauer. Binghamton, NY: The Haworth Publicity Press.

Méndez, Marcela Inéz. 1998. "Foreign Bodies: Migrant Latina Sex Workers in Contemporary Japan." Master of Arts, Sophia University.

Miller, William Ian. 1997. The Anatomy of Disgust. Cambridge, MA: Harvard University Press.

Moallem, Minoo. 1999. "Transnationalism, Feminism, and Fundamentalism." In Between Women and Nation: Nationalism, Transnational Feminisms and the State, edited by Caren Kaplan, Nina Alarcon and Minoo Moallem, 320-348. Durham, North Carolina: Dukre University Press.

Mohanty, Chaundra Talpade. 1997. "Women Workers and Capitalist Scripts: Ideologies of Domination, Common Interests and the Politics of Solidarity." In Feminist Genealogies, Colonial Legacies, Democratic Futures, edited by M. Jacqui Alexander and Chaundra Talpade Mohanty, 3-29. New York: Routledge.

—. 2003. Feminism without Borders: Decolonizing Theory, Practicing Solidarity. Durham: Duke University Press.

Montalvo, Frank and G. Edward Codina. 2001. "Skin Color and Latinos in the United States." Ethnicities 1 (3): 321-341.

Mountz, Alison and Jennifer Hyndman. 2006. "Feminist Approaches to the Global Intimate." Women's Studies Quarterly 34 (1-2): 613-632. 
Mullings, Beverly. 1999. "Globalization, Tourism, and the International Sex Trade." In Sun, Sex and Gold: Tourism and Sex Work in the Caribbean, edited by Kamala Kempadoo, 55-80. Oxford: Rowman \& Littlefield Publishers, Inc.

Nagar, Ricah and Amanda Lock Swarr. 2010. "Introduction: Theorizing Transnational Feminist Praxis." In Critical Feminist Transnational Praxis, edited by Richa Nagar and Amanda Lock Swarr, 1-22. Albany, NY: State of New York University Press.

Nakano Glenn, Evelyn. 2009. "Consuming Lightness: Segmented Markets and Global Capital in the Skin Whitening Trade." In Shades of Difference: Why Skin Color Matters, edited by Evelyn Nakano Glenn, 166-187. Palo Alto CA: Stanford University Press.

Nast, Heidi J. 1999. "Mapping the 'Unconscious': Racism and the Oedipal Family." Annals of the Association of American Geographers 90 (2): 215-255.

Nocentelli, Carmen. 2008. "The Erotics of Mercantile Imperialism: Cross-Cultural Requitedness in the Early Modern Period." Journal for Early Modern Cultural Studies 8 (1): 134-152.

O’Rourke, Kate. 2002. "To have and to Hold: A Postmodern Feminist Response to the Mail Order Bride Industry." Denver Journal of International Law and Policy 30 (4): 476-497.

O'Connell Davidson, Julia and Jacqueline Sanchez Taylor. 1999. "Fantasy Islands: Exploring the Demand for Sex Toursim." In Sux, Sex and Gold: Tourism and Sex Work in the Caribbean, edited by Kamala Kempadoo, 37-54. Lanham, MD: Rowman \& Littlefield.

Osipovich, Tatiana. 2005. "Russian Mail-Order Brides in U. S. Public Discourse: Sex, Crime and Cultural Stereotypes." In Sexuality and Gender in Postcommunist Eastern Europe and Russia, edited by Aleksander Stulhofer and Theo Sandfort, 231-242. Binghamton, NY: The Haworth Press Inc.

Oso, Laura Casas. 2010. "Money, Sex, Love and the Family: Economic and Affective Strategies of Latin American Sex Workers in Spain." Journal of Ethnic and Migration Studies 36 (1): 47-65.

Parreñas, Rhacel Salazar. 2000. "Migrant Filipina Domestic Workers and the International Division of Reproductive Labor." Gender and Society 14 (4): 560-581.

- 2001. Servants of Globalization: Women, Migration and Domestic Work. Palo Alto, CA: Stanford University Press. 
Patil, Vrushali. 2008. Negotiating Decolonization in the United Nations: The Politics of Space, Identity and International Community. New York: Routledge.

. 2013. "From Patriarchy to Intersectionality: A Transnational Feminist Assessment of how far we've really come." Signs: 38 (4): 847-867.

Pedwell, Carolyn and Anne Whitehood. 2012. "Affecting Feminism: Questions of Feeling in Feminist Theory." Feminist Theory 13 (2): 115-129.

Picard, David. 2012. "Tourism, Awe, and Inner Journeys." In Emotion in Motion: Tourism, Affect, and Emotion, edited by David Picard and Mike Robinson. Burlington, VT: Ashgate Publishing Limited.

Piller, Ingrid, ed. 2007. Cross-Cultural Communication in Intimate Relationships. Handbooks of Applied Linguistics: Communication Competence, Language and Communication Problems, edited by K. Knapp andG. Antos. Handbook of Intercultural Communication ed. Vol. 7. New York: Mouton de Gruyter.

Piper, Nicola and Mina Roces. 2003. "Marriage and Migration in an Age of Globalization " In Wife Or Worker?: Asian Women and Migration, edited by Nicola Piper and Mina Roces, 1-22. Oxford: Rowman Littlefield Publishers.

Pratt, Geraldine and Valerie Rosner. 2006. "Introduction: The Global and the Intimate." Women's Studies Quarterly 34 (1-2): 13-24.

Proudfoot, Jesse. 2010. "Interviewing Enjoyment, Or the Limits of Discourse." The Professional Geographer 62 (4): 507-518.

Pruitt, Deborah and Suzanne LaFont. 1995. "For Love and Money: Romance Tourism in Jamaica." Annals of Tourism 22 (2): 422-440.

Rachman, Stanley. 2004. Anxiety. New York: Psychology Press Ltd.

Raj, Senthorun. 2011. "Grindring Bodies: Racial and Affective Economies of Online Queer Desire." Critical Race and Whiteness Studies 7 (2): 1-12.

Ritterbusch, Amy. 2011. "A Youth Vision of the City: The Socio-Spatial Lives and Exclusion of Street Girls in Bogota, Colombia." PhD, Florida International University.

Robinson, Kathryn. 2007. "Marriage Migration, Gender Transformations, and Family Values in the 'Global Ecumene'." Gender, Place and Culture 14 (4): 483-497. 
Rondilla, Joanne. 2009. "Filipinos and the Color Complex: Ideal Asian Beauty." In Shades of Difference: Why Skin Color Matters, edited by Evelyn Nakano Glenn, 6380. Palo Alto, CA: Stanford University Press.

Rose, Gillian. 1997. "Situating Knowledges: Positionality, Reflexitivies and Other Tactics." Progress in Human Geography 21 (3): 305-320.

Rozin, Paul and April Fallon. 1987. "A Perspective on Disgust." Psychological Review 94 (1): 23.

Sanchez Taylor, Jacqueline. 2001. "Dollars are a Girl's Best Friend? Female Tourists' Sexual Behaviour in the Caribbean." Sociology 35 (3): 749-764.

_ 2006. "Female Sex Tourism: A Contradiction in Terms." Feminist Review 83 (1): 42-59.

Sanders, Teela. 2005. "'It’s just Acting': Sex Worker's Strategies for Capitalizing on Sexuality." Gender, Work, and Organization 12 (4): 319-342.

Saraswati, Ayu. 2010. "Cosmopolitan Whiteness: The Effects and Affects of SkinWhitening Advertisements in a Transnational Women's Magazine in Indonesia." Meridians: Feminism, Race, Transnationalism 10 (2): 15-41.

Sassen, Saskia. 2002. "Global Cities and Survival Circuits." In American Studies: An Anthology, edited by Janice Radway, Kevin Gains, Barry Shank, and Penny Von Eschen. West Sussex, United Kingdom: Wiley-Blackwell.

Savigliano, Marta. 1995. Tango and the Political Economy of Passion. Boulder, CO: Westview Press.

Schaeffer, Felicity. 2013. Love and Empire: Cybermarriage and Citizenship Across the Americas. New York: New York University Press.

Schaeffer-Grabiel, Felicity. 2004. "Cyberbrides and Global Imaginaries: Mexican Women's Turn from the National to the Foreign." Space and Culture 7: 33-48.

- 2006. "Flexible Technologies of Subjectivity and Mobility across the Americas." American Quarterly 58 (3): 891-914.

_ 2006. "Planet-Love.Com: Cyberbrides in the Americas and the Transational Routes of US Masculinity." Signs 31 (2): 331-356.

Scully, Eileen. 1998. "Prostitution as Privilege: The 'American Girl' of Treaty-Port Shanghai, 1860-1937." The International History Review 20 (4): 855-883. 
Seigworth, Gregory and Melissa Gregg. 2010. "An Inventory of Shimmers." In The Affect Reader, edited by Gregory Seigworth and Melissa Gregg, 1-28. Durham NC: Duke University Press.

Shah, Svati. 2012. "Interrogating Heteronorms of Development." GLQ: A Journal of Lesbian and Gay Studies 18 (4): 624-626.

Sharp, Joanne. 2009. "Geography and Gender: What Belongs to Feminist Geography? Emotions, Power, and Change." Progress in Human Geography 33 (1): 74-80.

Sharpe, Jenny. 1995. "Is the United States Postcolonial?: Transnationalism, Immigration, and Race." Diaspora: A Journal of Transnational Studies 4 (2): 181-199.

Singh, Amritjit and Peter Schmidt. 2000. "On the Borders between U.S. Studies and Postcolonial Theory." In Postcolonial Theory and the United States: Race, Ethnicity and Literature, edited by Amritjit Singh and Peter Schmidt, 3-10. Oxford, MS: University of Mississippi Press.

So, Christine. 2006. "Asian Mail Order Brides, the Threat of Global Capitalism and the Rescue of the U.S. Nation-State." Feminist Studies 32 (2): 395-419.

Stanfill, Mel. 2010. "Doing Fandom, Misdoing Whiteness: Heteronormativity, Racialization, and the Discursive Construction of Fandom." Transformative Works and Cultures 8.

Stoler, Ann Laura. 2002. Carnal Knowledge and Imperial Power: Race and the Intimate Colonial Rule. Berkeley: University of California Press.

1997. "Making Empire Respectable: The Politics of Race and Sexual Morality in Twentieth Century Colonial Cultures." In Dangerous Liasons: Gender, Nation and Post-Colonial Perspectives, edited by Anne McClintock, A. Mufti and E. Shohat, 344-368. Minneapolis: University of Minnesota Press.

2006. "Tense and Tender Ties: The Politics of Comparison in North American History and (Post) Colonial Studies." In Haunted by Empire: Geographies of Intimacy in North American History, edited by Ann Laura Stoler, 23-67. Durham, NC: Duke University Press.

Sue, Christine. 2009. "The Dynamics of Color: Mestizaje, Racism, and Blackness in Veracruz, Mexico." In Shades of Difference: Why Skin Color Matters, edited by Evelyn Nakano Glenn, 114-127. Palo Alto, CA: Stanford University Press.

Tambe, Ashwini. 2009. Codes of Misconduct: Regulating Prostitution in Colonial Bombay. Minneapolis: University of Minnesota Press. 
Taraban, Svitlana. 2007. "Birthday Girls, Russian Dolls and Others: Internet Bride as the Emerging Global Identity of Post-Soviet Women." In Living Gender After Communism, edited by Janet E. Johnson and Jean C. Robinson, 105-127. Bloomington, IN: University of Indiana Press.

Thurnell-Read, Thomas. 2012. "What Happens on Tour: The Premarital Stag Tour, Homosocial Bonding, and Male Friendship." Men and Masculinities 15 (3): 249270.

Tolentino, Roland. 1996. "Bodies, Letters, and Catalogs: Filipinas in Transnational Space." Social Text 48 (Autumn): 49-76.

Troyer, John and Chani Marchiselli. 2005. "Slack, Slacker, Slackest: Homosocial Bonding Practices in Contemporary Dude Cinema." In Where the Boys are: Cinemas of Masculinity and Youth, edited by Frances Gateward and Pomerance Murray, 264276. Detroit, MIchigan: Wayne State University Press.

Tyler, Imogen. 2008. "'Chav Mum, Chav Scum": Class Disgust in Contemporary Britain." Feminist Media Studies 8 (1): 17-34.

Tyner, James A. 1997. "Constructing Images, Constructing Policy: The Case of Filipino Migrant Performing Artists." Gender, Place and Culture 4 (1): 19-36.

Valentine, Gill. 2006. "Globalizing Intimacy: The Role of Information and Communication Technologies in Maintaining and Creating Relationships." Women's Studies Quarterly 34 (1/2): 365-393.

Wade, Peter. 1993. Blackness and Race Mixture: The Dynamics of Racial Identity in Colombia. Baltimore, MD: John Hopkins University Press.

Weed, Elizabeth. 1997. "Introduction." In Feminism Meets Queer Theory, edited by Elizabeth Weed and Naomi Schor, vii-xii. Bloomington, IN: Indiana University Press.

Wilson, Kathleen. 2004. "Empire, Gender and Modernity in the Eighteenth Century." In Gender and Empire, edited by Philippa Levine. Vol. 14, 45. Oxford UK: Oxford University Press.

Wollacott, Angela. 1994. "'Khaki Fever' and it's Control: Gender, Class, Age and Sexual Morality on the British Homefront in the First World War." Journal of Contemporary History 29 (2): 325-347.

Wyatt, Justin. 2001. "Identity, Queerness, and Homosocial Bonding: The Case of Swingers." In Masculinity: Bodies, Cultures, Movies, edited by Peter Lehman, 5165. New York: Routledge. 
Yegenoglu, Meyda. 1998. Colonial Fantasies: Towards a Feminist Reading of Orientalism. Cambridge UK: Cambridge University Press.

Young, Robert. 1995. Colonial Desire: Hybridity in Theory, Culture and Race. New York: Routledge.

Yuval-Davis, Nira. 1997. Gender and Nation. Thousand Oaks, CA: Sage Publications. 
APPENDICES 
Appendix 1- Pseudonyms and Demographic Information of Interview Participants 


\begin{tabular}{|l|l|l|l|}
\hline $\begin{array}{l}\text { Participant } \\
\text { Pseudonym }\end{array}$ & Age & Home & Role \\
\hline PHILIPPINES & & & \\
\hline Halia & 51 & Philippines & HLC Owner \\
\hline Zia & 24 & Philippines & Employee \\
\hline Dree & 27 & Philippines & Night Manager \\
\hline Wayne & 58 & Philippines/AZ & Brother Owner \\
\hline Jake & 54 & Washington & Male Participant \\
\hline Miles & 62 & California & Male Participant \\
\hline Travis & 37 & Alaska & Male Participant \\
\hline Matt & 45 & Texas & Male Participant \\
\hline Tom & 53 & Texas & Male Participant \\
\hline Ron & 58 & Iowa & Male Participant \\
\hline Dan & 52 & Arizona & Male Participant \\
\hline Carl & 35 & Hawaii & Male Participant \\
\hline Collin & 46 & Oregon & Male Participant \\
\hline Corey & 29 & Australia & Male Participant \\
\hline Denny & 38 & Philippines & Day Manager \\
\hline Olivia & 29 & Philippines & Employee/Profile \\
\hline Lyle & 57 & Virginia & Male Participant \\
\hline Rick & 62 & Texas & Male Participant \\
\hline Justin & 65 & California & Male Participant \\
\hline Missy & 22 & Philippines & Female Participant \\
\hline Mika & 21 & Philippines & Female Participant \\
\hline Debbie & 21 & Philippines & Female Participant \\
\hline Riley & 25 & Philippines & Employee/Profile \\
\hline Lily & 31 & Philippines & Employee \\
\hline Kristi & 32 & Philippines & Employee \\
\hline Mary & 24 & Philippines & Female Participant \\
\hline Jamey & 58 & Texas & Male Participant \\
\hline Betty & 23 & Hawaii & Female Participant \\
\hline Isis & 27 & Australia & Female Participant \\
\hline Vic & 28 & Philippines & Employee/Profile \\
\hline Lindy & 22 & Philippines & Female Participant \\
\hline Jerry & 53 & Ohio & Male Participant \\
\hline Denise & 34 & Philippines & Employee \\
\hline COLOMBIA & & & \\
\hline Name & Age & Location & Role \\
\hline Fernando & 45 & South Carolina & Male Participant \\
\hline Kyle & 52 & Georgia & Male Participant \\
\hline Jerry & 55 & Texas & Male Participant \\
\hline Greg & Florida & Male Participant \\
\hline Mel & Florida & Male Participant \\
\hline Howie & & \\
\hline & 52 & & \\
\hline
\end{tabular}




\begin{tabular}{|l|l|l|l|}
\hline Tim & 54 & Texas & Male Participant \\
\hline Kari & 19 & Colombia & Employee \\
\hline Salvador & 63 & Miami/LA & Male Participant \\
\hline Jessie & 22 & Colombia & Employee \\
\hline Elisa & 24 & Colombia & Female Participant \\
\hline Carolina & 27 & Colombia & Female Participant \\
\hline Isabella & 23 & Colombia & Female Participant \\
\hline Sofia & 26 & Colombia & Female Participant \\
\hline Josephina & 27 & Colombia & Female Participant \\
\hline Caren & 24 & Colombia & Female Participant \\
\hline Lana & 28 & Colombia & Female Participant \\
\hline Alejandra & 40 & Colombia & Female Participant \\
\hline Xiomara & 25 & Colombia & Assistant Manager \\
\hline Lindsay & 26 & Colombia & Manager \\
\hline Valerie & 24 & Colombia & Manager \\
\hline Maria & 36 & Colombia & Female Participant \\
\hline Jolyn & 19 & Colombia & Female Participant \\
\hline Kelin & 43 & Colombia & Male Participant \\
\hline Diana & 19 & Colombia & Employee \\
\hline UKRAINE & & & \\
\hline Name & Age & Location & Role \\
\hline Layla & 23 & Ukraine & Female Participant \\
\hline Henrik & 44 & New York & Male Participant \\
\hline Julissa & 25 & Ukraine & Employee \\
\hline Gary & 54 & Montana & Male Participant \\
\hline Josh & 44 & Texas & Male Participant \\
\hline Duncan & 59 & Texas & Male Participant \\
\hline Katya & 31 & Ukraine & Owner of Sumy \\
\hline Alexis & 29 & Ukraine & Employee/Profile \\
\hline Kristina & 33 & Ukraine & Female Participant \\
\hline Sandra & 24 & Ukraine & Employee \\
\hline Nadja & 24 & Ukraine & Employee/Profile \\
\hline Alina & 32 & Ukraine & Employee/Profile \\
\hline Bud & 42 & Ukraine & Employee \\
\hline Brad & 63 & Pennsylvania & Male Participant \\
\hline Jared & 36 & Alabama & Male Participant \\
\hline Paul & 28 & Michigan & Male Participant \\
\hline Alec & 60 & Maryland & Male Participant \\
\hline Rod & 42 & South Carolina & Male Participant \\
\hline Leroy & 39 & Pennsylvania & Male Participant \\
\hline Marley & 54 & Nevada & Male Participant \\
\hline Nick & 48 & Wisconsin & Male Participant \\
\hline Ilona & 35 & Russia & Female Participant \\
\hline
\end{tabular}


VITA

\section{JULIA MESZAROS}

Born, Milwaukee, Wisconsin

2000-2004

B.A., Political Science

University of Wisconsin-Whitewater

Whitewater, Wisconsin

2004-2006

M.A., Political Science

San Diego State University

San Diego, California

2009-2014

Doctoral Candidate

Florida International University

Miami, Florida

Teaching Assistant

Florida International University

Miami, Florida

\section{PUBLICATIONS AND PRESENTATIONS}

Meszaros, Julia. (2014). "Romance Tourism: the Ultimate Emotions Industry”, in The Emotions Industry edited by Mira Moshe. Nova Publications.

Meszaros, Julia. (August, 2014). "Defining desirability in the romance tour industry: Why are Muslim men considered undesirable?”. Paper presented at the meeting of the American Sociological Association in San Francisco, California.

Meszaros, Julia. (April, 2014). “Desiring Transnationally Mobile Brad Pitts: Race, Masculinity and Desire in the Commercialized Romance Tour Industry” Paper presented at the UC Berkeley $6^{\text {th }}$ Annual Sociology Symposium in Berkeley, California.

Meszaros, Julia. (April, 2014). "Desiring the 'Exotic Light': Race, Color, and Beauty in the Transnational Romance Tour Industry” Paper presented at the Associated Colleges of the South Gender Conference Furman University in Greenville, South Carolina.

Meszaros, Julia. (March, 2014). "Remittances and the Persistent Political Economy of Corruption in the Philippines.” Paper presented at the meeting of the International Studies Association in Toronto, Canada. 
Meszaros, Julia. (February, 2014). "Why are Muslim men undesirable in the commercial romance tour industry?” Paper presented at the meeting of the Sociologists for Women in Society in Nashville, Tennessee.

Meszaros, Julia. (August 2013). “Affective Racializations: Race, Desire and Romance Tourism in Colombia” Paper presented at the meeting of the American Sociological Association in New York, New York.

Meszaros, Julia. (April, 2013). “A Desire for Whiteness in the Philippines’ Romance Tour Industry.” Paper presented at the meeting of Intimate Migrations in Copenhagen, Denmark. 